PNL-2447

UC-79p

\title{
An Evaluation of Liquid Metal Leak Detection Methods for the Clinch River Breeder Reactor Plant
}

by

C. J. Morris

S. R. Doctor

December 1977

Prepared for the U.S. Nuclear Regulatory

Commission under Related Services Contract $8 D 08$ to the Prime Contract CY-76-C-06-1830 with the Department of Energy 


\title{
NOTICE
}

This report was prepared as an acrount of work sponsored by the United States Government. Neither the United States nor the Department of Energy, nor any of their employees, nor any of their contractors, subcontractors, or their employees, makes any warranty, express or implied, or assumes any legal liability or responsibility for the accuracy, completeness or usefulness of any information, apparatus, product or process disclosed, or represents that its use would not infringe privately owned rights.

The views, opinions and conclusions contained in this report are those of the contractor and do not necessarily represent those of the United States Covernment or the United States Department of Energy.

\author{
PACIFIC NORTHW:EST LABORATORY \\ operated by \\ BATTELLE \\ for the \\ UNITED STATES DEP.ARTMENT OF ENERGY \\ Under Contract EY-76-C-06-1830
}

\begin{tabular}{|c|c|c|}
\hline & & NTIS \\
\hline & "Pages & Steiling Price \\
\hline & $001-025$ & $\$ 4.50$ \\
\hline & $026-050$ & $\$ 5.00$ \\
\hline & $051-075$ & $\$ 5.50$ \\
\hline & $076-100$ & 56.00 \\
\hline & $101-125$ & $\$ 6.50$ \\
\hline & $126-150$ & $\$ 7.00$ \\
\hline & 151.175 & 5.75 \\
\hline & 176.200 & s8. 50 \\
\hline & $201-225$ & $\$ 8.75$ \\
\hline & $226-250$ & $\$ 9.00$ \\
\hline & 251.275 & 510.20 \\
\hline & 275.300 & 510.25 \\
\hline
\end{tabular}


AN EVALUATION OF LIQUID METAL LEAK DETECTION METHODS FOR THE

CLINCH RIVER BREEDER REACTOR PLANT

Prepared for the U.S. Nuclear Regulatory Commission under Related Services Contract 8D08

to the Prime Contract EY-76-C-06-1830 with the Department of Energy

by

C. J. Morris, Nondestructive Testing

S. R. Doctor, Nondestructive Testing

December 1977

BATTELLE

Pacific Northwest Laboratories

Richland, Washington 99352 


\section{CONTENTS}

1.0 INTRODUCTION

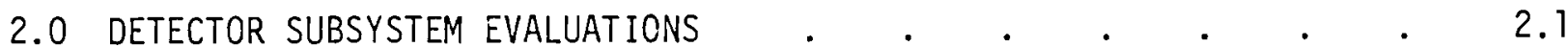

2.1 SODIUM-TO-ATMOSPHERE LEAK DETECTORS $\quad \cdot \quad \cdot \quad \cdot \quad \cdot \quad \cdot \quad \cdot 2.1$

2.1.1 Sodium Ionization Detector . . . . . . . $\quad$. 2.2

2.1.2 Differential Pressure Detector . . . . . 2.12

2.1 .3 Smoke Detector . . . . . . . . . 2.18

2.1 .4 Hydrogen Detector. . . . . . . . . . 2.21

2.1.5 Surface Ionization Monitor for Particulates . $\quad 2.28$

2.1 .6 Radiation Detector . . . . . . . . . 2.31

2.1 .7 Cable Detector . . . . . . . . 2.32

2.1 .8 Contact Detector . . . . . . . . . 2.38

2.2 SODIUM-TO-SODIUM LEAK DETECTORS $\quad . \quad$. $\quad . \quad . \quad . \quad . \quad 2.50$

2.2.1 Level Sensors . . . . . . . . . 2.52

2.2.2 Radiation Detectors . . . . . . . . . 2.52

2.2 .3 Pressure Sensors . . . . . . . . . . 2.53

2.3 STEAM/WATER-TO-SODIUM LEAK DETECTORS . . . . . . 2.53

2.3.1 Hydrogen Detectors . . . . . . . . 2.60

2.3.2 Gas Chromatographs . . . . . . . . 2.65

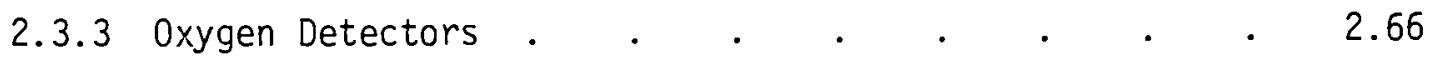

3.0 LEAK DETECTION SYSTEM EVALUATIONS •

3.1 SODIUM-TO-ATMOSPHERE LEAK DETECTION SYSTEMS • • • . . . 3.1

3.1.1 Radiation Monitoring . . . . . . . . . . . 3.1

3.1 .2 Aerosol Monitoring . . . . . . . . . 3.2

3.1.3 Cable and Contact Monitoring . . . . . . 3.4

3.2 SODIUM-TO-SODIUM LEAK DETECTION SYSTEMS ..$\quad \cdot \quad \cdot \quad \cdot \quad \cdot 3.5$

3.3 STEAM/WATER-TO-SODIUM LEAK DETECTION SYSTEMS • • . . . 3.6

3.3.1 Hydrogen Detectors . . . . . . . . . . 3.6

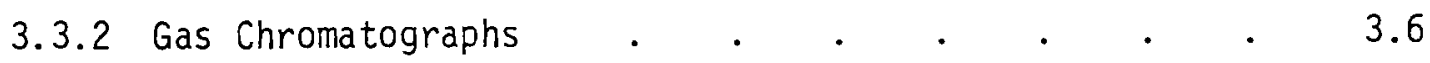

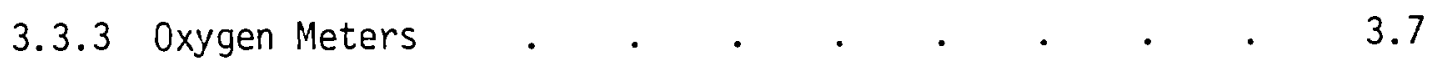




\begin{tabular}{|c|c|c|c|c|c|c|c|c|c|c|c|c|}
\hline \multirow[t]{12}{*}{4.0} & \multicolumn{2}{|c|}{ SUMMARY } & - & • & - & • & • & • & $\bullet$ & - & • & 4.1 \\
\hline & \multirow[t]{5}{*}{4.1} & \multicolumn{6}{|c|}{ SODIUM-TO-ATMOSPHERE LEAK DETECTION SYSTEMS } & - & • & . & . & 4.1 \\
\hline & & 4.1 .1 & Engineering & Capability & . & . & . & • & $\cdot$ & $\bullet$ & . & 4.1 \\
\hline & & 4.1 .2 & Location Adec & quacy . & . & - & . & & & & . & 4.6 \\
\hline & & 4.1 .3 & Detectabilit) & y Zones & . & . & . & & & 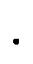 & . & 4.8 \\
\hline & & 4.1 .4 & Sensitivity & . & . & - & . & & & & . & 4.11 \\
\hline & 4.2 & \multicolumn{6}{|c|}{ SODIUM-TO-SODIUM LEAK DETECTION SYSTEMS } & & & 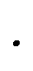 & - & 4.14 \\
\hline & \multirow[t]{5}{*}{4.3} & \multicolumn{7}{|c|}{ STEAM/WATER-TO-SODIUM LEAK DETECTION SYSTEMS } & $\cdot$ & ${ }^{\circ}$ & . & 4.14 \\
\hline & & 4.3 .1 & Engineering & Capability & . & . & . & • & 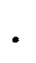 & ${ }^{\circ}$ & . & 4.14 \\
\hline & & 4.3 .2 & Location Adec & quacy. & - & . & . & $\cdot$ & 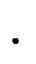 & ${ }^{\circ}$ & • & 4.15 \\
\hline & & 4.3 .3 & Detectabilits & y Zones & . & . & . & & & & • & 4.16 \\
\hline & & 4.3 .4 & Sensitivity & - & . & . & - & 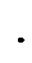 & 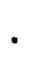 & 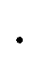 & . & 4.17 \\
\hline \multicolumn{3}{|c|}{ REFERENCES } & . & - & - & - & • & • & & & - & $\operatorname{Ref}-1$ \\
\hline \multicolumn{5}{|c|}{$\begin{aligned} \text { APPENDIX A - } & \text { PRIMARY AND INTERMEDIATE } \\
& \text { COOLANT SYSTEM BOUNDARIES }\end{aligned}$} & $\cdot$ & $\cdot$ & - & & & & • & $A-1$ \\
\hline \multicolumn{2}{|c|}{ APPENDIX B } & $B-C R B$ & R SYSTEMS & . & . & . & . & ${ }^{\circ}$ & - & - & - & $B-1$ \\
\hline \multicolumn{2}{|c|}{ APPENDIX 0} & $C-L M F$ & BR LEAK HISTOF & $R Y$ & . & . & . & $\cdot$ & • & • & . & $C-1$ \\
\hline
\end{tabular}




\section{FIGURES}

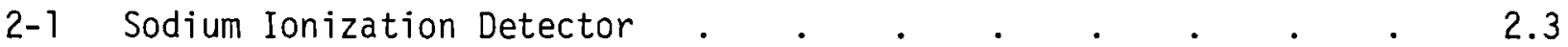

2-2 Sodium Ionization Detector Instrumentation . $. \quad . \quad . \quad . \quad . \quad 2.3$

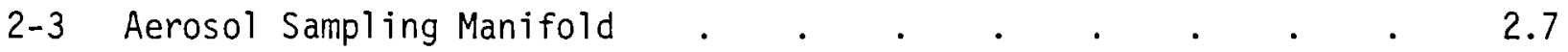

2-4 Sodium Aerosol Concentration Versus

Time and Vault Size for a 100-g/hr Leak . . . . . . . $2.1 \mathrm{i}$

2-5 Differential Pressure Detector Physical Layout . . . . . 2.14

2-6 Differential Pressure Detector Instrumentation . . . . . 2.14

2-7 Pyr-A-Larm Smoke Detector System . . . . . . . . . 2.19

2-8 Basic Elements of a Gas Chromatograph . . . . . . . . . 2.24

2-9 Surface Ionization Monitor for Particulates . . . . . . . 2.29

2-10 Surface Ionization Monitor Instrumentation . . . . . . . 2.29

2-11 Cable Detector and Circuit A . . . . . . . . . . 2.33

2-12 Cable Detector Circuit Schematic . . . . . . . . . . 2.33

2-13 Cable Detector and Circuit B. . . . . . . . . . . 2.34

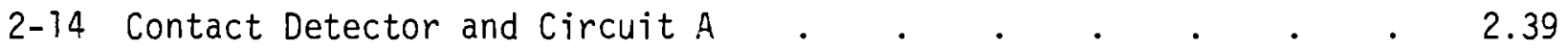

2-15 Contact Detector Circuit Schematic . . . . . . . . . . 2.39

2-16 Contact Detector : . . . . . . . . . . . . . . 2.40

2-17 Contact Detector Circuit B . . . . . . . . . . . 2.40

2-18 Contact Detector Installation for LMEC Tests . . . . . 2.41

2-19 Typical CRBR Pipe Clamp Installation . . . . . . . . . 2.42

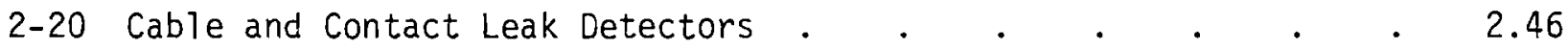

2-21 Cable and Contact Leak Detector Circuit Schematic . . . 2.46

2-22 Circuit A Wire Sensor . . . . . . . . . . . . . 2.47

2-23 Circuit B . . . . . . . . . . . . . . . . . . 2.48

2-24 Cable Detector and Sheath . . . . . . . . . . 2.49

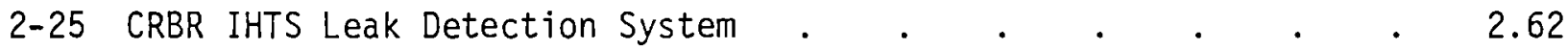

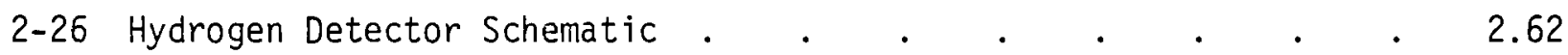

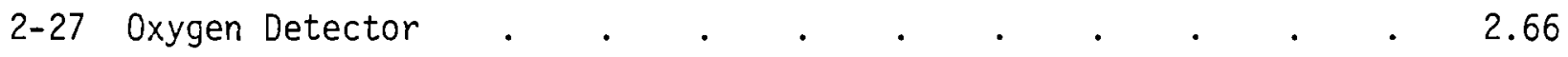




\section{$\underline{\text { TABLES }}$}

2-1 LMEC Sodium-to-Gas Leak Detection Mockup Tests . . . . 2.4

2-2 Sodium Ionization Detector Test Data (LMEC Test) . . . . . 2.6

2-3 Sodium Ionization Detector Cell Test Data . . . . . . 2.8

2-4 Sodium-to-Gas Leak Detector Location . . . . . . . 2.10

2-5 Differential Pressure Detector Cel1 Test Data . . . . 2.15

2-6 Differential Pressure Detector Cell Test Data . . . . 2.16

2-7 Smoke Detector Test Data . . . . . . . . . 2.20

2-8 Smoke Detector Cell Test Data . . . . . . . 2.22

2-9 LMEC Test Data for Hydrogen Detector . . . . . . 2.25

2-10 LMEC Test Data for Hydrogen Detector . . . . . . 2.27

2-11 Surface Ionization Monitor Cel1 Test Data . . . . . 2.30

2-12 Cable Detector Test Data . . . . . . . . . 2.35

2-13 Cable Detector Test Data . . . . . . . . . . . 2.36

2-14 Contact Detector Test Data . . . . . . . . 2.44

2-15 Contact Detector Test Data . . . . . . . . 2.45

2-16ydrogen Detector Response Times:
Steam/Water-to-Sodium Leaks . . . . . . . . . 2.63 
. 
AN EVALUATION OF LIQUID METAL LEAK DETECTION METHODS

FOR THE CLINCH RIVER BREEDER REACTOR PLANT

\subsection{INTRODUCTION}

This report is the result of work performed by the Pacific Northwest Laboratory (PNL) under "Task 3 - Sodium Leak Detection" of the LMFBR Materials Behavior Project. The project was sponsored by the Materials Engineering Branch, Division of System Safety, Office of Nuclear Regulation, U.S. Nuclear Regulatory Commission.

This report documents an independent review and evaluation of sodium leak detection methods described in the Clinch River Breeder Reactor Preliminary Safety Analysis Report (PSAR). Only information in publicly available documents was used in making the assessments. The majority of work reported is from the following sources:

- Atomics International (AI)

- Westinghouse--Advanced Reactors Divsion (W-ARD)

- the Liquid Metal Engineering Center (LMEC)

- Argonne National Laboratory (ANL)

- the Fast Flux Test Facility (FFTF)

- Hanford Engineering Development Laboratory (HEDL)

- the Experimental Breeder Reactor-II (EBR-II)

- foreign LMFBR programs.

Section 2.0 reviews the individual leak sensor descriptions and test data available in the PSAR and other cited sources. Section 3.0 documents PNL's assessment of the available data and provides specific recommendations for needed additional information and/or test data. Based on the review and evaluations presented in Sections 2.0 and 3.0, Section 4.0 summarizes sensor subsystems in terms of engineering capability, location adequacy, detectability zones and sensitivity. 


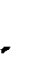




\subsection{DETECTOR SUBSYSTEM EVALUATIONS}

Data from specific references were examined to evaluate the individual leak detectors proposed for the CRBRP. This section describes each sensor subsystem and presents PNL's evaluation of available test data.

\subsection{SODIUM-TO-ATMOSPHERE LEAK DETECTORS}

Sodium-to-atmosphere leaks result from a positive pressure differential between sodium and the gaseous environment. The escaping sodium can react with many materials, producing numerous by-products such as aerosols or vapors. In some reactions, hydrogen gas can be released. In addition, sodium will react exothermically, producing heat, smoke or fire.

Detectors designed to respond to leaking sodium are under development. Candidate detector systems for the CRBRP include:

1. sodium ionization detectors

2. differential pressure detectors

3. smoke detectors

4. hydrogen detectors

5. surface ionization monitors for particulates

6. radiation detectors

7. cable detectors

8. contact detectors.

To date, these detectors have been tested principally at Atomics International's Liquid Metal Engineering Center (LMEC). Tests were conducted in two chambers, one $40 \mathrm{ft}^{3}$ for characterization tests and the other $1540 \mathrm{ft}^{3}$ for system comparison tests.

Detector test procedures and results reported in the PSAR and other supporting references were reviewed by PNL. Results of the review are documented by detector subsystem in the following subsections. 


\subsubsection{Sodium Ionization Detector}

The sodium ionization detector (SID) monitors sodium aerosol/vapor leaks from the primary and intermediate heat transport systems to the surrounding atmosphere. The SID physical layout is shown in Figure 2-1; instrumentation is illustrated in Figure 2-2.

The SID is activated by the passage of a sample gas through an ionization chamber operating on a hot filament technique. The hot filament ionizes sodium and sodium species, generating a recordable signal.

When the sample gas contains no sodium vapor or aerosols, the ionization current is low, 0.01 to 0.2 nanoampere. However, as the sodium aerosol concentration increases, the SID ionization current increases. This increase is proportional to the concentration of sodium vapor/aerosol in the gas passing through the SID chamber at any given time; the increase is not a function of sodium aerosol collection with time.

\subsubsection{SID Test Data Evaluation}

PNL evaluated the SID test data available in the PSAR. The findings are documented in this section.

2.1.1.1.1 Test Conditions. The first test series, Tests 1 through 8 , was conducted using forced convection of the sample gas. Tests 9 through 17 , conducted using natural convection, were designed to examine the possibility of sodium aerosol/vapor detection by cell gas monitoring.

Reference 3 indicates that the leak detection criterion for the SID in Tests 1 through 10 was changed three times (see Table 2-1). The detection criterion during Tests 1 through 3 was defined as an increase of 10 nanoamperes over the initial, near zero, background current. In Tests 4 through $7 Y$, the criterion was changed to 1 nanoampere if the background current was initially less than 0.2 nanoampere. If the background current was greater than 0.2 nanoampere, then the detection criterion was five times the background current. In Tests 8 through 10, a logarithmic readout feature was utilized. 


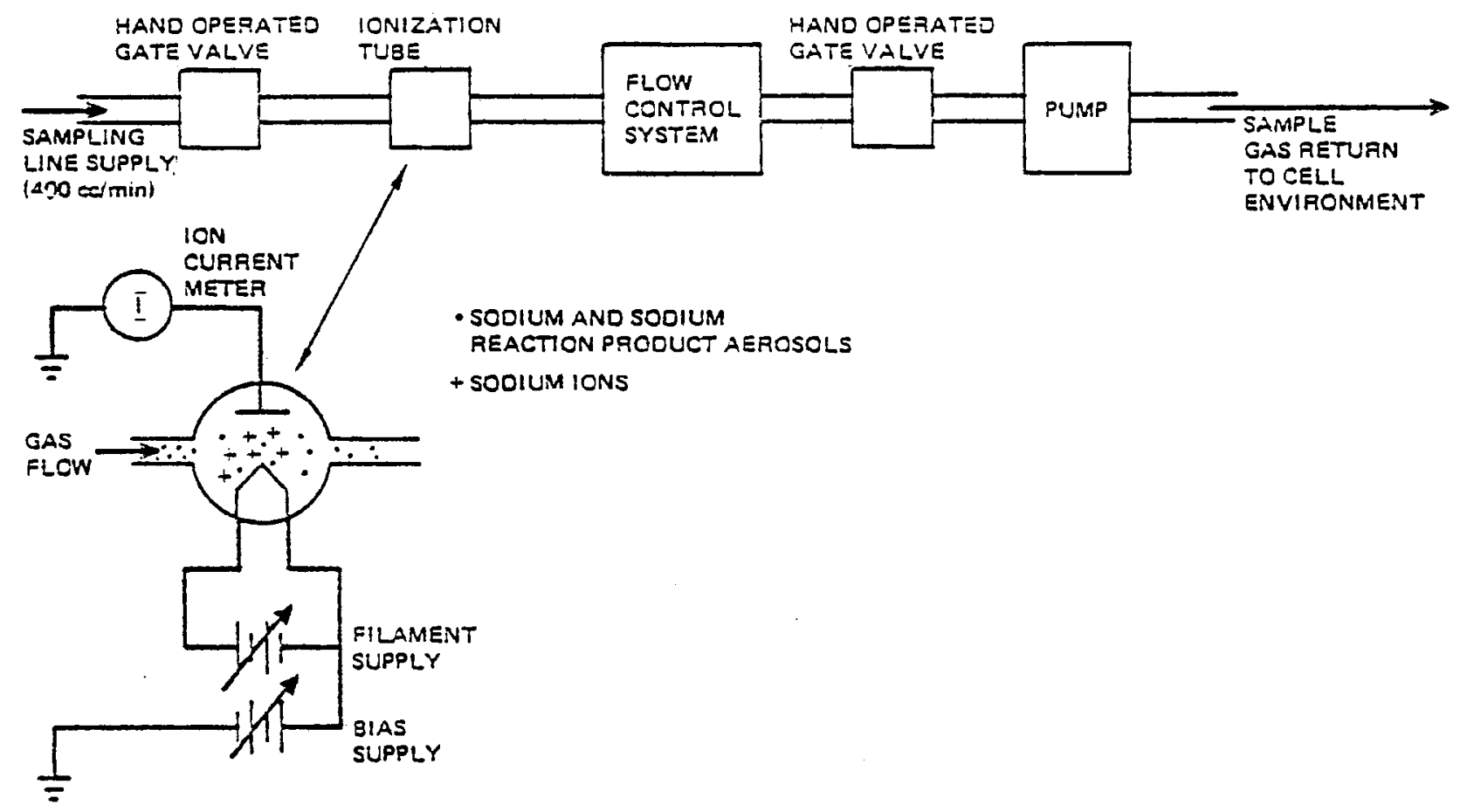

FIGURE 2.1. Sodium Ionization Detector (2)

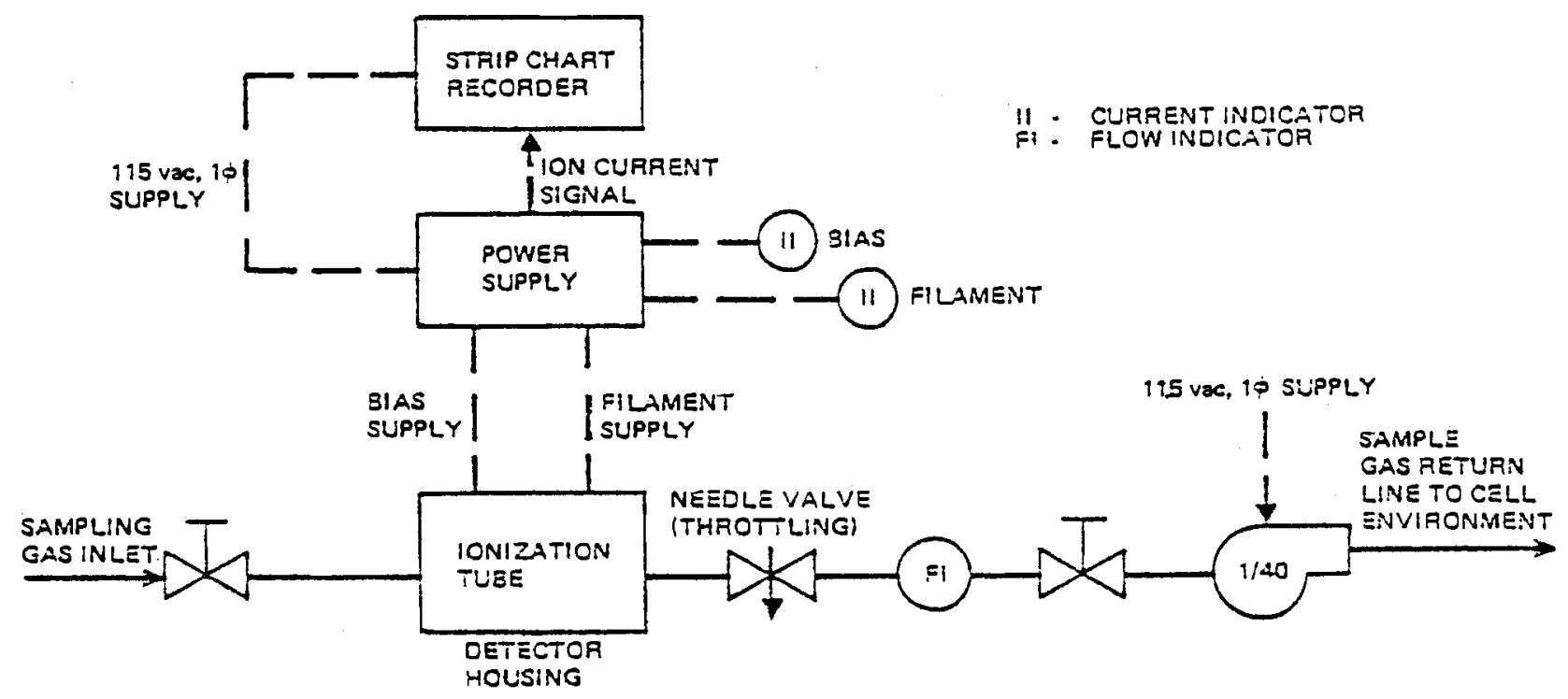

FIGURE 2.2. Sodium Ionization Detector Instrumentation (2) 
TABLE 2-1. LMEC Sodium to Gas Leak Detection Mockup Tests ${ }^{(3)}$

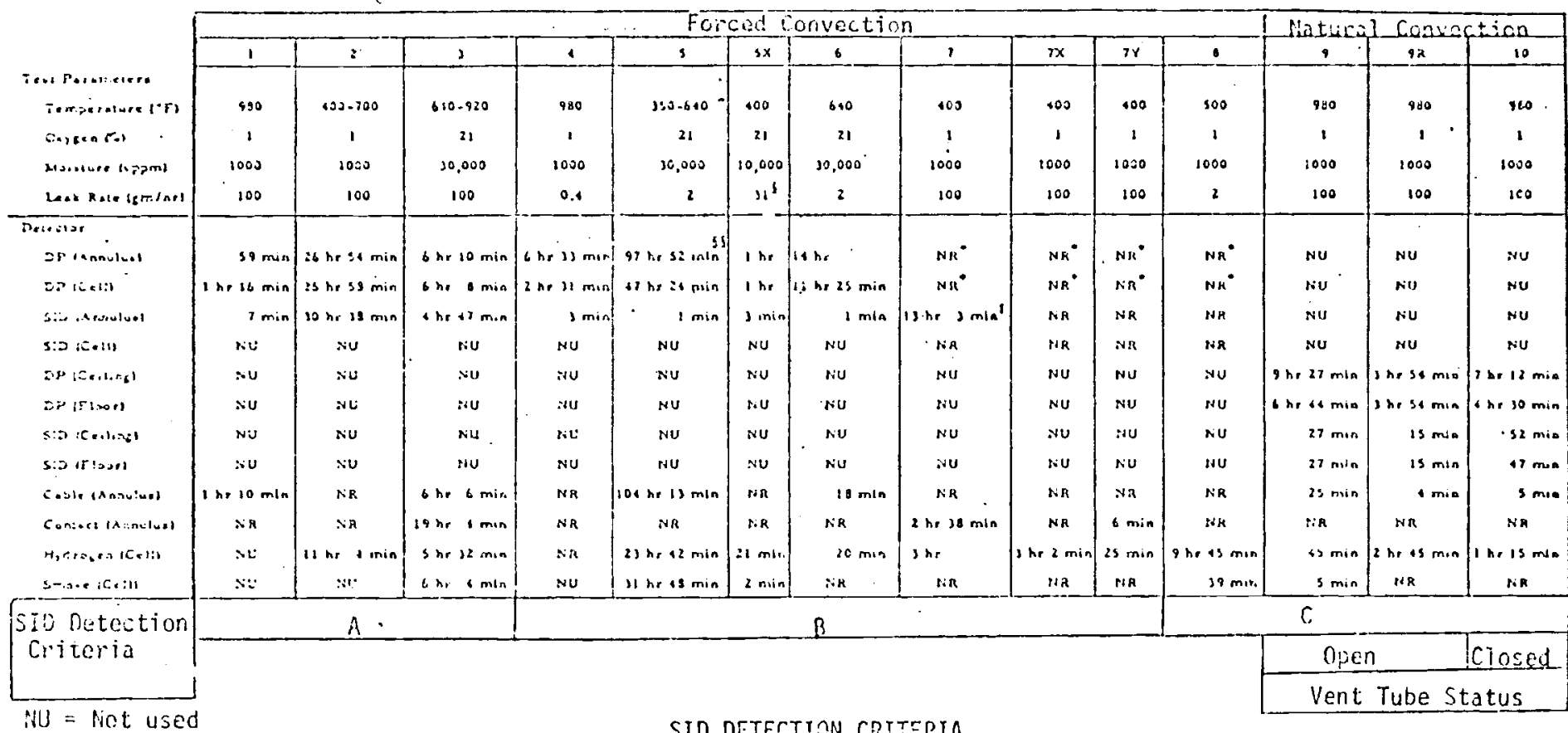

NUS = Not used
HR - Ho Response

* Sodiun was fourd present in filter pads

+ Responce may have been due to leak rate contrel broblems

$f 3$ ! gim injected in $<1$ min as a spray

fi gas leak fourid in sanpling system

\section{SID DETECTION CRITEPIA}

$A=A n$ incrcase of 10 manoanips over the initial background current (wo nanoump). Samping flow rate 150 cc/min.

$B=A n$ increase of 1.0 narioamps if the inftial background current is iess than 0.2 nanoamps, or an increase of 5 tines the initial background it greater than 0.2 nanoamips. Sampling flow rate $400 \mathrm{cc} / \mathrm{min}$.

$C=$ Logarithmic scale utillzed; an increase of 3 times the initial background current. Sampling flow rate $400 \mathrm{cc} / \mathrm{min}$.

Note: Initial background currents greater than 0.5 nanoamps indicate a diriy system.

\section{DP OETECTYON CRITERIA} A change in differential pressure of $10 \mathrm{in.} \mathrm{of} \mathrm{H}_{2} \mathrm{O}$. Sampling flow rate
$5000 \mathrm{cc} / \mathrm{min}$. 
The detection criterion for these tests was an increase of three times the initial background current. In all tests, initial background currents in excess of 0.5 nanoampere indicate a dirty system. Tests $8,9 R$ and 10 utilized the logarithmic recording feature.

The sampling flow rate for the SID during Tests 1 through 3 was $150 \mathrm{cc} / \mathrm{min}$. During Tests 4 through 17, the flow rate increased to $400 \mathrm{cc} / \mathrm{min}$. The PSAR gave no details as to the length and path complexity of the sampling tubes used in these tests.

\subsection{PHTS Test Environment. An analysis of Tests 7 through 8} (Table 2-2) shows that the SID in the annulus did not respond in three of four tests. The one test in which the SID responded in $13 \mathrm{hr}$ was apparently a false alarm. The annunciator signal clearly indicated detection; however, upon visual inspection of the sensor, there was no evidence of sodium to activate the detector. This is interesting when one considers that a reference leak of $100 \mathrm{~g} / \mathrm{hr}$ was used in three of the tests, with as much as $4000 \mathrm{~g}$ of sodium spilled. If the manifold sampling system (see Figure 2-3) to be utilized is attached to a 140-ft main sampling tube as is proposed for CRBR, the question as to whether the aerosol/vapor will condense, cool, diffuse, and/or plateout in the long sampling length is of concern. Many factors affecting the aerosol/vapor behavior are important to SID performance. These include

- aerosol generation from the leak source

- particle size (submicron particles have low mobilities)

- sodium oxidation effects

- leak orientation and path complexity

- convective mixing

- roll cell and stagnant zone formation

- thermal gradients which give rise to thermophoresis

- diffusion.

One report on the analysis of sodium aerosol transport in the FFTF guard vessel annulus indicates the high level of complexity and uncertainty encountered in trying to predict aerosol generation and behavior. (7) 
TABLE 2-2. Sodium Ionization Detector Test Data (LMEC Test) (3)

\begin{tabular}{|c|c|c|c|c|c|c|c|c|}
\hline \multirow{3}{*}{$\begin{array}{l}\text { Test } \\
\text { - No. }\end{array}$} & \multicolumn{6}{|c|}{ Test Parameters } & & \\
\hline & \multirow{2}{*}{$\begin{array}{l}\text { Sodium } \\
\text { Leak } \\
\text { Rate } \\
(\mathrm{gm} / \mathrm{hr})\end{array}$} & \multirow{2}{*}{$\begin{array}{c}\text { Test } \\
\text { Temperature } \\
\left({ }^{\circ} F\right)\end{array}$} & \multirow[t]{2}{*}{$\begin{array}{l}\mathrm{O}_{2} \\
\left(\%^{\circ}\right)\end{array}$} & \multirow[t]{2}{*}{$\begin{array}{c}\text { Moisture } \\
\text { (ppmv) }\end{array}$} & \multirow[t]{2}{*}{$\begin{array}{l}\text { Actual } \\
\text { Na Leak } \\
\text { Duration }\end{array}$} & \multirow{2}{*}{$\begin{array}{l}\text { Total } \\
\text { Sodium } \\
\text { Leaked } \\
\text { (gm) }\end{array}$} & \multicolumn{2}{|c|}{$\begin{array}{c}\text { Detector } \\
\text { Regponse } \\
\text { (Ir) }\end{array}$} \\
\hline & & & & & & & Annulus & CEII \\
\hline 1 & 100 & 1000 & 1 & 1,000 & 10 & 1000 & 0.12 & \\
\hline 2 & 100 & $400-700$ & 1. & $\therefore, 000$ & 10 & 1000 & 30.63 & \\
\hline 3 & 100 & $6 \div 0-920$ & $2 !$ & 30,000 & $\begin{array}{l}\text { t/raise } \\
\text { temp/6 }\end{array}$ & 1200 & 4.79 & \\
\hline 4 & 0.4 & 1000 & 1 & 1,000 & 250 & 100 & $0.1^{*}$ & \\
\hline 5 & $31^{\dagger}$ & 400 & 21 & 10,000 & 0.016 & 31 & $0.016^{2}$ & \\
\hline 5 & 2.0 & $350-650$ & $2 !$ & 30,000 & 200 & 400 & $1.0 \%$ & \\
\hline ó & $2.0^{\dagger}$ & 650 & $2 !$ & 30,000 & 20 & 40 & $0.016^{*}$ & \\
\hline$i x$ & 100 & 400 & 1 & 1,000 & 2.5 & 200 & $N R$ & $N R$ \\
\hline $7 Y$ & $100^{5}$ & 400 & 1 & 1,000 & $\sim 0.1$ & 4000 & $N R$ & $N R$ \\
\hline$i$ & 100 & 400 & 1 & 15,160 & 20 & 2000 & 13.0 & $N R$ \\
\hline 8 & 2 & 500 & 1 & 1,000 & 50 & 100 & $N R$ & $N R$ \\
\hline 9 & 100 & 980 & $i$ & 1,000 & 9.5 & 950 & $\frac{\text { Ceiling }}{0.5}$ & $\frac{F 100 \mathrm{r}}{0.5}$ \\
\hline 98 & 100 & 980 & 1 & 1,000 & 4.3 & 4.30 & 0.3 & 0.3 \\
\hline 10 & 100 & 980 & 1 & 1,000 & 8.4 & 840 & 0.9 & 0.8 \\
\hline
\end{tabular}

$\therefore S I D$ response time requirements changed

\$ 3 g $\mathrm{g}$ injected in less than ! mirute as a spray

Operaticnal difficulties with socium leak rate

The performance of the SID in Tests 7 through 8 in the cell was poor. The SID did not respond to any sodium leaks with as much as $4000 \mathrm{~g}$ of sodium injected. In light of this, one cannot simply state a limiting detection criterion because the actual amount of aerosol generated is undetermined. However, the test data do show that, for sodium temperatures below $600^{\circ} \mathrm{F}$, aerosol formation is reduced. Natural convection Tests 9 through 12, and 15 


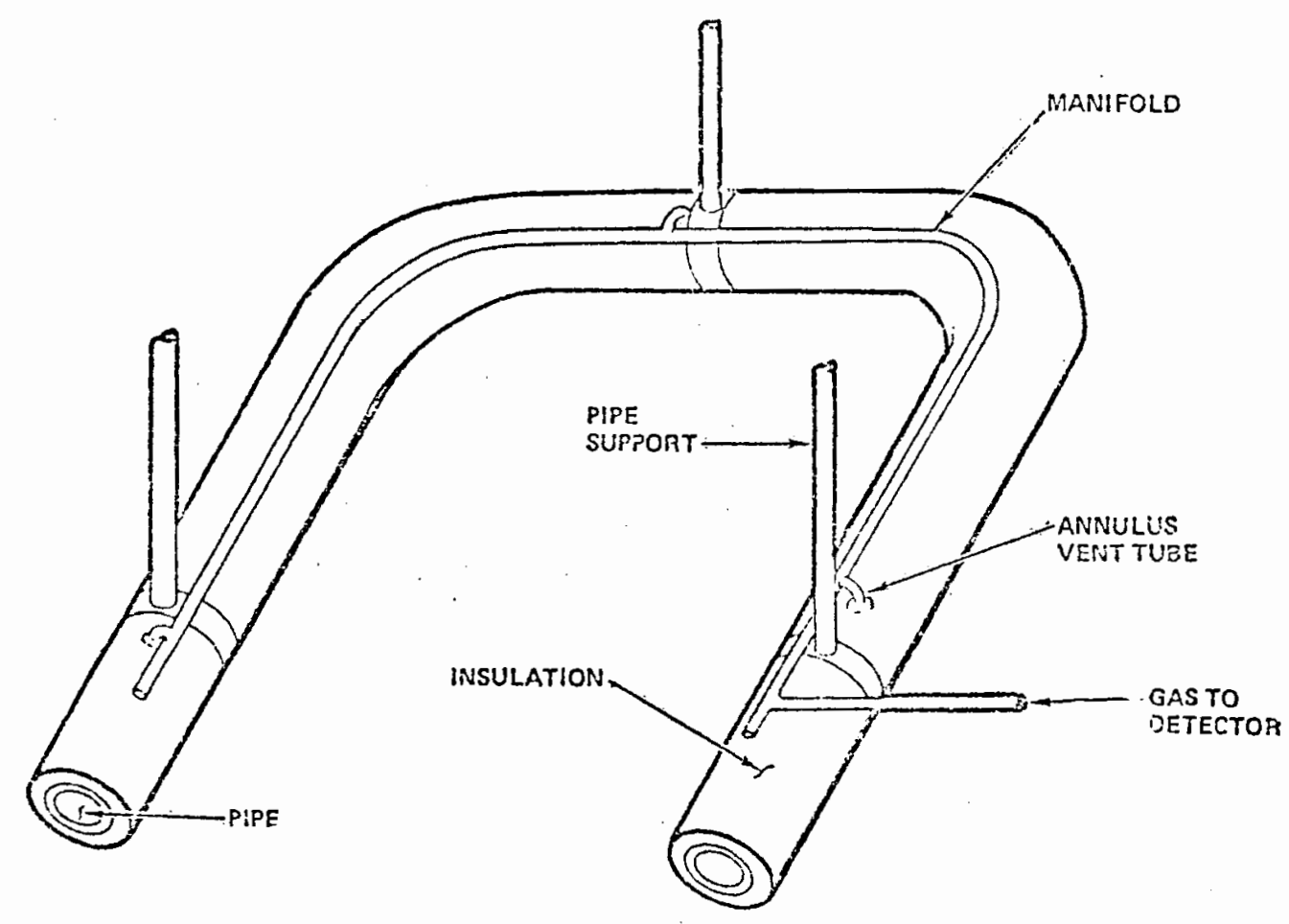

FIGURE 2-3. Aerosol Sampling Manifold (a)

(Table 2-3) show that the SID was capable of detecting small leaks in less than $1 \mathrm{hr}$ in a PHTS environment. In Test 16 (natural convection) the response of the SID (ceiling and floor) was very poor; the SID (floor) did respond after $115.6 \mathrm{hr}$. This response of $115 \mathrm{hr} 36 \mathrm{~min}$ is interesting, considering that the SID failed to respond to these identical test parameters (i.e., $2 \mathrm{~g} / \mathrm{hr}$, $500^{\circ} \mathrm{F}$, etc.) of Test 8 . Albeit, Test 8 used forced convection as opposed to natural convective flow of Test 16. Yet the SID was sampling the 1-in. annular region around the 24-in. pipe in Test 8, whereas the SID sampled at the floor in Test 16. One should note that this response at $115 \mathrm{hr} 36 \mathrm{~min}$ is significant when the actual sodium injection period was $100 \mathrm{hr}$. The SID responded $15 \mathrm{hr}$ and $36 \mathrm{~min}$ after the sodium injection had been turned off. Questionable areas concerning aerosol transport and migration via natural convective flow became apparent in this specific case.

(a) PNL visualized concept of manifold sampling. 
TABLE 2-3. Sodium Ionization Detector Cell Test Data(3)

\begin{tabular}{|c|c|c|c|c|c|c|c|c|c|c|}
\hline \multirow{2}{*}{$\begin{array}{l}\text { Test } \\
\text { No. }\end{array}$} & \multirow{2}{*}{$\begin{array}{l}\text { Sodium } \\
\text { Leak } \\
\text { Race } \\
\text { (gm/hr) }\end{array}$} & \multirow{2}{*}{$\begin{array}{c}\text { Test } \\
\text { Temperature } \\
\left({ }^{\circ} \mathrm{F}\right)\end{array}$} & \multirow{2}{*}{$\begin{array}{c}\mathrm{O}_{2} \\
\text { Content } \\
(\%)\end{array}$} & \multirow{2}{*}{$\begin{array}{l}\text { Motsture } \\
\text { Content } \\
\text { (ppory) }\end{array}$} & \multicolumn{2}{|c|}{$\begin{array}{l}\text { SID Cutzent } \\
\text { Bacigrd. }-3 X\end{array}$} & \multirow{2}{*}{$\begin{array}{l}\text { Leak } \\
\text { Duration } \\
\text { (iir) }\end{array}$} & \multirow{2}{*}{$\begin{array}{l}\text { Total } \\
\text { Sodium } \\
\text { Leaked } \\
\text { (gn) }\end{array}$} & \multicolumn{2}{|c|}{$\begin{array}{l}\text { Detector } \\
\text { Response }\end{array}$} \\
\hline & & & & & $\mathrm{C}$ & $\bar{F}$ & & & $\mathrm{C} 1$ & $F$ \\
\hline 11 & $2 \div$ & $\$ 20$ & 1 & 1000 & $0.2-$ & $\mathrm{NU}$ & 87.5 & 181 & $j<1,4$ & 汭 \\
\hline$I I R$ & 2 & 980 & 1 & 1000 & $\begin{array}{l}0.034- \\
0.102\end{array}$ & $\begin{array}{l}1.0525- \\
0.0975\end{array}$ & 85 & 170 & $<1.91$ & $<1 M$ \\
\hline 12 & $2 \div$ & 240 & 1 & 1000 & $\begin{array}{l}0.75- \\
2.25 \\
\end{array}$ & NU & 100 & 209 & $\begin{array}{r}4 \\
12 M \\
\end{array}$ & 讨 \\
\hline 13 & 2 & 900 & 21 & 1500 & $0.032-$ & $\begin{array}{l}0.027- \\
0.081\end{array}$ & 100 & 200 & 579 & $52 M$ \\
\hline $13 x$ & 2 & 900 & 21 & 1500 & $\begin{array}{l}0.042- \\
1.25 \\
\end{array}$ & $\begin{array}{l}0.38- \\
i .08\end{array}$ & 0.5 & 25 & $\begin{array}{l}15 \mathrm{H} \\
12 \mathrm{M}\end{array}$ & $\begin{array}{l}157 \\
124 \\
\end{array}$ \\
\hline 14 & 2 & 640 & 21 & 1500 & $\begin{array}{l}0.046- \\
0.136\end{array}$ & $\begin{array}{l}0.050- \\
0.150\end{array}$ & 100 & 200 & 3.4 & $5 M$ \\
\hline 15 & 2 & 400 & 21 & 1500 & $\begin{array}{l}0.020- \\
0.060 \\
\end{array}$ & $\begin{array}{l}0.021- \\
0.063 \\
\end{array}$ & 89 & 150 & $<7 M$ & $<7$ \\
\hline 16 & 2 & 500 & $i$ & 1000 & \begin{tabular}{|c|}
$0.015-1$ \\
0.045 \\
$402-1$
\end{tabular} & $\begin{array}{l}0.004- \\
0.022\end{array}$ & 100 & 200 & NR & $\begin{array}{r}1154 \\
35 i 1 \\
\end{array}$ \\
\hline 17 & 2 & 650 & 1 & 5000 & 0.072 & $\mathrm{NU}$ & 123.27 & 247 & $N R$ & NO! \\
\hline
\end{tabular}

SiD current $=$ nanoamps

$C=$ csiling $F=$ ficor

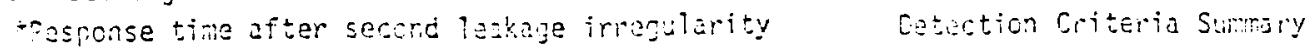

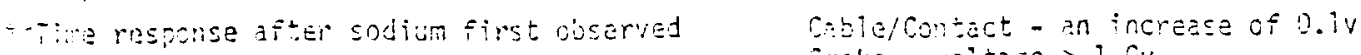

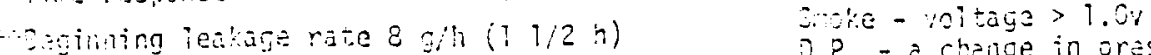

-3.1 gom injected within 12 mindtes after start D.p. - a change in pressire of 2 in. $"$ g i: irogen - an increase of $3 x$

:i test

sid - an increase of $3 x$

a. jint of sodium extrapoiated fiom test data;

?/5 (total sodium accuniulated)

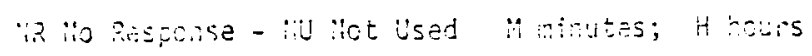

\begin{tabular}{|c|c|c|c|c|c|c|c|c|c|c|}
\hline \multirow{3}{*}{\multicolumn{2}{|c|}{ 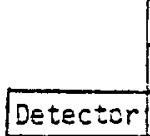 }} & \multicolumn{9}{|c|}{ FLOW RATE IN SAMPLING LINE (cc/min.) } \\
\hline & & \multicolumn{9}{|c|}{ TEST } \\
\hline & & 11 & $11 R$ & 12 & 13 & $13 x$ & 14 & 15 & 16 & 17 \\
\hline \multicolumn{2}{|c|}{$D P(C, F)$} & \multicolumn{9}{|c|}{ Flow Rate for All Tests $\$ 000$} \\
\hline \multirow[b]{2}{*}{ SID } & C & 400 & 400 & 400 & 400 & 400 & 400 & 400 & 400 & 400 \\
\hline & $F$ & Hit & 400 & iN & 400 & 400 & 400 & 400 & 400 & NU \\
\hline \multicolumn{2}{|c|}{ Hyersọen } & 1000 & 200 & 200 & 200 & 200 & 200 & 250 & 250 & 250 \\
\hline \multicolumn{2}{|c|}{ SIMP } & 1400 & 1200 & 1800 & 2000 & $\begin{array}{l}\text { See } \\
\text { Mote }\end{array}$ & $40 \Omega 0$ & Pi: & $: W$ & 满 \\
\hline
\end{tabular}

iote: The flow rate at the start of test i3x was 1000 co/mir; at the end of test $\operatorname{sog} \mathrm{cs} / \mathrm{mir}$. 
2.1.1.1.3 IHTS Test Environment. The test data show that the SID was capable of detecting small leaks in the IHTS. The majority of the test data indicated a response in less than $1 \mathrm{hr}$. However, in the tests of the 3-in. pipe section leak monitoring (Tests 16 and 17), the SID failed to respond. If small leaks are left undetected in critical auxiliary piping and components, severe corrosion of a 3-in. pipe section could become a significant plant hazard.

\subsubsection{Observer Comments on the SID}

Most sampling tubes scheduled to be used in CRBR are $100 \mathrm{ft}$ or longer (see Table 2-4). Reference 8, a proposed test plan for small-scale tests designed to study the response time characterization and optimization for LMFBR leak detectors, specifies sampling tubes $50-\mathrm{ft}$ long. These tests should give needed insight into the aerosol/vapor transport phenomena and additional performance data on the SID detector. However, PNL feels that additional tests with 100-ft lengths with appropriate bends and thermal effects typical of CRBR are warranted. It would also be instructive to put heating tape on a selected sampling line which would run exactly in parallel with a nonheated line to observe the effects of aerosol transport under nonthermal gradient conditions. Analysis of the differential pressure sensor filter would give information concerning aerosol diffusion and plateout.

Even if sampling tubes are placed in the pipe annuli and the cell, it is possible that the aerosol/vapor may be swept out of the cell before detectable quantities of aerosol exist. In actual LMFBR applications the cell environs (2000 to $\left.320,000 \mathrm{ft}^{3}\right)$ will be cooled via a recirculation cooling system. Approximately $10 \%$ of the cell volume will be recirculated by the cooling system every minute. As an example, a 100,000- $\mathrm{ft}^{3}$ vault would have a recirculation rate of $10,000 \mathrm{ft}^{3} / \mathrm{min}$. In Reference 1 Appendix $B$, the effects of cell size versus aerosol concentration for the SID were studied. Aerosol concentrations as a function of time and cell size are shown in Figure 2-4. The standard aerosol concentration (C) equation used in the analysis wâs: 
TABLE 2-4. Sodiun-to-Gas Leak Detector Location(a)

\begin{tabular}{|c|c|c|c|c|c|}
\hline & & & & & Sampling Line \\
\hline Location & Qty & Type & 10. & Elev. & Length (Ft.) \\
\hline Reactor Guard Vessel & 3 & Aeroscl & 1 & $794^{\prime}$ & 140 \\
\hline Reactor Guard Vessel & 3 & Cable & 1 & $794^{\prime}$ & 140 \\
\hline Reactor Cavity & 2 & Aerosol & 1 & $794^{\prime}$ & 100 \\
\hline (Reactor Cavity, to & Bel10 & & & & \\
\hline Cold Leg $\# 1$ & 1 & Aerosol & 1 & $794^{\prime}$ & 80 \\
\hline 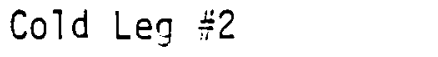 & 1 & Aerosol & 2 & $779^{\prime}$ & 50 \\
\hline Cold Leg $\cong 3$ & 1 & Aerosol & 2 & $779^{\prime}$ & 100 \\
\hline (Reactor Cavity to & Dello & & & & \\
\hline Hot Leg $\frac{n}{\pi} 1$ & 1 & Aerosol & 1 & $794^{\prime}$ & 60 \\
\hline Hot Leg $\stackrel{*}{*} 2$ & 1 & Aerosol & 2 & $779^{\prime}$ & 80 \\
\hline Hot Leg $\# 3$ & 1 & Aeroso 1 & 2 & $779^{\prime}$ & 80 \\
\hline Primary Pumps & 2 ea & Aerosol & $1 \& 2$ & $794 / 779$ & 90 \\
\hline Primary Pumps & $2 \in a$ & Cable & $1 \& 2$ & $794 / 779$ & 90 \\
\hline IHX & 2 ea & Aerosol & $1 \& 2$ & $794 / 779$ & 100 \\
\hline IHX & 2 ea & Cabie & $1 \& 2$ & $794 / 779$ & 100 \\
\hline PHTS Pipes & 3 ea & Aerosol & $1 \& 2$ & $794 / 779$ & 140 \\
\hline PHTS CeTis & 2 ea & Aerosol & $1 \& 2$ & $794 / 779$ & 100 \\
\hline (a) NRC supplied data & & & & & \\
\hline & & $\left(1-e^{-}\right.$ & & & \\
\hline where $\begin{aligned} V & =\text { volume of } \\
& t=\text { time }(\mathrm{sec}) \\
P & =\text { gas flow } \\
R & =\text { aerosol } 1 \mathrm{t}\end{aligned}$ & $\begin{array}{l}\text { test } \\
\text { through } \\
\text { eakage }\end{array}$ & $\begin{array}{l}1\left(\mathrm{~cm}^{3}\right) \\
\text { he two ga } \\
\text { te throug }\end{array}$ & $\begin{array}{l}\text { ling } \\
\text { aeros }\end{array}$ & $\begin{array}{l}(\mathrm{cc} / \mathrm{sec}), \\
\text { pling noz }\end{array}$ & $(g / \sec )$ \\
\hline $\begin{array}{l}\text { The gas flow rate use } \\
\text { sampling rate is not } \\
\text { AI tests. The SID f }\end{array}$ & $\begin{array}{l}\text { ed in } \\
\text { indica } \\
\text { low rat }\end{array}$ & $\begin{array}{l}\text { analysi } \\
\text { ef tho }\end{array}$ & $\begin{array}{l}167 \\
\text { w rat }\end{array}$ & $\begin{array}{l}(10,020 \\
t \text { have } b \\
\text { indicate }\end{array}$ & $\begin{array}{l}n) \text {. This } \\
\text { sed during } \\
t \text { flow }\end{array}$ \\
\hline
\end{tabular}




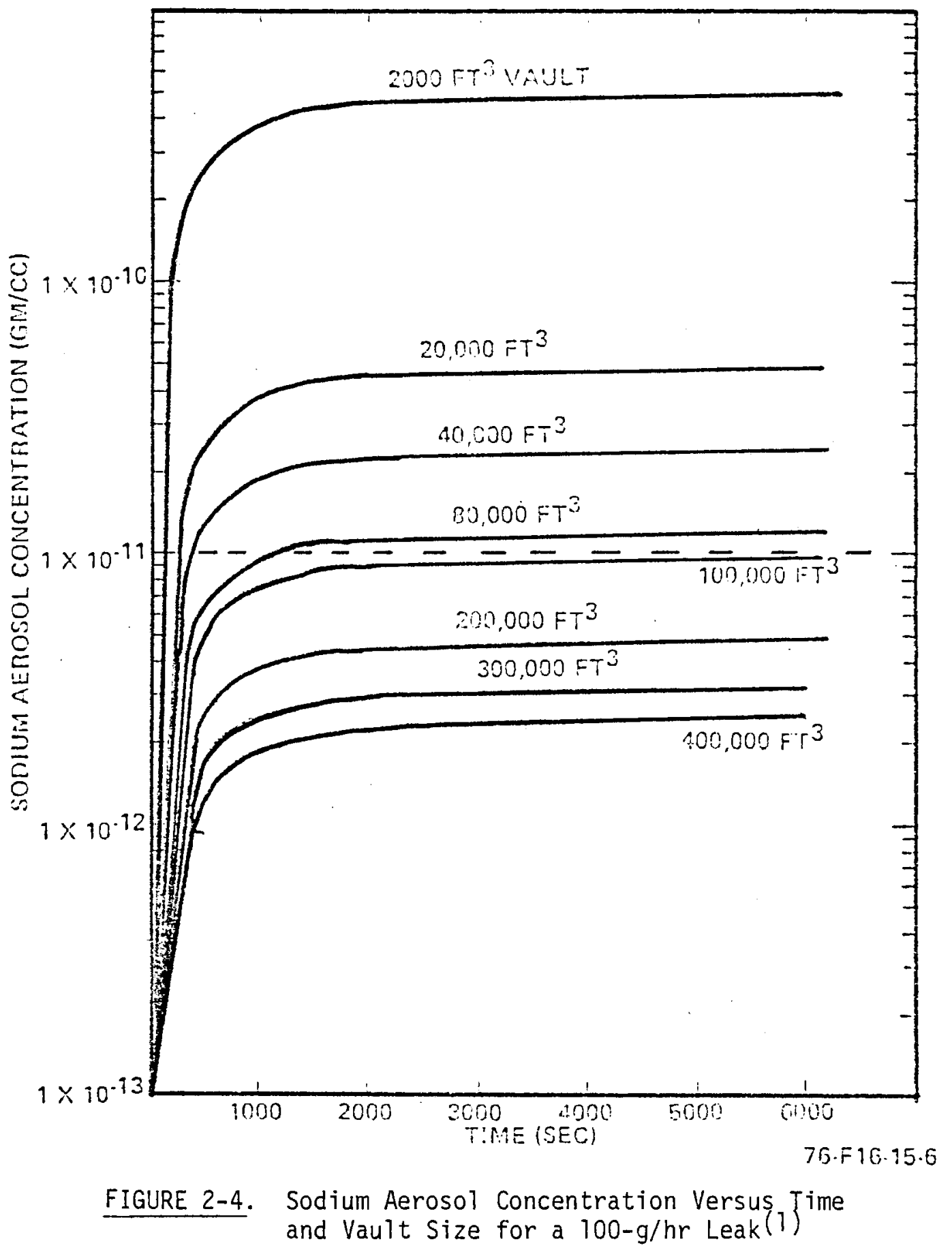


rates of $5.0 \mathrm{l} / \mathrm{min}(5000 \mathrm{cc} / \mathrm{min})$ will be tested. Therefore, the value of $R$ used in Reference 1 is a factor of two over that specified in the PSAR. It is also interesting to note in this analysis and in tests reported by $A I$, there is no mention of the placement or use of the electric heating tape that will circle the inner stainiess steel 1iner. This 1/8-in. thick 1ayer of electrically insulated tape could affect the aerosol leakage rate $(R)$.

Regardless of this inconsistency, Figure 2-4 does illustrate an interesting point with respect to the cell recirculation cooling system. A typical primary cell volume is $100,000 \mathrm{ft}^{3}$. The conclusion of this study stated that a detection threshold of $10^{-11} \mathrm{~g} / \mathrm{cc}$ for aerosol monitors would be reached for a maximum cell size of $100,000 \mathrm{ft}^{3}$. A conservative estimate of $3000 \mathrm{sec}$ $\left(0.8 \mathrm{hr}\right.$ ) would be required before the $10^{-11} \mathrm{~g} / \mathrm{cc}$ criterion was met. When one considers a $10,000 \mathrm{ft}^{3} /$ min recirculation rate, it becomes apparent that the total cell volume will have been cooled and recycled approximately five times in that time span. It is likely that $100 \%$ of the aerosols entering the cell recirculation system is lost. Thus, a detection level of $10^{-11} \mathrm{~g} / \mathrm{cc}$ may never occur under these conditions. To our knowledge, the recirculation rates of interest were not simulated during the LMEC Mockup and Natural Convection Tests. Because some primary contairment cells will be larger than 100,000 $\mathrm{ft}^{3}$, one would infer that the detection threshold in these cells may never be reached.

\subsubsection{Differential Pressure Detector}

The differential pressure detector (DP) consists of a filter holder, a filter pad and a differential pressure transducer. Gases are drawn and passed through the filters at a constant flow rate of $5000 \mathrm{cc} / \mathrm{min}$. A sodium leak is indicated by an increase in pressure across the filter resulting from the plugging of the filter pad by aerosol particles collected (integrated) as a function of time. The required response time is a function of the leak rate and the concentration of aerosols generated. The filter pads can be removed and chemically analyzed to verify the presence of sodium. 
The DP detector physical layout and instrumentation are shown in Figures 2-5 and 2-6, respectively. Response to pressure changes is indicated by pressure gauges and a strip chart recorder. Under plant conditions, the electrical signal from the differential pressure transducer can be transmitted to an annunciator panel with preset alarm limits. When the differential pressure increases across the filter, the transducer output will increase to a predetermined alarm condition.

\subsubsection{DP Test Data Evaluation}

PNL's evaluation of the DP included a review of the test conditions and detector performance in the PHTS and IHTS test environments.

\subsection{Test Conditions. The DP detection criterion in Tests 1} through 10 (Table 2-5) was based on a differential pressure change of $10 \mathrm{in}$. of $\mathrm{H}_{2} \mathrm{O}$ from the initial pressure reading. In Tests 11 through 17 (Table 2-6), the detection criterion was changed to 2 in. of $\mathrm{H}_{2} \mathrm{O}$.

The DP detector sampling flowrate was $5000 \mathrm{cc} / \mathrm{min}$ for a11 17 tests. The length and path complexity of the sampling tubes used in these tests were not documented in the references.

Natural convection Tests 9 through 17 were designed to examine the possibility of sodium aerosol/vapor detection by cell gas monitoring.

2.1.2.1.2 PHTS Test Environment. Results for Tests 7 through 8 (Table 2-5) show that the DP (annulus) did not give an alarm response in any of the four tests. However, upon chemical inspection of the DP filter element, significant quantities $(130 \mathrm{\mu g})$ of sodium were found. This finding does constitute leak detection. The chemical analysis technique appears to be the major advantage of the DP over the SID, providing the DP detector with additional redundancy, sensitivity and reliability.

Forced convection Tests 7 through 8 show that the DP will respond with chemical detection under low temperature, low leak rate conditions. In general, the forced convection test results for the PHTS environment indicate that the DP response rate with respect to a pressure buildup and alarm indication is slower than the SID. 


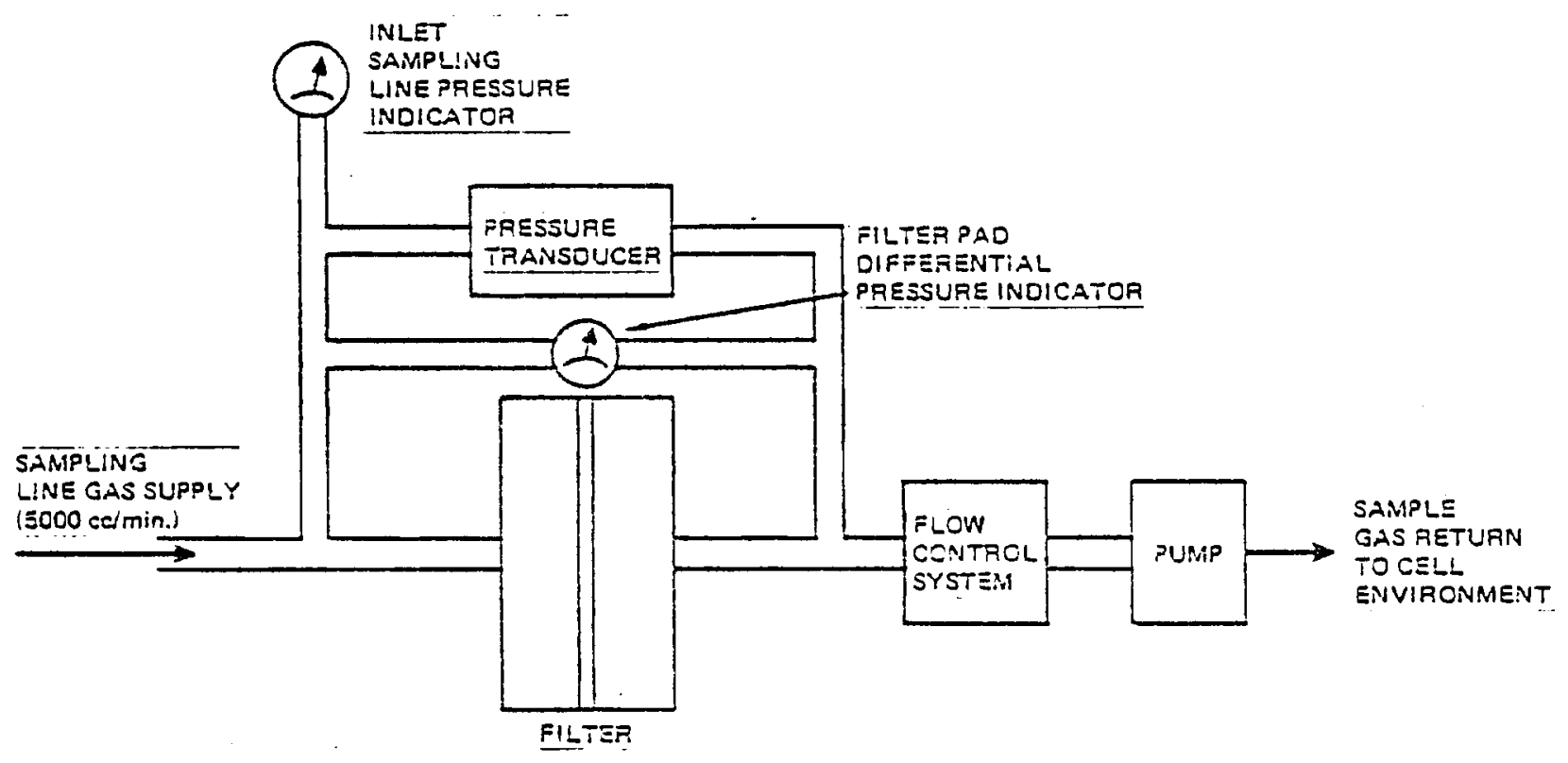

FIGURE 2-5. Differential Pressure Detector Physical Layout ${ }^{(2)}$

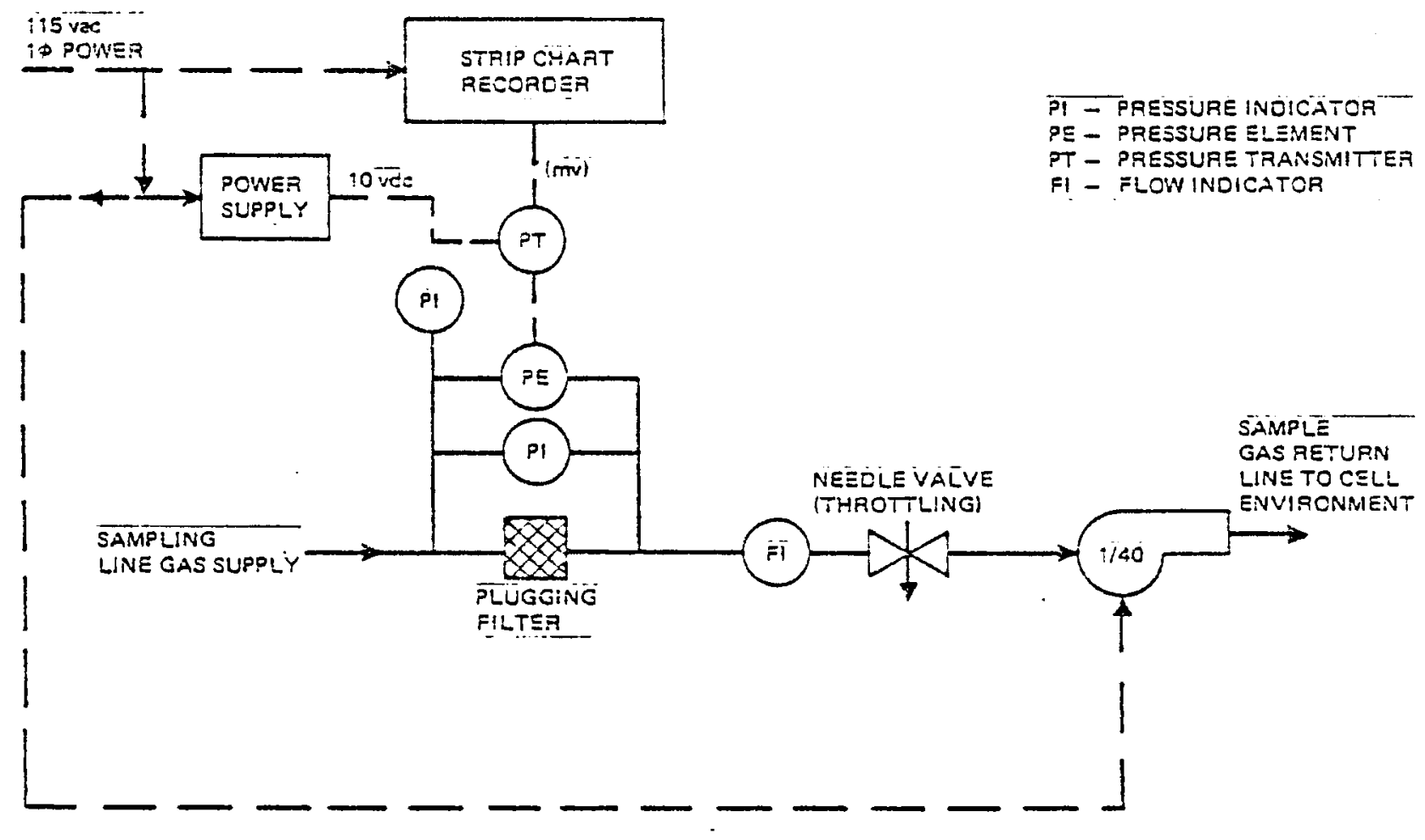

FIGURE 2-6. Differential Pressure Detector Instrumentation (2) 
TABLE 2-5. Differential Pressure Detector Ce17 Test Data (3)

\begin{tabular}{|c|c|c|c|c|c|c|c|c|}
\hline \multirow{3}{*}{$\begin{array}{c}T c s t \\
\therefore o .\end{array}$} & \multicolumn{6}{|c|}{ Jas: Parancess } & \multirow{2}{*}{\multicolumn{2}{|c|}{$\begin{array}{l}\text { Detector } \\
\text { Rriponse } \\
\text { (hir) }\end{array}$}} \\
\hline & \multirow{2}{*}{ 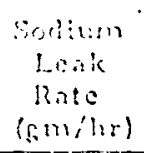 } & \multirow{2}{*}{$\begin{array}{c}\text { Test } \\
\text { Teniperature } \\
\text { (0) }\end{array}$} & \multirow{2}{*}{$\begin{array}{l}\mathrm{O}_{2} \\
(" i u)\end{array}$} & \multirow{2}{*}{$\begin{array}{c}\text { Boisture } \\
\text { (bpar) }\end{array}$} & \multirow{2}{*}{$\begin{array}{l}\text { Artual } \\
\text { Oaleak } \\
\text { buation } \\
\text { (hr) }\end{array}$} & \multirow{2}{*}{$\begin{array}{l}\text { Tobal } \\
\text { Solinan } \\
\text { ledsut } \\
\text { (gm) }\end{array}$} & & \\
\hline & & & & & & & Annulis & $C 0.11$ \\
\hline 1 & 100 & 9,50 & 1 & 1,000 & 10 & 1000 & 0.933 & 1.26 \\
\hline 2 & 100 & $\$ 00-300$ & 1 & 1,000 & 10 & 1000 & 26.90 & $26.93^{\circ}$ \\
\hline 3 & 100 & $\begin{array}{c}6: 0-320 \\
.\end{array}$ & 21 & 30,000 & $\begin{array}{l}6 / \text { raise } \\
\text { temp/6. }\end{array}$ & 1200 & 6.16 & 6.16 \\
\hline 4 & 0.4 & 5,50 & 1 & 1,000 & 250.0 & 100 & 6.55 & 2.5 \\
\hline 5 & $31.0^{1}$ & $\therefore 00$ & 21 & 10,000 & 0.016 & 31 & 1.0 & 1.0 \\
\hline 5 & 2.0 & $350-650^{\circ}$ & 21 & 30,000 & 200 & $\div 00$ & $97.9^{*}$ & 47.4 \\
\hline 6 & $2.0^{\xi}$ & 650 & 21 & 30,000 & 20 & 40 & 14.0 & 11.4 \\
\hline $7 x$ & 100 & 400 & 1 & 1,000 & 2.5 & 200 & $N R^{\star \star}$ & $\therefore x^{* *}$ \\
\hline $7 Y$ & 100 & 400 & 1 & $.1,000$ & -0.1 & 4000 & $N R * \star$ & $\operatorname{lin} x$ \\
\hline 7 & 100 & 400 & 1 & 15,160 & 20 & 2000 & $N R^{* \star}$ & $\because R^{* \star}$ \\
\hline 8 & 2 & 500 & 1 & 1,000 & 50 & 100 & $\therefore R^{\star \star}$ & $\operatorname{Nin} * x$ \\
\hline$?$ & 100 & 930 & 1 & 1,000 & 9.5 & 950 & $\frac{\text { Ceili:: }}{9.5}$ & $\frac{51005}{0,50}$ \\
\hline $3 R$ & 100 & .90 & 1 & 1,000 & 4.3 & 430 & 3.9 & 3.9 \\
\hline 10 & 100 & 980 & 1 & 1,000 & 8.4 & $3 \div 0$ & 7.2 & 8.4 \\
\hline
\end{tabular}

$N R=$ No response wiss observed

$\because \Lambda$ lcak was found in the has system at the DPCell

$131 \mathrm{fm}$ injecter? in less ti:an 1 minute as a spray

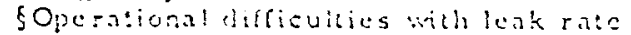

$\dot{x}$ Chemical detection (filter pad analysis)

DETECTION CRITERION

The DP detection criterion is a change

in differential pressure of 10 in. of $\mathrm{H}_{2} \mathrm{O}$.

Sampling flow rate $5000 \mathrm{cc} / \mathrm{min}$. 
TABLE 2-6. Differential Pressure Detector Cel1 Test Data(2)

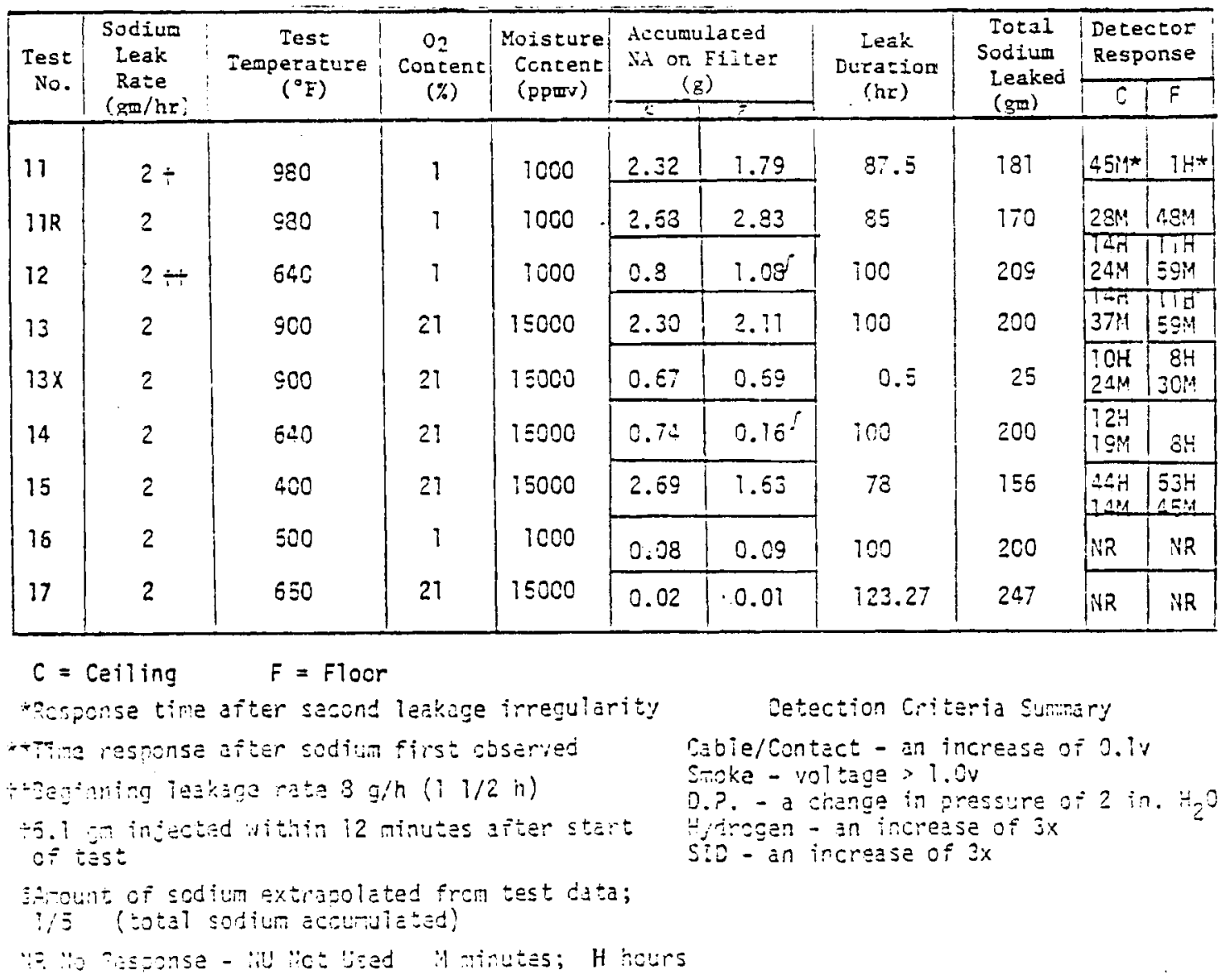

\begin{tabular}{|c|c|c|c|c|c|c|c|c|c|}
\hline & \multicolumn{9}{|c|}{ FLOW RATE IN SAMPLING LINE (csimin.) } \\
\hline & \multicolumn{9}{|c|}{ TEST } \\
\hline Detactori & 111 & $17 R$ & 32 & 131 & $13 x$ & 14 & 15 & 10 & 17 \\
\hline$D P(C, F)$ & \multicolumn{9}{|c|}{ Fiow Rate for Ail Tests 5000} \\
\hline \multirow[b]{2}{*}{$5 i 0$} & 400 & 400 & 400 & 400 & 400 & 1400 & 4001 & 400 & 400 \\
\hline & iU & 400 & $8 \mathrm{iU}$ & 400 & 400 & 400 & 402 & $\div 00$ & $\mathrm{Nij}$ \\
\hline Hydrocen & 1000 & 200 & 200 & 200 & 200 & 200 & 250 & 250 & $2 \Xi 0$ \\
\hline SIMP & 1400 & $i 300$ & 1800 & 2000 & $\left\{\begin{array}{l}\text { Ses } \\
10=0\end{array}\right.$ & $\operatorname{seco}$ & 汭 & NU & iu \\
\hline
\end{tabular}


The usefulness of the chemical analysis technique is further revealed upon inspection of the natural convection test data (Table 2-6). In Test 16, the tightly insulated 3-in. pipe was leak-monitored by the DP at the ceiling and floor. The DP did not give an alarm indication. However, the test data show that major quantities of sodium had accumulated on the DP filter element (ceiling $80,000 \mu \mathrm{g}$, floor $90,000 \mu \mathrm{g}$ ) after $100 \mathrm{hr}$ leak duration $(200 \mathrm{~g}$ released). Data from Tests 11 through 17 show that, for a typical PHTS environment (smal1 cel1, $1500 \mathrm{ft}^{3}, 2 \mathrm{~g} / \mathrm{hr}$ leak rate), the aerosol/vapor mixing is not uniform. Examination of the amount of sodium accumulated on the DP filter element from the ceiling and floor sampling locations in Tests 11 through 12, and 16 shows that the majority of sodium was accumulated from floor sampling. Only in Test 11 did the ceiling sampling location yield a greater accumulation of sodium on the DP filter than the floor. Data from these natural convection tests show that for constant leak rates, higher temperature sodium generates larger quantities of microgram aerosols.

2.1.2.1.3 IHTS Test Environment. The DP detector response in tests simulating the IHTS environment was very similar to that in the PHTS environment. In both the forced and natural convection tests the DP response to sodium accumulation and subsequent pressure buildup which trips an alarm ranged from $130 \mu \mathrm{g}$ to $2.83 \mathrm{~g}$. The natural convection test data indicate that the aerosol mixing is not uniform under small cell (1500 $\mathrm{ft}^{3}$ ) laboratory conditions. Most of the sodium had accumulated at the ceiling sampling location. This result is opposite to that achieved under PHTS conditions, in which the majority of sodium had accumulated via floor sampling. Only in Test $13 X$ was there an increase in sodium accumulated via floor sampling.

Test 17 is another example of the unique response achieved by the chemical analysis of filter technique. This test had a leak duration of $123.27 \mathrm{~h}$ which injected $247 \mathrm{~g}$ of sodium at $650^{\circ} \mathrm{F}$ into the cell (3-in. pipe). The DP filter analysis showed that some $20,000 \mu \mathrm{g}$ (ceiling) and 10,000 $\mu \mathrm{g}$ (floor) of sodium had accumulated on the DP filter element. 


\subsubsection{Observer Comments on the DP Detector}

The comments of Section 2.1.1.2 concerning the SiD directly relate to the operational performance of the differentiai pressure detector.

\subsubsection{Smoke Detector}

The smoke detector is a commercially available unit, proposed for CRBRP use to monitor the cell atmosphere for sodium aerosols. The physical layout of the smoke detector is shown in Figure 2-7. The smoke detector tested at LMEC operates on an ionization principle; combustion products entering the detector's outer chamber disturb the balance between it and the inner reference chamber. This unbalance causes the gas discharge tube to ignite, generating a signal indicating the presence of combustion products. The detector has a sensitivity adjustment permitting easy calibration over a wide range of values. Responses to sodium aerosols or smoke are indicated on a data logger.

\subsubsection{Smoke Detector Test Data Evaluation}

PNL evaluated the smoke detector test data from the supporting references. The review included test conditions and detector performance in both PHTS and IHTS environments.

2.1.3.1.1 Test Conditions. The smoke detector was subjected to 17 tests. The criterion for leak detection in all tests was defined as a voltage greater than 1.0 .

2.1.3.1.2 PHTS Test Environment. As indicated by Table 2-7, the smoke detector did not respond in Tests $7,7 X$, and $7 Y$ but did respond very rapidly (within $39 \mathrm{~min}$ ) in Test 8 . This is interesting when one considers that a $2 \mathrm{~g} / \mathrm{hr}$ leak rate was used in Test 8 and only $1.3 \mathrm{~g}$ of sodium was injected before the detection criterion was reached. The sodium temperature was $500^{\circ} \mathrm{F}$ in Test 8, compared to $400^{\circ} \mathrm{F}$ in Tests $7,7 \mathrm{X}$, and $7 \mathrm{Y}$. However, in Tests 7 and $7 Y$, sodium was injected at a rate of $100 \mathrm{~g} / \mathrm{hr}$, with total sodium quantities leaked being $2000 \mathrm{~g}$ and $4000 \mathrm{~g}$, respectively. Therefore, the response achieved in Test 8 with $1.3 \mathrm{~g}$ of sodium spilled is puzzling when compared to responses to Tests 7 and $7 Y$, where as much as $4000 \mathrm{~g}$ went undetected. 


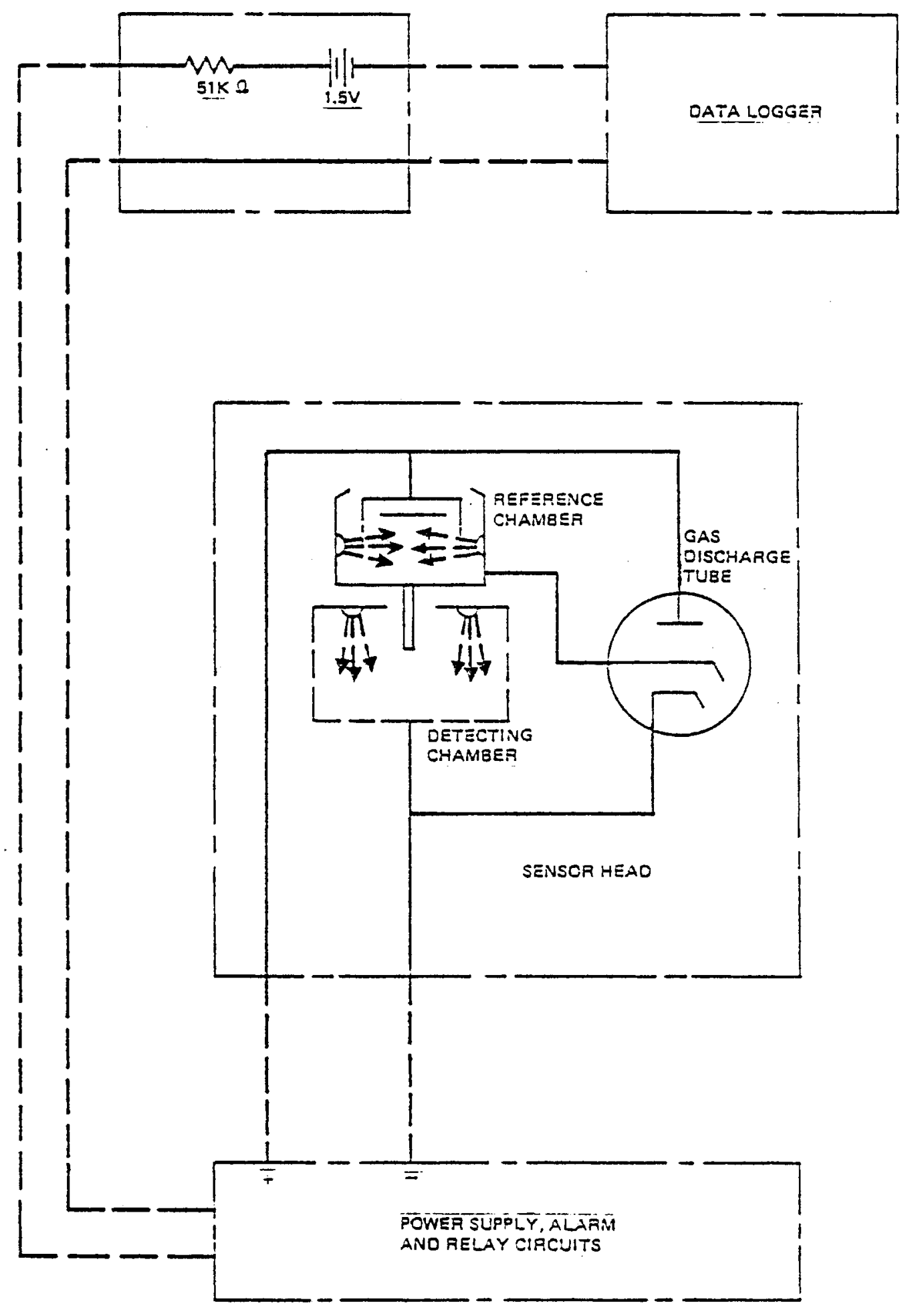

FIGURE 2-7. Pyr-A-Larm Smoke Detector System ${ }^{(2)}$ 
TABLE 2-7. Smoke Detector Test Data (3)

\begin{tabular}{|c|c|c|c|c|c|c|c|}
\hline \multirow[b]{2}{*}{$\begin{array}{l}T: 5 t \\
\because 0 .\end{array}$} & \multicolumn{6}{|c|}{ Test Paramelers } & \multirow[b]{2}{*}{$\begin{array}{l}\text { Patector } \\
\text { Sesponse } \\
\text { (hir) }\end{array}$} \\
\hline & $\mid \begin{array}{l}\text { Sodium } \\
\text { Lask } \\
\text { Ratio } \\
(\mathrm{gm} / \mathrm{in})\end{array}$ & $\begin{array}{c}\text { Test } \\
T e x p e r a t u e \\
(05)\end{array}$ & $\begin{array}{l}O_{2} \\
(\because, 0)\end{array}$ & $\begin{array}{c}\text { Moisture } \\
\text { (pposis) }\end{array}$ & $\begin{array}{c}\text { Actual } \\
\text { Na Lenk } \\
\text { Diration } \\
\text { (hr) }\end{array}$ & $\begin{array}{l}\text { Total } \\
\text { Sotiugu } \\
\text { lonfed } \\
\text { (g:n) }\end{array}$ & \\
\hline 1 & 100 & 990 & 1 & 1,000 & 10 & 1000 & NU \\
\hline 2 & 200 & $400-700$ & 1 & 1,000 & 10 & 1000 & NU \\
\hline 3 & .100 & $6 \div 0-920$ & 21 & 30,000 & $\begin{array}{l}6 \mathrm{hr} / \mathrm{raise} \\
\text { temp/6 hr }\end{array}$ & 1200 & 6.06 \\
\hline 4 & 0.4 & 990 & 1 & 1,000 & & 100 & $\mathrm{NU}$ \\
\hline $5 x$ & $31.0 *$ & $\$ 00$ & $2 !$ & 10,000 & 0.016 & 31 & 0.03 \\
\hline 5 & 2.0 & $350-5,50$ & 21 & 30,000 & 250.0 & 400 & 31.8 \\
\hline 6 & $2.0^{\dagger}$ & 650 & 21 & 30,000 & 20.0 & 40 & NR \\
\hline $7 x$ & $100^{t}$ & 400 & 1 & 1,000 & 2.5 & $\sim 200$ & NR. \\
\hline $7 Y$ & 100 & 400 & 1 & 1,000 & $\sim 0.1$ & $\sim 5000$ & $N R$ \\
\hline 7 & 100 & 400 & 1 & $15,160^{5}$ & 20 & 2000 & $\mathrm{NR}$ \\
\hline 8 & 2 & 500 & 1 & 1,000 & 50 & 100 & 0.65 \\
\hline 9 & 100 & 920 & 1 & 1,000 & 9.5 & 950 & 0.08 \\
\hline $9 \mathrm{R}$ & 100 & 9.80 & 1 & 1,000 & 4.3 & $\therefore 30$ & $N R$ \\
\hline 10 & 100 & 980 & 1 & 1,000 & 8.4 & 340 & NR \\
\hline $\begin{array}{l}\because U= \\
\because \mathrm{U}= \\
\because \quad= \\
\dagger= \\
\tilde{j}=\end{array}$ & $\begin{array}{l}\text { Oot lised } \\
\text { Oe respo } \\
31 \text { gms i } \\
\text { operation } \\
\text { operation }\end{array}$ & 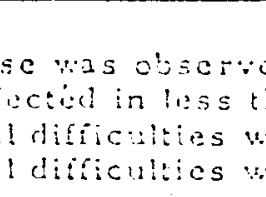 & $\begin{array}{l}a n c 5 \\
\vdots 2 \leq 0 \\
\vdots=0\end{array}$ & $\begin{array}{l}\text { eminute } \\
\text { ilm loak } \\
\text { isiuresens }\end{array}$ & . & $\leq:$ & \\
\hline
\end{tabular}


In Test 9 (natural convection, vent tubes open), the smoke detector responded in $5 \mathrm{~min}$. However, there was no response in Test $9 R$ where identical parameters were used. The response in Test 9 was achieved after only $8 \mathrm{~g}$ of sodium had been injected into the cell. There was no response in Test 10 from the smoke detector; however, in this particular test the vent tubes were closed. As shown in Table 2-8, the smoke detector did not respond in natural convection Tests $11,11 \mathrm{R}, 12$ and 16. However, it is interesting to note the rapid response of Test 8 (forced convection). This was not achieved in Tests 11, 11R or 12, considering the quantity of sodium spilled was approximately twice that of Test $8(\sim 200 \mathrm{~g}$ versus $100 \mathrm{~g})$.

2.1.3.1.3 IHTS Test Environment. The smoke detector responded in Tests 3, 5, and $5 x$, but failed to respond in Test 6 . In Test 3 (cel1) the smoke detector responded in $6 \mathrm{hr} 4 \mathrm{~min}$. In Test 5 the smoke detector responded in $31 \mathrm{hr} 48 \mathrm{~min}$. In Test $5 \mathrm{X}$, the smoke detector responded in $2 \mathrm{~min}$.

The smoke detector response in forced convection Test 5 was $31 \mathrm{hr} 48 \mathrm{~min}$ with a total sodium spill of $400 \mathrm{~g}$. Natural convection Tests 13, 14, and 15 were similar, yet the smoke detector failed to respond to approximately $200 \mathrm{~g}$ of sodium spilled during these tests.

\subsubsection{Observer Comments on the Smoke Detector}

The comments stated in Section 2.1.1.2 directly relate to the operational performance of the smoke detector. Refer to Section 2.1.1.2 for pertinent comments.

\subsubsection{Hydrogen Detector}

The hydrogen detector proposed for CRBRP use is a commercially available laboratory-grade gas chromatograph. This device separates and analyzes sample gas from the test cell environment. In the presence of moisture, a sodium leak will generate hydrogen gas that can be monitored by the detector and used as an indicator of a sodium leak. 
TABLE 2-8. Smoke Detector Cel1 Test Data (2)

\begin{tabular}{|c|c|c|c|c|c|c|c|}
\hline \multirow[b]{2}{*}{$\begin{array}{r}T \cdot{ }_{1} t \\
\therefore 0 .\end{array}$} & \multicolumn{6}{|c|}{ Lse paranded } & \multirow[b]{2}{*}{$\begin{array}{c}\text { Desecor } \\
\text { andons } \\
\text { and }\end{array}$} \\
\hline & 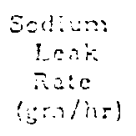 & $\begin{array}{c}\text { Test } \\
\text { Tengesture } \\
\left(0^{\circ} F\right)\end{array}$ & $\begin{array}{l}02 \\
1 \therefore 9\end{array}$ & 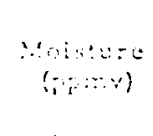 & 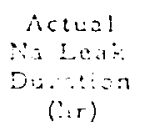 & 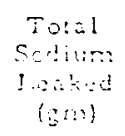 & \\
\hline 11 & $2 \div$ & 980 & 1 & 1000 & 87.5 & 181 & $N R$ \\
\hline IIR & 2 & 980 & 1 & 1000 & 85 & 170 & PiR \\
\hline 12 & $2 \div$ & 540 & 1 & $i 000$ & 100 & 209 & iR \\
\hline 13 & 2 & 900 & 21 & 15000 & 100 & 200 & NR \\
\hline $13 x$ & 2 & 900 & 21 & 15000 & 0.5 & 25 & NR \\
\hline 14 & 2 & 640 & 21 & 15000 & 100 & 200 & NR \\
\hline$! 5$ & 2 & 400 & $2 i$ & 15000 & 78 & 156 & HiR \\
\hline 16 & 2 & 500 & 3 & 1000 & 100 & 200 & $N R$ \\
\hline 17 & 2 & 650 & $2 ?$ & 15000 & 123.27 & 247 & MR \\
\hline
\end{tabular}

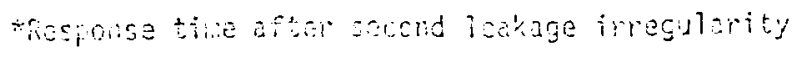

* Tine response after sodiun first cbsared Titeginning leaknge rate $8 \mathrm{~g} / \mathrm{h}(1 / 2 \mathrm{~h})$

tó.1 gm injected within 12 minutes after start of test

Eximount of sodiun extrapolated from test dita;

$1 / 5$ (total sodiun acclinilated)

AR :Hesponse - in iot used if ninutes; it hours
Cetection Criteria Eurary Cabie/Conizct - an increase of $0.1 \mathrm{y}$ croke - voltage > 1.0v D.P. - a change in pressure of $2 \mathrm{in} . !_{2} 0$ lycrocen - an increase of $3 x$ Sid - an increase of $3 x$ 
The gas chromatograph shown in Figure $2-8$ consists of:

- a column containing the substrate or stationary phase;

- a supply of inert carrier gas (nitrogen), which is designated as the moving phase and continuously passed through the column;

- inlets for injecting the sample gases into the carrier stream;

- a detector to sense sample gases as they elute; and

- a recorder.

\subsubsection{Hydrogen Detector Test Data Evaluation}

The test conditions and detector responses reported in the specified references were evaluated by PNL.

2.1.4.1.1 Test Conditions. A commercial hydrogen gas chromatograph was used in Tests 1 through 17 to monitor for increases in hydrogen resulting from the reaction of sodium with water vapor present in the cell gas. This reaction is expressed chemically as $\mathrm{Na}+\mathrm{H}_{2} \mathrm{O} \rightarrow \mathrm{NaOH}+1 / 2 \mathrm{H}_{2}$; as shown, the resulting reaction products are sodium hydroxide and hydrogen gas.

The hydrogen leak detection criterion was defined as a concentration three times that of the background level recorded at the beginning of the test. Typical background levels were 0 to $5 \mathrm{vppm}$.

2.1.4.1.2 PHTS Test Environment. An analys is of Tests 1 through 10, summarized in Table 2-9, indicates that the hydrogen detector is a most sensitive instrument. Test 4 especially supports this indication. In this test, $908^{\circ} \mathrm{F}$ sodium was injected at a leak rate of $0.4 \mathrm{~g} / \mathrm{hr}$. The hydrogen detector responded to this very small leak with a peak level increase above the initial background of $16 \mathrm{ppm}$.

In Tests $2,7,7 X, 7 Y$ and 8 , sodium at temperatures ranging from 400 to $500^{\circ} \mathrm{F}$ was tested at leak rates of 100 and (Test 8 ) $2 \mathrm{~g} / \mathrm{hr}$. The hydrogen detector (ce11) responded in every case. 


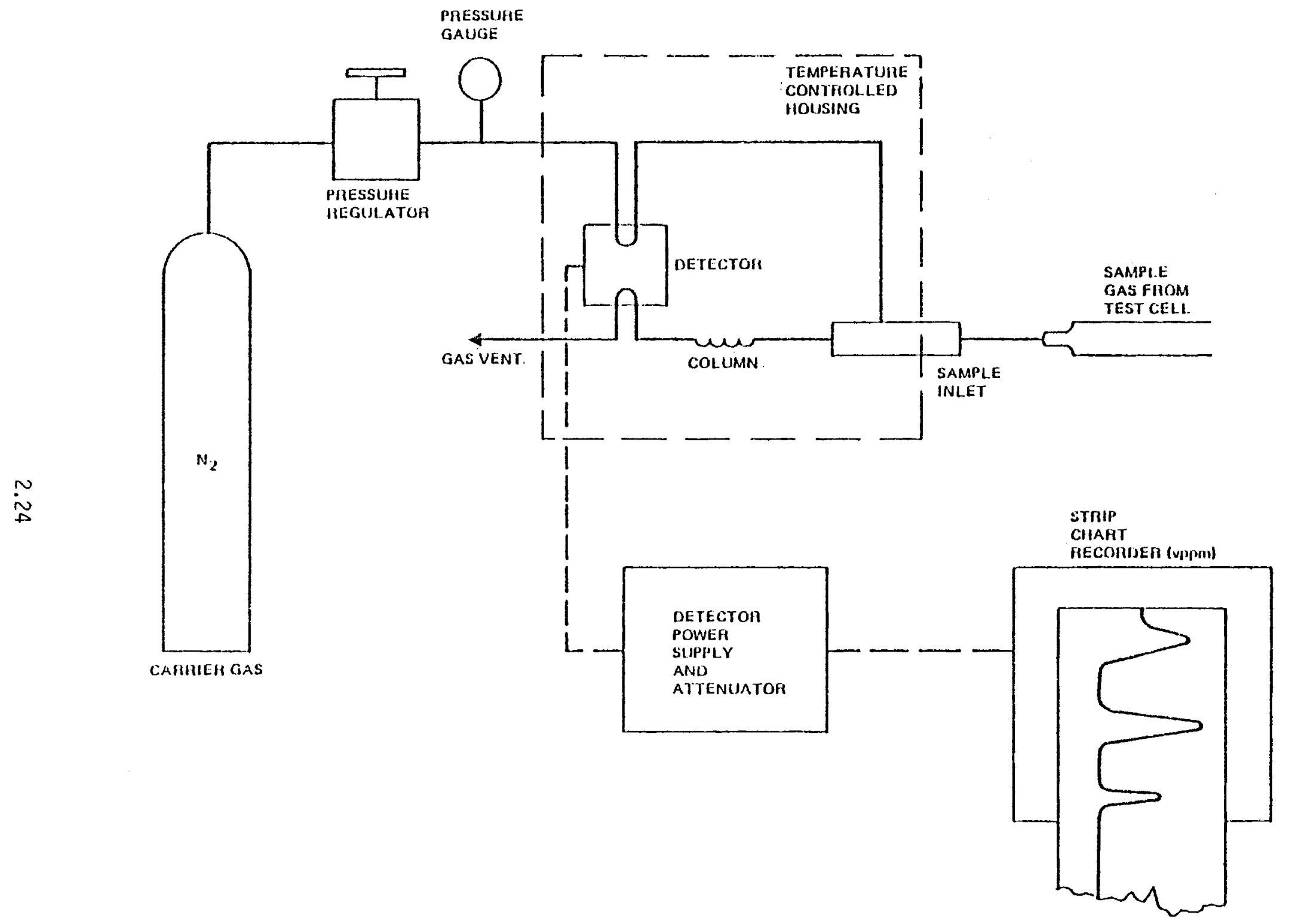

FIGURE 2-8. Basic Elements of a Gas Chromatograph (2) 
TABLE 2-9. LMEC Test Data for Hydrogen Detector (3)

\begin{tabular}{|c|c|c|c|c|c|c|c|}
\hline $\begin{array}{l}\text { Test } \\
\text { No. }\end{array}$ & $\begin{array}{l}\text { Sodium } \\
\text { Leak } \\
\text { Rate } \\
\text { (gm/hr) }\end{array}$ & $\begin{array}{c}\text { Test } \\
\text { Temperature } \\
\left({ }^{\circ} \mathrm{F}\right)\end{array}$ & $\begin{array}{c}\mathrm{O}_{2} \\
\text { Content } \\
\left(n^{\prime}(1)\right.\end{array}$ & $\begin{array}{l}\text { Moisture } \\
\text { Content } \\
\text { (ppriv) }\end{array}$ & $\begin{array}{c}112 \text { Levels } \\
\text { Initial-lithhest } \\
\text { (ppn) }\end{array}$ & $\begin{array}{l}\text { Leak } \\
\text { Duration } \\
\text { (hr) }\end{array}$ & $\begin{array}{l}\text { Total } \\
\text { Sodium } \\
\text { Leaked } \\
(\mathrm{gm})\end{array}$ \\
\hline 1 & \multicolumn{7}{|c|}{ No $I_{2}$ monitoring during this test } \\
\hline 2 & .100 & $400-700$ & 1 & 1,000 & $<5,>520$ & 10 & 1000 \\
\hline 3 & 100 & $640-920$ & 21 & 30,000 & $<5,200$ & $\begin{array}{l}6 / \text { raise } \\
\text { temp/6 }\end{array}$ & 1200 \\
\hline 4 & 0.4 & 1000 & 1 & 1,000 & $<5,16$ & 250 & 100 \\
\hline 5 & 2.0 & $350-650$ & 21 & 30,000 & $<5,>500$ & 200 & 400 \\
\hline $5 x$ & 31.0 & 400 & $2 !$ & 10,000 & $<5,85$ & 0.016 & 31 \\
\hline 5 & 2.0 & $350-650$ & 21 & 30,000 & $<5,>500$ & 200 & 400 \\
\hline 6 & 2.0 & 650 & 21 & 30,000 & $<5,480$ & 20 & 40 \\
\hline $7 x$ & 100 & 400 & 1 & 1,000 & $<5,>43$ & 2.5 & 200 \\
\hline $7 Y$ & 100 & 400 & 1 & 1,000 & $<5,>1000$ & 0.1 & 4000 \\
\hline 7 & 100 & 400 & 1 & 15,160 & $<5,>850$ & 20 & 2000 \\
\hline 8 & 2 & 500 & 1 & 1,000 & $<5,>400$ & 50 & 100 \\
\hline 9 & 100 & 980 & 1 & 1,000 & $<5,>250$ & 9.5 & 950 \\
\hline OR & 100 & 980 & 1 & 1,000 & $<5,>55$ & 4.3 & 430 \\
\hline 10 & 100 & 980 & 1 & 1,000 & $<5,>220$ & 8.4 & 840 \\
\hline $\begin{array}{l}\text { Inci- } \\
\text { dent } \\
\text { No. } 1\end{array}$ & NA & $27 !$ & 21 & 30,000 & $<5,>1500$ & 0.1 & 3632 \\
\hline $\begin{array}{l}\text { Irei- } \\
\text { dent } \\
\text { No. } 2\end{array}$ & $N A$ & 275 & 21 & 30,000 & $<5,>275$ & 0.1 & 681 \\
\hline
\end{tabular}

NA - not applicable 
In Tests 9 and $9 R$ vent tubes were used. These tubes were sealed in Test 10 , and tight insulation was used with natural convection flow. In every case the hydrogen detector (ce11) responded.

Table 2-10 shows that, in natural convection Tests 11 through 12, the hydrogen detector did not respond. This is interesting considering the total leak duration ( 85 to $100 \mathrm{hr}$ ) and quantity of sodium injected (170 to $209 \mathrm{~g}$ ). In Tests 11 and $11 R$, the hydrogen levels did not change at al1, yet in Test 8 (forced convection) with sodium at a reduced temperature $\left(500^{\circ} \mathrm{F}\right.$ ), the hydrogen level changed from $<5 \mathrm{ppm}$ to $<400 \mathrm{ppm}$ in $50 \mathrm{hrs}$. However, the al arm indication ( $3 \times$ background) in Test 8 was achieved in $9 \mathrm{hr} 45 \mathrm{~min}$, which corresponds to $19.48 \mathrm{~g}$ of sodium leaked. In Test 12, with sodium injected at $640^{\circ} \mathrm{F}$, the hydrogen level increased $2 \mathrm{ppm}$.

The hydrogen detector responded in Test 16 (3-in. pipe tightly insulated) in $12 \mathrm{hr} 42 \mathrm{~min}$. This response was achieved after only $25.4 \mathrm{~g}$ of sodium had been injected. Again, this is a particularly interesting result in reference to the test results discussed above.

2.1.4.1.3 IHTS Test Environment. In forced convection Tests 3, 5, 5X, and 6 the hydrogen detector responded in every case. In Test 3 the hydrogen detector (ce11) responded faster than the DP (annulus, cell) and within $1 \mathrm{hr}$ of the SID (annulus). In Tests $5 X$ and 6 it again responded faster than the DP and within 20 min of the SID.

The hydrogen detector in natural convection Tests 13 through 15 only responded in Test 14. A response in $15 \mathrm{hr} 56 \mathrm{~min}$ was achieved after $31.86 \mathrm{~g}$ of sodium had been injected. This result is puzzling considering the lack of response in Tests $13,13 X$, and 15, and the leak detection response achieved in the forced convection tests.

The hydrogen detector did not respond in Test 17 where $217 \mathrm{~g}$ of sodium was injected over 123.27 hours.

Two separate incidents occurred at LMEC prior to initiating Test 6. Expansion tank diaphragms boiled and sodium spills of $3632 \mathrm{~g}$ (Incident No. 1) and $681 \mathrm{~g}$ (Incident No. 2) resulted. The sodium temperature was approximately $275^{\circ} \mathrm{F}$ with cell moisture at $30,000 \mathrm{vppm}$. The hydrogen detector was the only sensor indicating the sodium had leaked. 
TABLE 2-10. LMEC Test Data for Hydrogen Detector (2)

\begin{tabular}{|c|c|c|c|c|c|c|c|c|c|}
\hline $\begin{array}{l}\text { Tes: } \\
\text { No. }\end{array}$ & $\begin{array}{l}\text { Sodium } \\
\text { Leak } \\
\text { Rate } \\
(\mathrm{gm} / \mathrm{hr})\end{array}$ & $\begin{array}{c}\text { Test } \\
\text { Temperature } \\
(\cdot F)\end{array}$ & $\begin{array}{c}\mathrm{O}_{2} \\
\text { Content } \\
(\%)\end{array}$ & $\begin{array}{l}\text { Noisiure } \\
\text { Contenil } \\
\text { (pomy) }\end{array}$ & \multicolumn{2}{|c|}{$\begin{array}{c}\mathrm{Hz}_{2} \mathrm{Leveis} \\
\text { start.- end } \\
\text { (ppny) }\end{array}$} & $\begin{array}{l}\text { Leak } \\
\text { Duration } \\
\text { (hir) }\end{array}$ & $\begin{array}{l}\text { Tobal } \\
\text { Sodium } \\
\text { beaked } \\
\text { (gm) }\end{array}$ & $\begin{array}{l}\text { Petector } \\
\text { Pespollse }\end{array}$ \\
\hline 11 & $2 \div$ & 980 & 1 & 1090 & $<5$ & $<5$ & 87.5 & 181 & MP \\
\hline $11 R$ & 2 & 980 & 1 & 1000 & 4 & 4 & 85 & 170 & $N R$ \\
\hline 12 & $2+\div$ & 649 & 1 & 1000 & $<2$ & $<4$ & 100 & 209 & NR \\
\hline 13 & 2 & 900 & 21 & 15000 & 15 & 15 & 100 & 200 & NR \\
\hline $13 x$ & 2 & 900 & 21 & 15000 & $<5$ & וו & 0.5 & 25 & NR \\
\hline 14 & 2 & 640 & 21 & 15000 & $<5$ & 17 & 100 & 200 & $15 \mathrm{H} 56 \mathrm{M}$ \\
\hline 15 & 2 & 400 & 21 & 1500 & 8 & 20 & 78 & 156 & NR \\
\hline 16 & 2 & 500 & 1 & 1000 & $<5$ & 17 & 100 & 200 & $12 \mathrm{H} 42 \mathrm{M}$ \\
\hline i7 & 2 & 650 & 21 & 15000 & 5 & 5 & 123.27 & 217 & $M R$ \\
\hline
\end{tabular}

* Response time after second leakage irregularity

**Tine response after sodium first observed t+reginning leakage rate $8 \mathrm{~g} / \mathrm{h}(1 \mathrm{l} / 2 \mathrm{~h})$

$\$ 6.1 \mathrm{gm}$ injected within 12 minutes afier stät of test

Detection Criteria Surifiary Cable/Contact - an increase of $0.1 \mathrm{~V}$ Siroke - vol tage > 1.Ov D.P. - a change in pressure of 2 in. $13_{2} 0$ Hydrogen - an increase of $3 x$ SID - an increase of ix

5imount of sodium extrapolated from test data;

$1 / 5$ (total sodium accunulated)

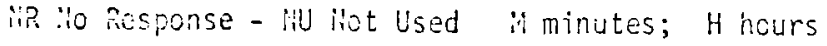

\begin{tabular}{|c|c|c|c|c|c|c|c|c|c|c|}
\hline \multirow{3}{*}{\multicolumn{2}{|c|}{ Detector }} & \multicolumn{9}{|c|}{ FLCW RATE IN SAMPLING LINE (cc/min.) } \\
\hline & & \multicolumn{9}{|c|}{ TEST } \\
\hline & & 11 & $11 R$ & 12 & 13 & $13 x$ & 14 & 15 & 16 & 17 \\
\hline \multicolumn{2}{|c|}{$D P(C, F)$} & \multicolumn{9}{|c|}{ Flow Rate for All Tests 5000} \\
\hline \multirow[b]{2}{*}{ SID } & C & 400 & 400 & 400 & 400 & 400 & 400 & 400 & 400 & 400 \\
\hline & $F$ & RiU & 400 & NU & 400 & 400 & 400 & 400 & 400 & $\mathrm{NU}$ \\
\hline \multicolumn{2}{|c|}{ Hydrogen } & 1000 & 200 & 200 & 200 & 200 & 200 & 250 & 250 & 250 \\
\hline \multicolumn{2}{|c|}{ SIMP } & 1400 & 1500 & 1800 & 2000 & $\begin{array}{l}\text { See } \\
\text { Note }\end{array}$ & 4000 & $\mathrm{NU}$ & NU & NU \\
\hline
\end{tabular}

Note: The flow rate at the start of test $13 x$ was $4000 \mathrm{cc} / \mathrm{min}$; at the end of test $900 \mathrm{cc} / \mathrm{min}$. 


\subsubsection{Observer Comments on the Hydrogen Detector}

The comments in Section 2.1.1.2 directly relate to the operational performance of the hydrogen detector. Refer to Section 2.1.1.2 for specific comments.

\subsubsection{Surface Ionization Monitor for Particulates}

A surface ionization monitor for particulates (SIMP) is proposed to monitor the CRBRP cell environment for sodium and sodium reaction products in the form of aerosols. The SIMP detector, shown in Figures 2-9 and 2-10, can respond to sodium aerosol presence in two ways:

- measure the average ion current

- measure the "counts" of particulates.

When particulate "counts" are measured, they can be displayed via 1) a digital count meter, from a signai processed within the SIMP; and 2) a strip chart recorder signal, which is the integrated output of a sawtooth signal originating within a triggering unit synchronized to the detector's ionization current.

\subsubsection{SIMP Test Data Evaluation}

2.1.5.1.1 Test Conditions. The SIMP detector was subjected to Tests 11 through 17. No detection criteria were defined prior to testing due to the unknown response of the instrument to sodium aerosols. These initial tests at LMEC were performed primarily to provide baseline information as to the SIMP's applicability to sodium aerosoi detection.

2.1.5.1.2 PHTS Test Environment. The SIMP was used in Tests 11 through 12. Test results summarized in Table 2-11 indicate that the device is extremely sensitive to low aerosol concentrations.

2.1.5.1.3 IHTS Test Environment. In Tests 13 through 14, the SIMP also evidenced extreme sensitivity to low concentrations of sodium aerosols.

\subsubsection{Observer Comments on the Surface Ionization Monitor}

The SIMP's count/rate feature may permit detection of sodium aerosol concentrations orders cf magnitude lower than the sodium ionization detector. 


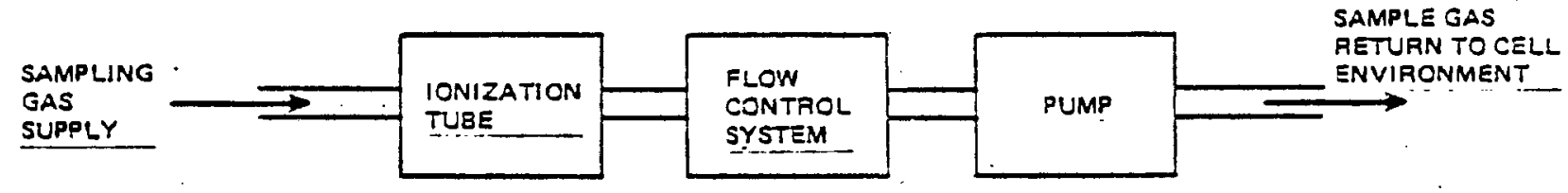

FIGURE 2-9. Surface Ionization Monitor for Particulates (2)

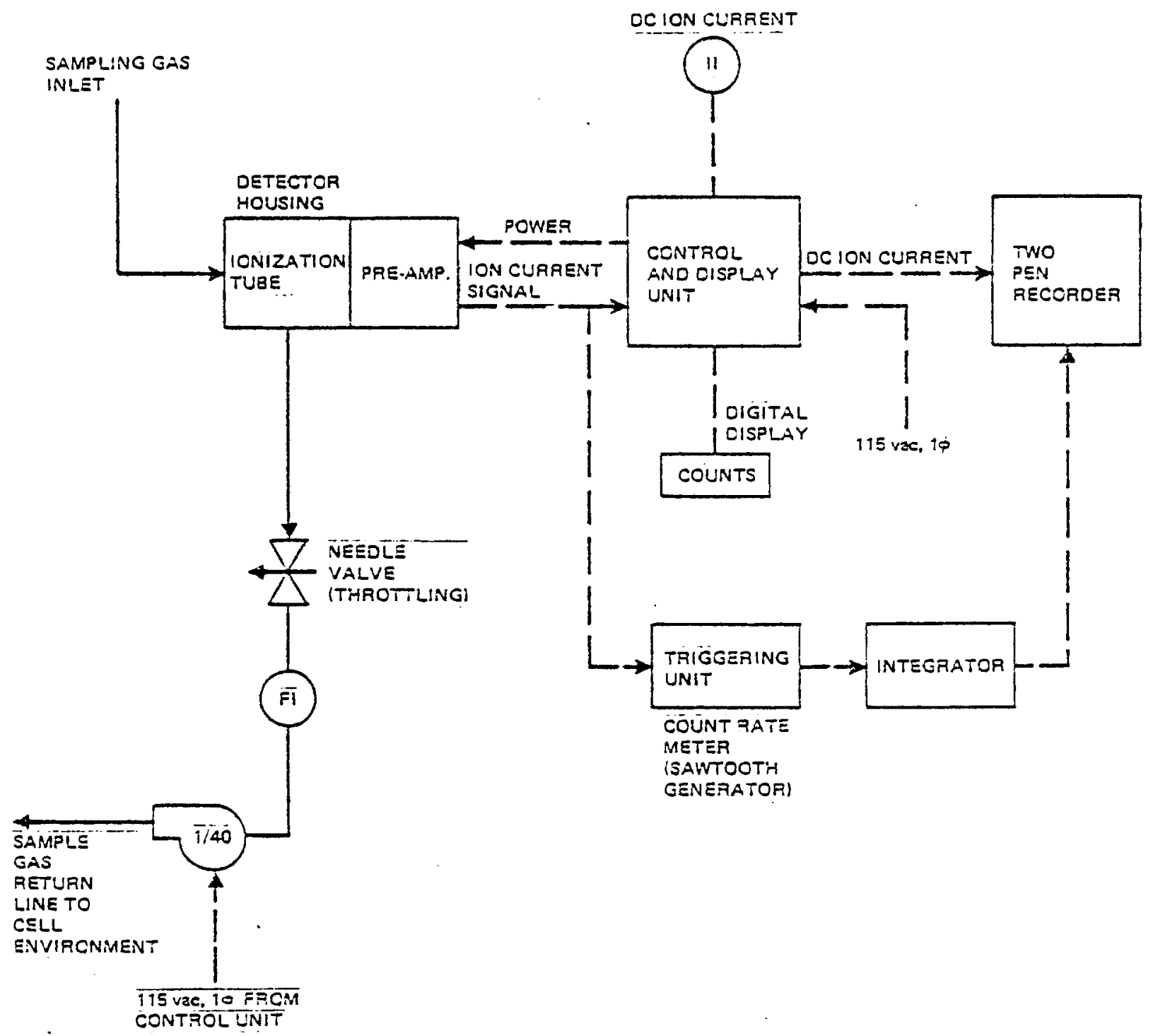

FIGURE 2-10. Surface Ionization Monitor Instrumentation (2) 
TABLE 2-11. Surface Ionization Monitor Cell Test Data(2)

\begin{tabular}{|c|c|c|c|c|c|c|c|c|c|}
\hline \multirow[t]{2}{*}{$\begin{array}{l}\text { Test } \\
\text { No. }\end{array}$} & \multirow{2}{*}{$\begin{array}{l}\text { Sodium } \\
\text { Leak } \\
\text { Race } \\
(\text { go/hr) }\end{array}$} & \multirow{2}{*}{$\begin{array}{c}\text { Test } \\
\text { Temperatire } \\
\left({ }^{\circ} \mathrm{F}\right)\end{array}$} & \multirow{2}{*}{$\begin{array}{c}\mathrm{O}_{2} \\
\text { Content } \\
(\%)\end{array}$} & \multirow{2}{*}{$\begin{array}{l}\text { Moisture } \\
\text { Content } \\
\text { (ppmi) }\end{array}$} & \multirow{2}{*}{$\begin{array}{l}\text { SIRP Curfene } \\
\text { Baciegd.-Min. Re. } \\
\text { (nanoamos) }\end{array}$} & \multirow{2}{*}{$\begin{array}{l}\text { Leak } \\
\text { Duration } \\
\text { (hr) }\end{array}$} & \multirow{2}{*}{$\begin{array}{l}\text { Tocal } \\
\text { Sodium } \\
\text { Leaked } \\
(g a)\end{array}$} & \multicolumn{2}{|c|}{$\begin{array}{l}\text { Counts } \\
\text { per sec }\end{array}$} \\
\hline & & & & & & & & $s+r$ & End \\
\hline 11 & $2 \div$ & 980 & 1 & 1000 & $0.13-1.00$ & 87.5 & 187 & 10 & 7 \\
\hline $11 R$ & 2 & 980 & $i$ & 1000 & $0-1.00$ & 85 & 170 & 10 & 7 \\
\hline 12 & $2 \div$ & $6<0$ & 1 & 1000 & $i .2-3.6$ & 100 & 209 & 0 & $N R$ \\
\hline 13 & 2 & 900 & 21 & $i 5000$ & $0-1.00$ & 100 & 200 & 0 & NR \\
\hline $13 x$ & 2 & 900 & 21 & 15000 & $0-1.00$ & 0.5 & 25 & 0 & NR \\
\hline 14 & 2 & 640 & 21 & 15000 & $0-1.00$ & 100 & 200 & $c-3$ & 0 \\
\hline 15 & \multirow{3}{*}{\multicolumn{9}{|c|}{ SIMP not usad. }} \\
\hline 16 & & & & & & & & & \\
\hline 17 & & & & & & & & & \\
\hline
\end{tabular}

SIMP CURRENT = nenoamps

$C=$ ceiling $F=$ floor

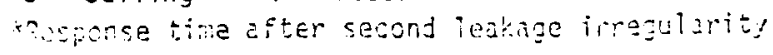

Cetection Criteria Suimary

-rina rescons? ifter sodium first roseryed

ratie/contact - an increase of g.iv

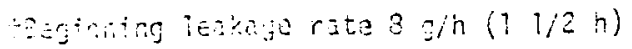

Coke - vol tage > ?.CV

a.p. - a chonge in pressure ot a : 11 . ${ }^{2}$ ?

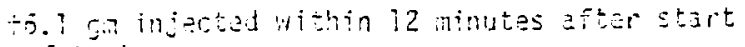

oi test

Hyogen - en incrasse of $2 x$

sij-än increase of $2 x$

a-ount of sodiun extrapciated fron tast data;

$1 / 5$ (:otal sodiun accioliated)

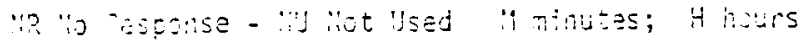

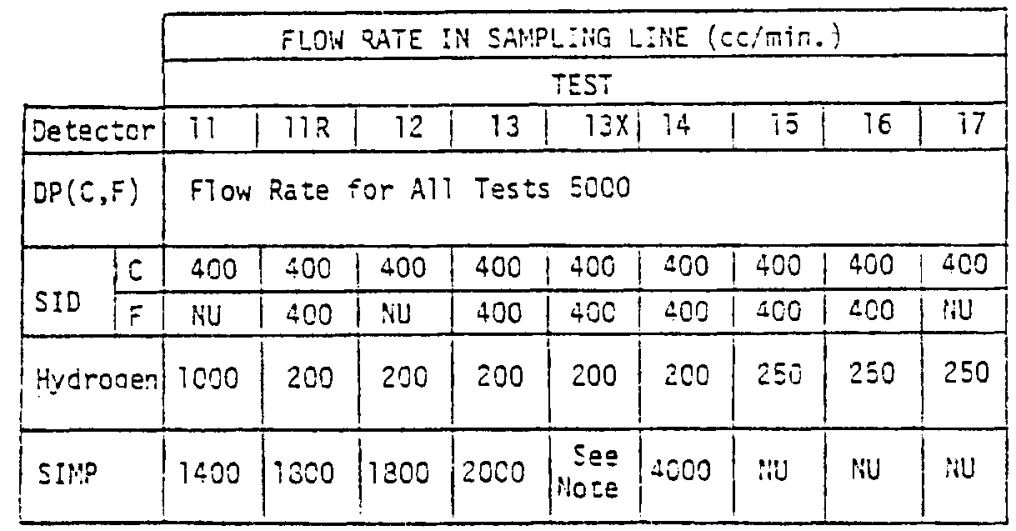

Hote: The fiow rate at tha start of test $13 x$ was $600065 / \mathrm{min}$; at the end of tes: $300 \mathrm{cc} / \mathrm{min}$. 


\subsubsection{Radiation Detector}

Radiation detectors are scheduled for use in the CRBR to monitor leakage in the PHTS. However, no description(s) of the specific detector(s) selected for CRBR use was included in the PSAR or supporting references.

\subsubsection{Radiation Detector Test Data Evaluation}

The references contained no information regarding the radiation detector test program or data. Consequently, PNL was unable to evaluate this device, due to:

- absence of test condition descriptions

- lack of radiation detector test data generated in the PHTS environment

- unavailability of IHTS environment-generated test data.

\subsubsection{Observer Comments on the Radiation Detector}

In the available literature, the only report describing the use of gamma radiation detectors for leak detection is Reference 4. Pertinent comments are quoted below:

Radiation detectors respond to the characteristically high energy gamma-rays from the decay of radioactive sodium. Aerosols are deposited on a filter pad which is viewed by a gamma sensitive radiation element. Because of the high specific activity of $24 \mathrm{Na}$ $\left(2.94 \times 10^{4} \mu \mathrm{Ci} / \mathrm{gm}\right)$, small deposits on the filter will easily be detected above background levels.

These detectors can only be used in the primary sodium circuit and only after the sodium has become activated. They will be available to detect sodium aerosols in inerted cells in the Reactor Containment Building.

The radiation detector, not yet tested, is still believed to be the most sensitive instrument available for leak detection, provided that an integrating sampling procedure is used and the sodium is activated.

There have been questions concerning reactor startup as to the time required to achieve an equilibrium concentration of ${ }^{24} \mathrm{Na}$. Our talks with HEDL have indicated that an equilibrium ${ }^{24} \mathrm{Na}$ level would be reached in approximately $60 \mathrm{hr}$ (or 4 half lives). 


\subsubsection{Cable Detector}

The cable detector consists of a thin, stainless steel-sheathed, mineralinsulated (magnesium oxide) coaxial cable, with perforations in the outer (grounded) sheath. The physical layout and instrumentation of the cable detector are shown in Figures 2-11 through 2-13. Liquid sodium penetrating the perforated sheath causes a low resistance path to ground. This produces an increased voltage drop across $R_{2}(47 \Omega$ in circuit $A$ and $100 \Omega$ in circuit $B$ ), activating an alarm.

Electrically the cperation of both the cable and contact detectors (a) is identical. Resistor $R_{3}$ (of both circuits) is electrically shorted when the exposed junction (contact detector) or perforated sheath (cable detector) is wetted by a sufficient amount of liquid sodium. The response to liquid sodium is indicated on a strip recorder and data logger.

\subsubsection{Cable Detector Test Data Evaluation}

2.1.7.1.1 Test Conditions. The cable detector was tested under CRBR PHTS and IHTS environments with sodium leaks ranging from $0.4 \mathrm{~g} / \mathrm{hr}$ to $100 \mathrm{~g} / \mathrm{hr}$.

In Tests i through 10 (Table 2-12), electrical circuit $B\left(R_{2}=100 \Omega\right)$ was used. In Tests 11 through 17 (Table 2-13), circuit $A\left(R_{2}=47 \Omega\right.$ ) was used for detection. Tests 1 through 15 were conducted using the 24-in. diameter pipe. Tests 16 and 17 were conducted using a 3-in. diameter pipe in a nonvented configuration. Starting with Test 9 , a natural convection environment was utilized. Tests 9 and 10 were conducted using extremely tight insulation. Further, in Tests 9 and $9 R$, vent tubes were provided for the annulus.

In the 23 tests performed at LMEC, the cable detector was positioned in the annular region in 21 of the tests and failed to respond in $57 \%$, or 12 , of the 21 tests. This high failure rate occurred although the detector was directly below the sodium injection nozzle.

(a) Contact detectors are discussed in Section 2.1.8. 


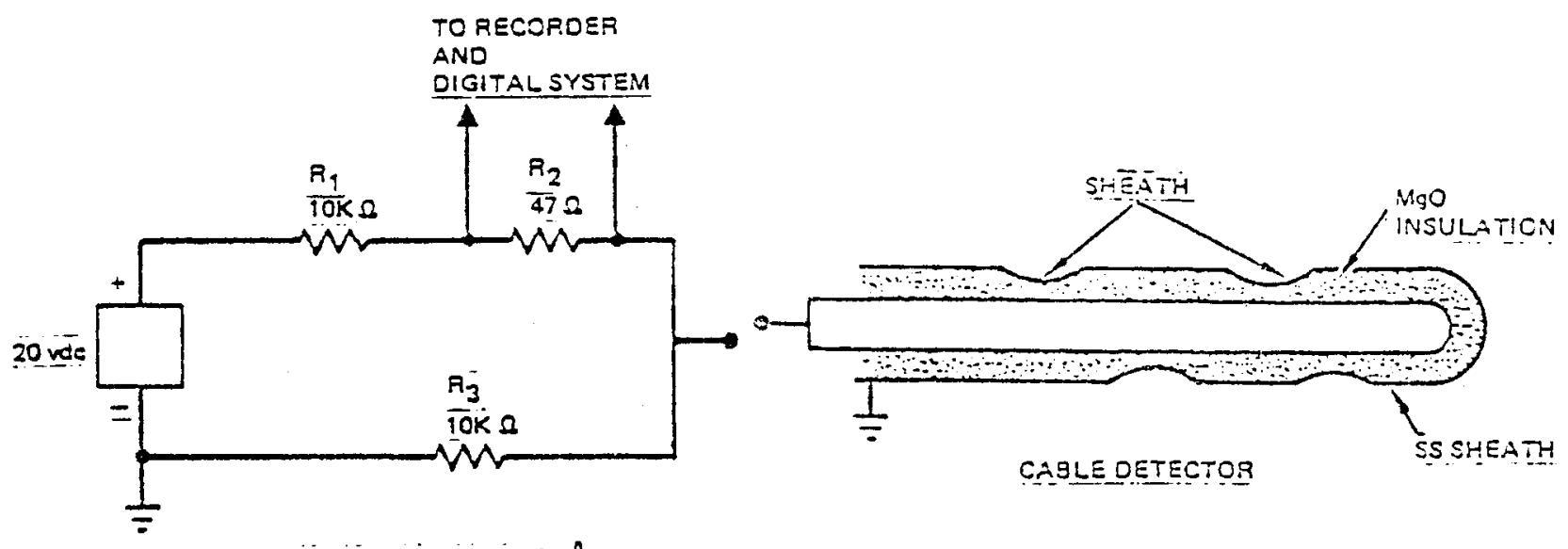

CIRCIIIT SCHEMATIC A

FIGURE 2-11. Cable Detector and Circuit $A^{(2)}$

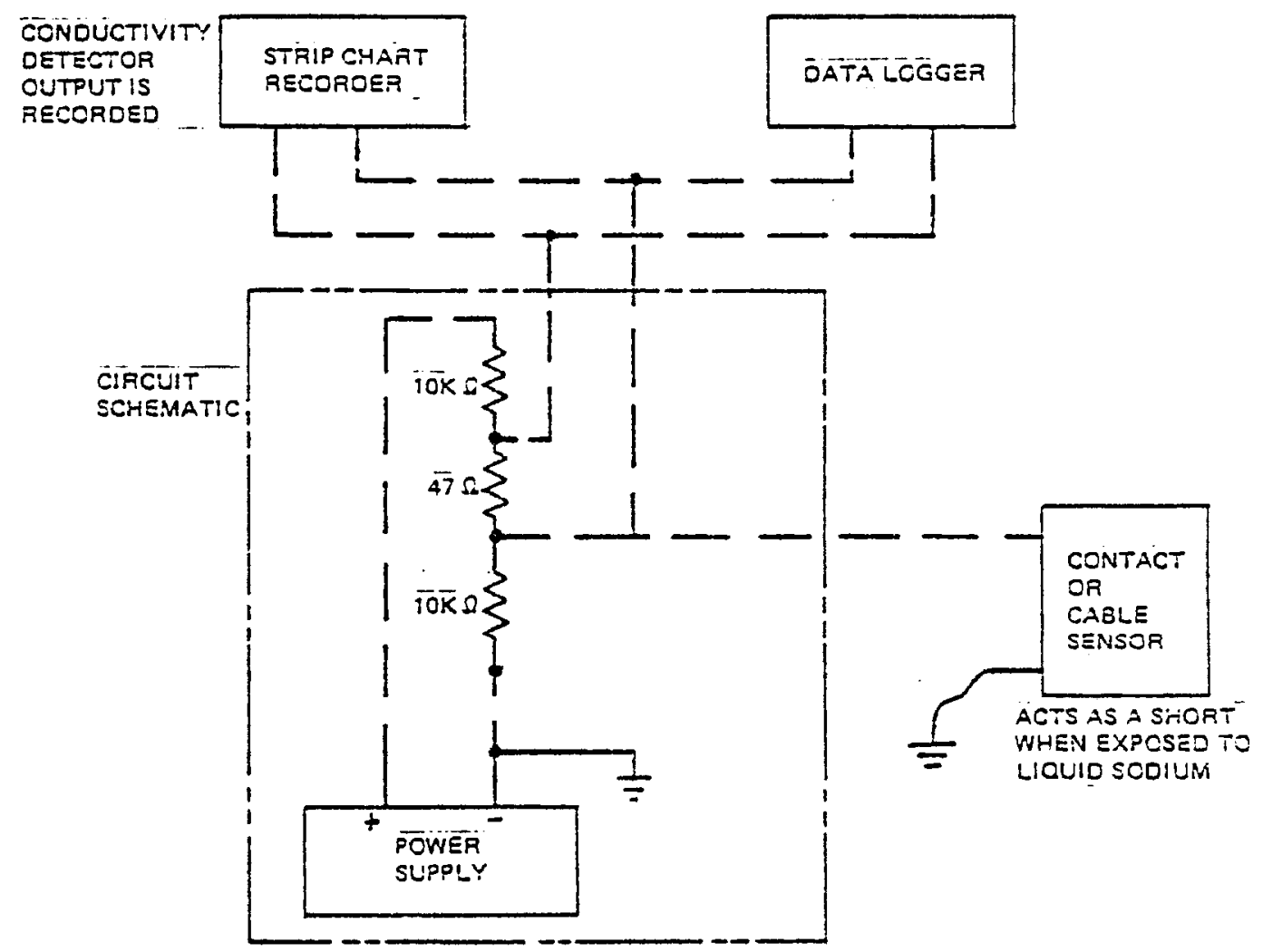

FIGURE 2-12. Cable Detector Circuit Schematic (2) 

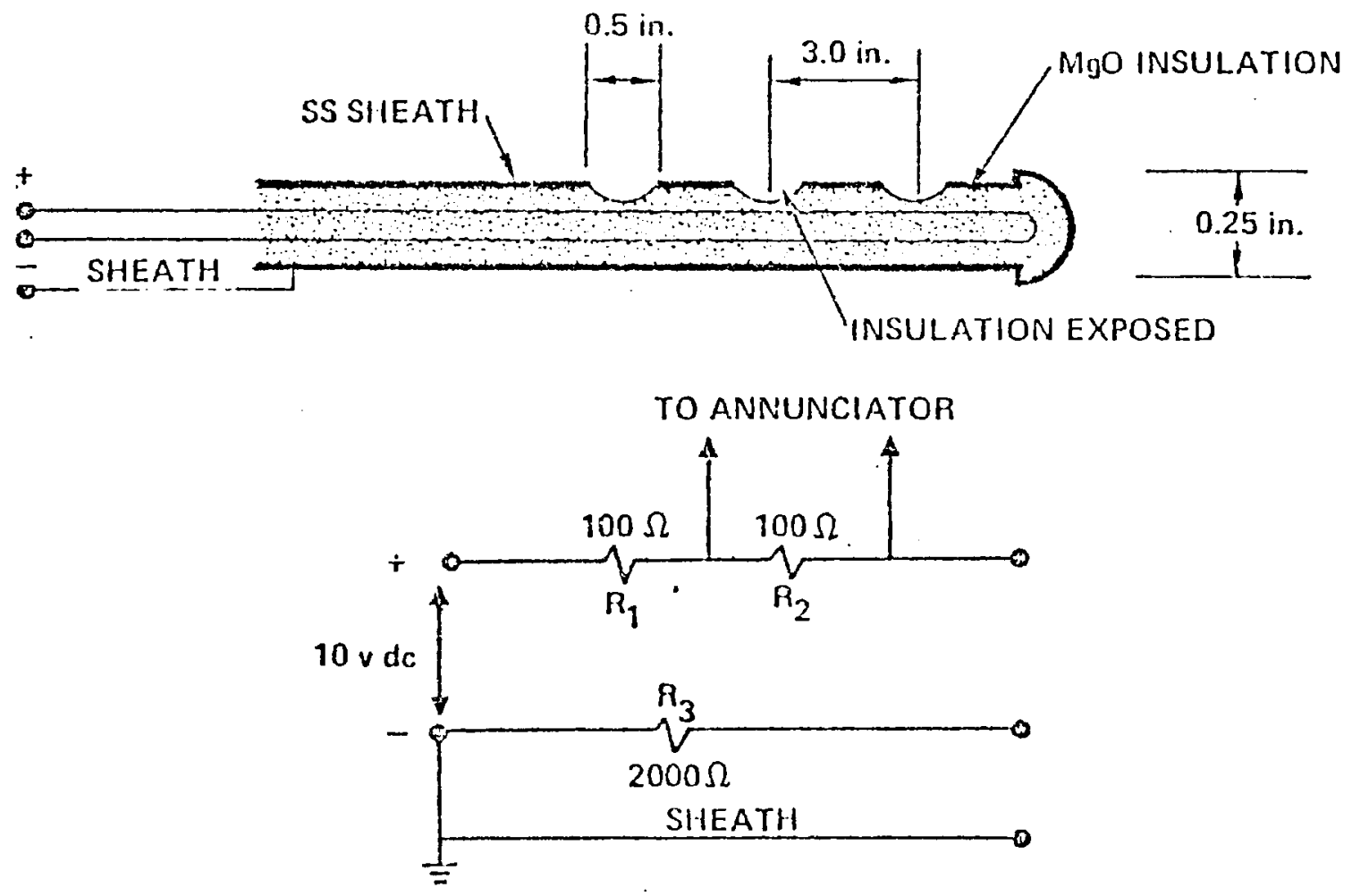

\section{CIRCUIT B}

FIGURE 2-13. Cable Detector and Circuit $\mathrm{B}^{(2)}$

2.1.7.1.2 PHTS Test Environment. In forced convection Test 1 , the cable detector indicated a sodium leak at $1 \mathrm{hr} 10 \mathrm{~min}$; yet AI $(3, \mathrm{p} .7)$ stated that the detector responded in $1 \mathrm{hr} 37 \mathrm{~min}(1.55 \mathrm{hr})$. Regardless of this discrepancy, it is interesting to note the rapid response in natural convection Tests $9,9 R$ and $10\left(100 \mathrm{~g} / \mathrm{hr}\right.$ at $\left.980^{\circ} \mathrm{F}\right)$. Indeed, a response in Test 9 was achieved after only 6 min of sodium injection. This resulted in detection from a mere $10 \mathrm{~g}$ of sodium injected. However: in Test 1 (forced convection), $166 \mathrm{~g}$ of sodium were injected before the detector responded. Test 9 gives an indication that the cable detector nay respond to sodium aerosols under environmental conditions characteristic of the PHTS. The rapid response may be attributed to the establishment of natural convection currents which accumulate and transport the sodium directiy to the cable detector beneath 
TABLE 2-12. Cable Detector Test Data ${ }^{(3)}$

\begin{tabular}{|c|c|c|c|c|c|c|c|}
\hline \multirow[b]{2}{*}{$\begin{array}{l}\text { Test } \\
\text { No. }\end{array}$} & \multicolumn{6}{|c|}{ lest Parameters } & \multirow[b]{2}{*}{$\begin{array}{l}\text { Detector } \\
\text { Response } \\
\text { (hr) }\end{array}$} \\
\hline & $\left\{\begin{array}{c}\text { Sodium } \\
\text { Leak } \\
\text { Rate } \\
\text { (gm/hr) }\end{array}\right.$ & $\begin{array}{c}\text { Test } \\
\text { Temperature } \\
\left({ }^{\circ} \mathrm{F}\right)\end{array}$ & $\begin{array}{l}\mathrm{O}_{2} \\
\left(\sigma_{0}\right)\end{array}$ & $\begin{array}{l}\text { Moisture } \\
\text { (ppmv) }\end{array}$ & $\begin{array}{l}\text { Actual } \\
\text { Na Leak } \\
\text { Duration } \\
\text { (hr) }\end{array}$ & $\begin{array}{l}\text { Total } \\
\text { Sodium } \\
\text { Leaked } \\
\text { (gm) }\end{array}$ & \\
\hline 1 & 100 & 980 & 1 & 1,000 & 10 & 1000 & 1.66 \\
\hline 2 & 100 & $400-700$ & 1 & 1,000 & 10 & 1000 & 23.77 \\
\hline 3 & .100 & $640-920$ & 21 & 30,000 & $\begin{array}{l}6 \mathrm{hr} / \mathrm{raise} \\
\mathrm{temp} / 6 \mathrm{hr}\end{array}$ & 1200 & 0.10 \\
\hline 4 & 0.4 & 980 & 1 & 1,000 & . & 100 & $N R$ \\
\hline $5 x$ & $31.0^{*}$ & 400 & 21 & 10,000 & 0.016 & $3 \cdot 1$ & $N R$ \\
\hline 5 & 2.0 & $350-650$ & 21 & 30,000 & 250.0 & 400 & 104.2 \\
\hline 6 & $2.0^{\dagger}$ & 650 & 21 & 30,000 & 20.0 & 40 & 0.3 \\
\hline $7 x$ & $100^{\dagger}$ & 400 & 1 & 1,000 & 2.5 & $\sim 200$ & NR \\
\hline $7 Y$ & 100 & 400 & 1 & 1,000 & $\sim 0.1$ & $\sim 4000$ & NR \\
\hline 7 & 100 & 400 & 1 & $15,160^{\S}$ & 20 & 2000 & NR \\
\hline 8 & 2 & 500 & 1 & 1,000 & 50 & 100 & $N Q$ \\
\hline 9 & 100 & 980 & 1 & 1,000 & 9.5 & 950 & $0.4=0.1$ \\
\hline $9 R$ & 100 & 980 & 1 & 1,000 & 4.3 & 430 & 0.1 \\
\hline 10 & 100 & 980 & 1 & 1,000 & 8.4 & 840 & 0.1 \\
\hline $\begin{array}{ll}N U & = \\
N R & = \\
\vdots & = \\
\vdots & =\end{array}$ & $\begin{array}{l}\text { Not used } \\
\text { No respo } \\
31 \mathrm{gms} \text { it } \\
\text { operation } \\
\text { operation }\end{array}$ & $\begin{array}{l}\text { se was observ } \\
\text { jected in less } \\
\text { l difficulties } \\
\text { ldifficulties }\end{array}$ & $\begin{array}{ll}n & \text { on } \\
\text { h so } & \text { so }\end{array}$ & $\begin{array}{l}\text { minute } \\
\text { ium leak ra } \\
\text { isture scnsi }\end{array}$ & probec & test. & \\
\hline
\end{tabular}

the injection nozzle before the sodium is dispersed, as one might infer under forced convective flow. The effects on aerosol generation, diffusion, and agglomeration due to forced or natural convective flow are undetermined. The PSAR does not specify which flow, forced or natural convection, will be used at Clinch River. 
IABLE 2-13. Cable Detector Test Data (2)

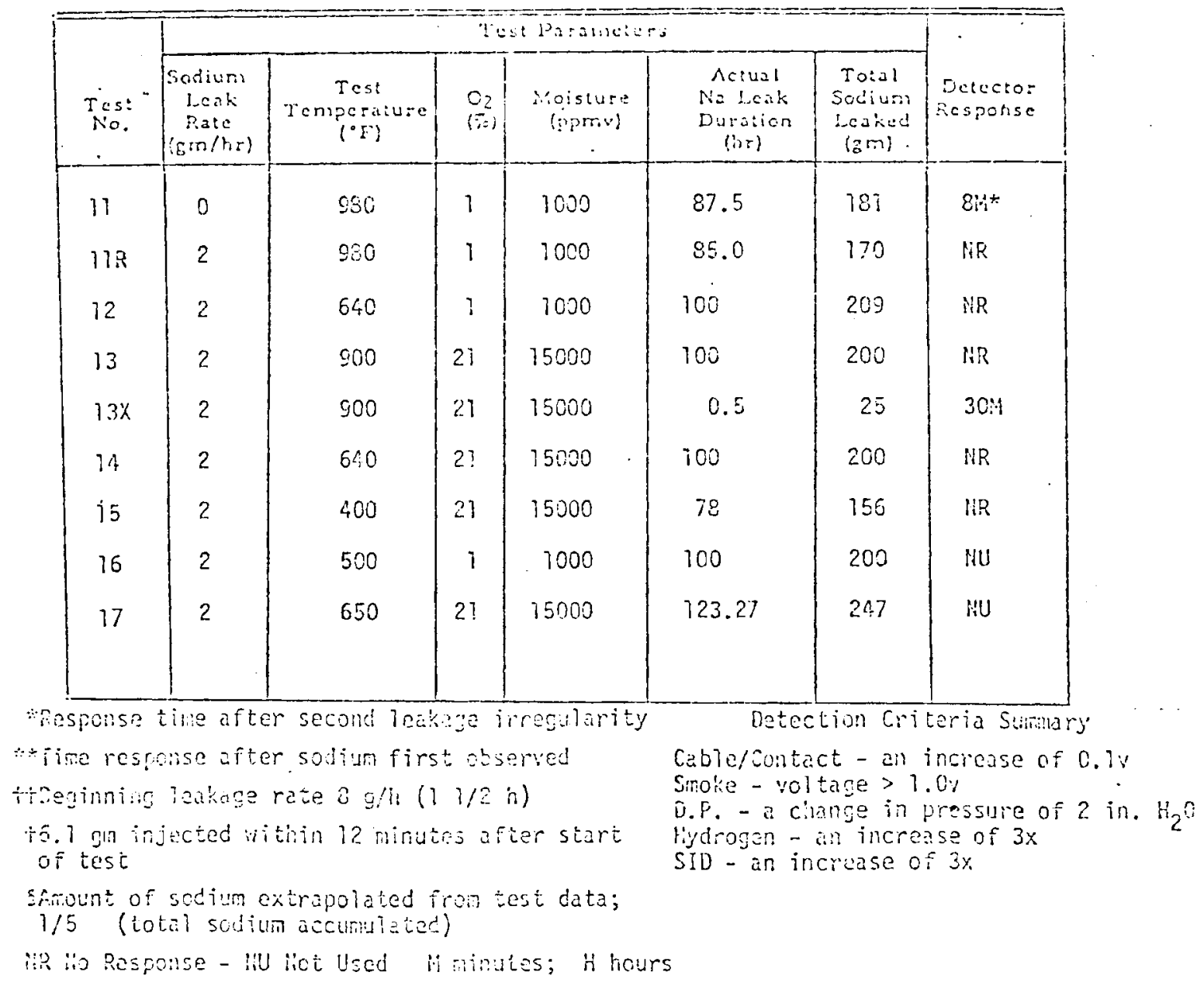

Test 9 showed a response of $0.4 \pm 0.1 \mathrm{hr}$. The cable detector is designed such that it requires physical contact by liquida sodium to indicate a leak. This instrument is referred to as a go, no-go device, which should give a clear leak indication when sodium contacts the cable and produces a short circuit. The \pm 0.1 hour uncertainty was not explained in Reference 3 .

This may indicate that sodium aerosol is capable of providing a sufficientiy conductive path to indicate a leak condition. On the other hand, if a small leak were to go undetected by aerosol detectors, and the cable detector were to indicate a response to the aerosol, followed by the alarm going off seconds later, the reactor operator may be all the more confused. The situation depicted here is one of poor electrical conduction such that a sufficiently conductive path is never achieved, resulting in sporadic alarm indications. 
Reference 3, Test 2 indicate there was no response from the cable detector. However, AI reported that only after the pipe was heated to $650^{\circ} \mathrm{F}$, it gave a response $(23.77 \mathrm{hr}$ ) to a $1000 \mathrm{~g}$ release of sodium. $(3, \mathrm{p} .7)$

On Tests 7, 7Y and 8, the cable detector was installed incorrectly. The perforations in the cable sensor were installed facing upward when they should have been face down. This is not to say that no response is expected should this installation error occur. However, one would think that this detector should be designed with perforations on all faces of the device so that this type of error could not occur. Yet, the detector did not respond to as much as $4000 \mathrm{~g}$ injected in approximately $6 \mathrm{~min}$. This is a significant amount of sodium regardless of the expected error. The acknowledgment to this particular AI report is of note. Credit is given to the LMEC Instrumentation Department, "whose respective groups provided AI with excellent personnel to achieve the results presented herein." This same error could occur at CRBR.

The results of Tests 11 and $11 \mathrm{R}$ are questionable. With identical parameters for these tests, the cable in Test 11 responded in $8 \mathrm{~min}$, while in Test $11 R$ there was no response (considering the leakage irregularity in Test 11).

2.1.7.1.3 IHTS Test Environment. Tests 5 and 6 are similar. However, the response of $18 \mathrm{~min}$ in Test 6 seems out of place to that of $104 \mathrm{hr} 13 \mathrm{~min}$ in Test 5 . There were operational difficulties with the sodium leak rate in Test 6 (see Table 2-12).

The results of Tests 13 and $13 X$ show no response in Test 13 and a response in $30 \mathrm{~min}$ in Test $13 \mathrm{x}$. This is another example of the questionable performance of the cable detector.

Another interesting comparison is that of Test 14 (natural convection) to Test 6 (forced convection). The humidity in Test 6 is 15,000 vppm greater than in Test 14. Test 14 indicated no response, while the detector responded in $18 \mathrm{~min}$ in Test 6. 


\subsubsection{Observer Comments on the Cable Detector}

Due to the identical electrical circuitry in the cable and contact detectors, specific comments concerning these detectors are presented in Section 2.1.8.2.

\subsubsection{Contact Detector}

The physical layout and instrumentation of the contact detector is shown in Figures 2-14 through 2-17. The contact detector (spark plug) consists of a stainless steal-sheathed, mineral-insulated (MgO) coaxial cable, joined as an exposed junction in a bonnet at the end. Liquid sodium flowing into the gap between the electrodes provides an electrical short circuit between the exposed junction and the stainiess steel sheath.

\subsubsection{Contact Detector Test Data Evaluation}

2.1.8.1.1 Test Conditions. The contact detector was tested under CRBR PHTS and IHTS environments with leaks ranging from 0.4 to $100 \mathrm{~g} / \mathrm{hr}$.

In Tests 1 through 10 , electrical circuit $B\left(R_{2}=100 s_{0}\right)$ was used. In Tests 11 through 17 , circuit $A\left(R_{2}=47 \Omega\right)$ was used for detection. Tests 1 through 15 were conducted using the 24-in. diameter pipe. Tests 16 and 17 were conducted using a 3 -in. diameter pipe in a nonvented configuration. Starting with Test 9, a natural convection environment was utilized. Tests 9 and 10 were conducted using extremely tight insulation and by providing vent tubes for the annuTus in Tests 9 and $9 R$.

Figure 2-18 illustrates the placement of the contact detector in the test ce11 during LMEC Mockup Tests 1 through 10. The installation of a pipe support member (Figure 2-19) prevented sodium from contacting the detector in Tests $4,5,5 \mathrm{X}, 6$, and 8 . These tests used low leak rates; consequently, small quantities of sodium were released. 


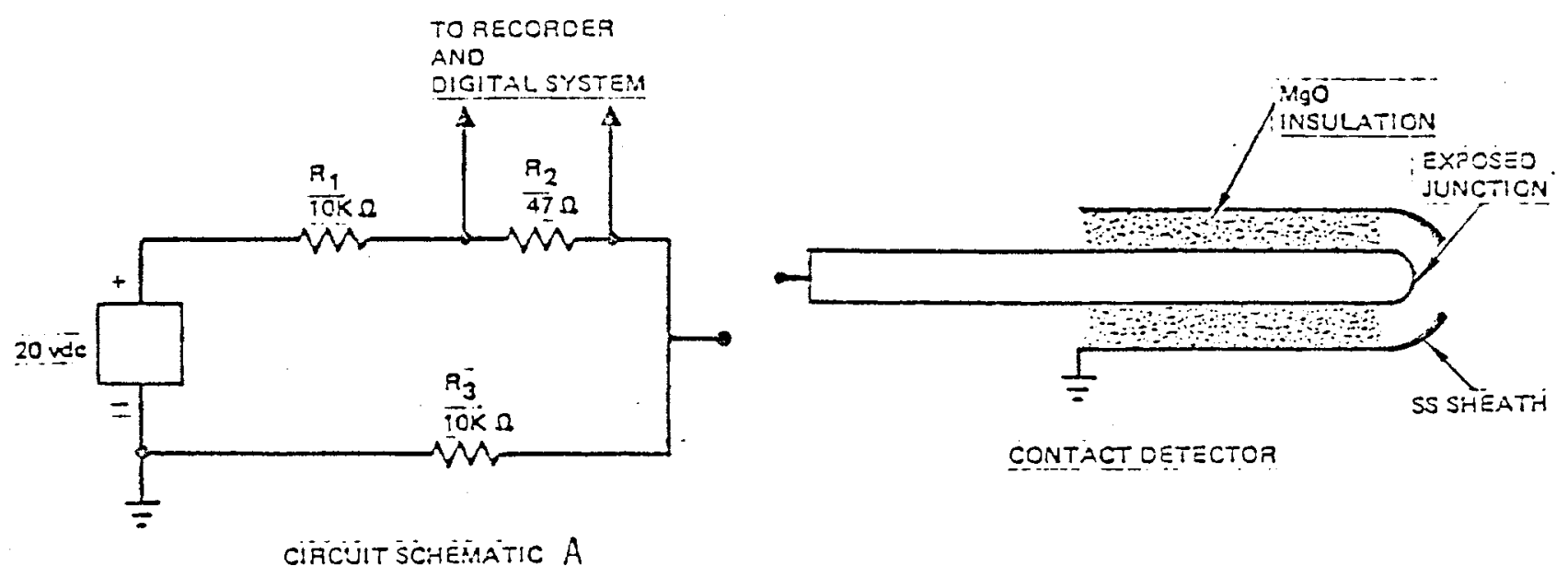

CIRCUITSCHEMATIC A

FIGURE 2-14. Contact Detector and Circuit A (2)

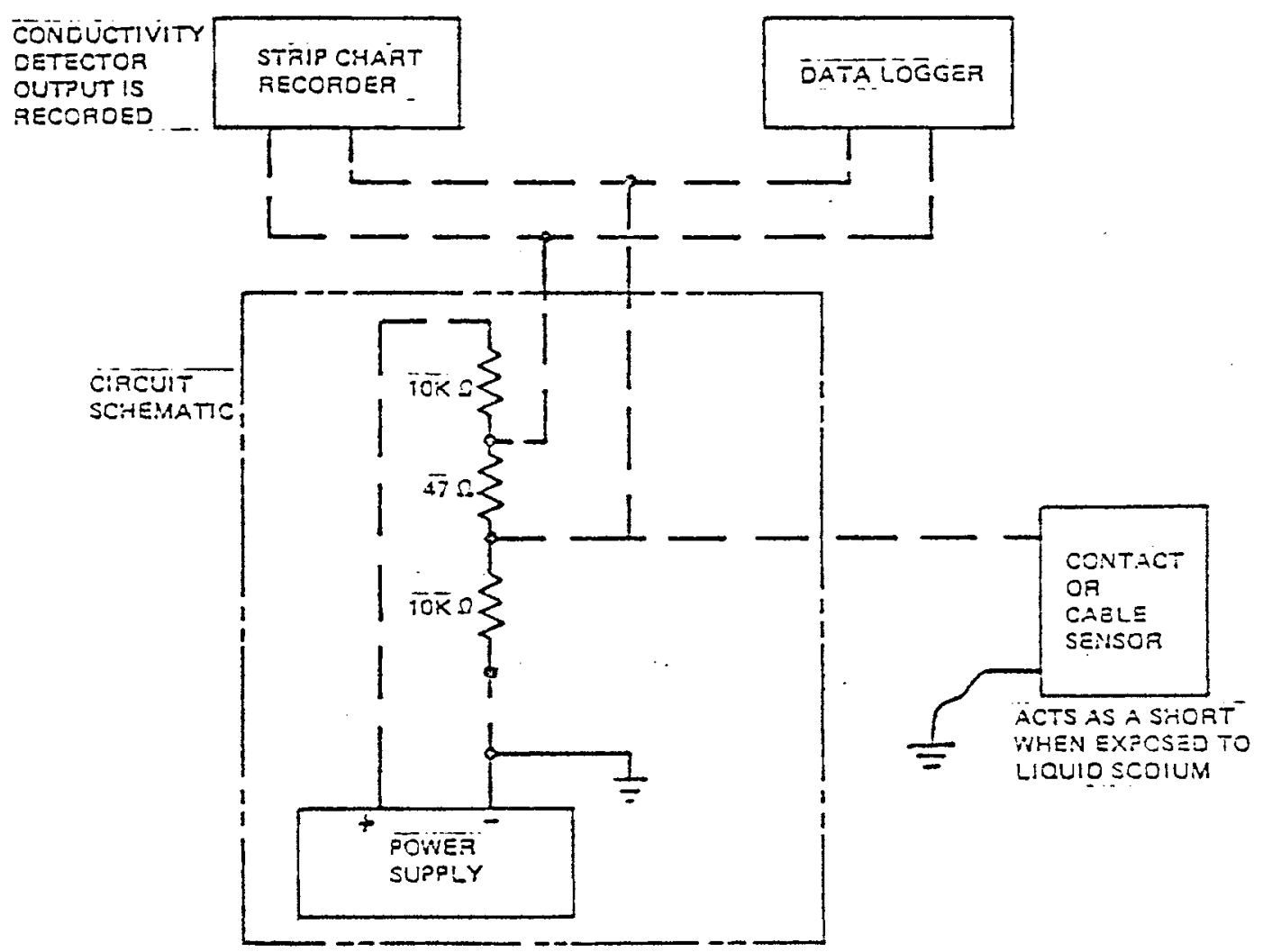

FIGURE 2-15. Contact Detector Circuit Schematic(2) 


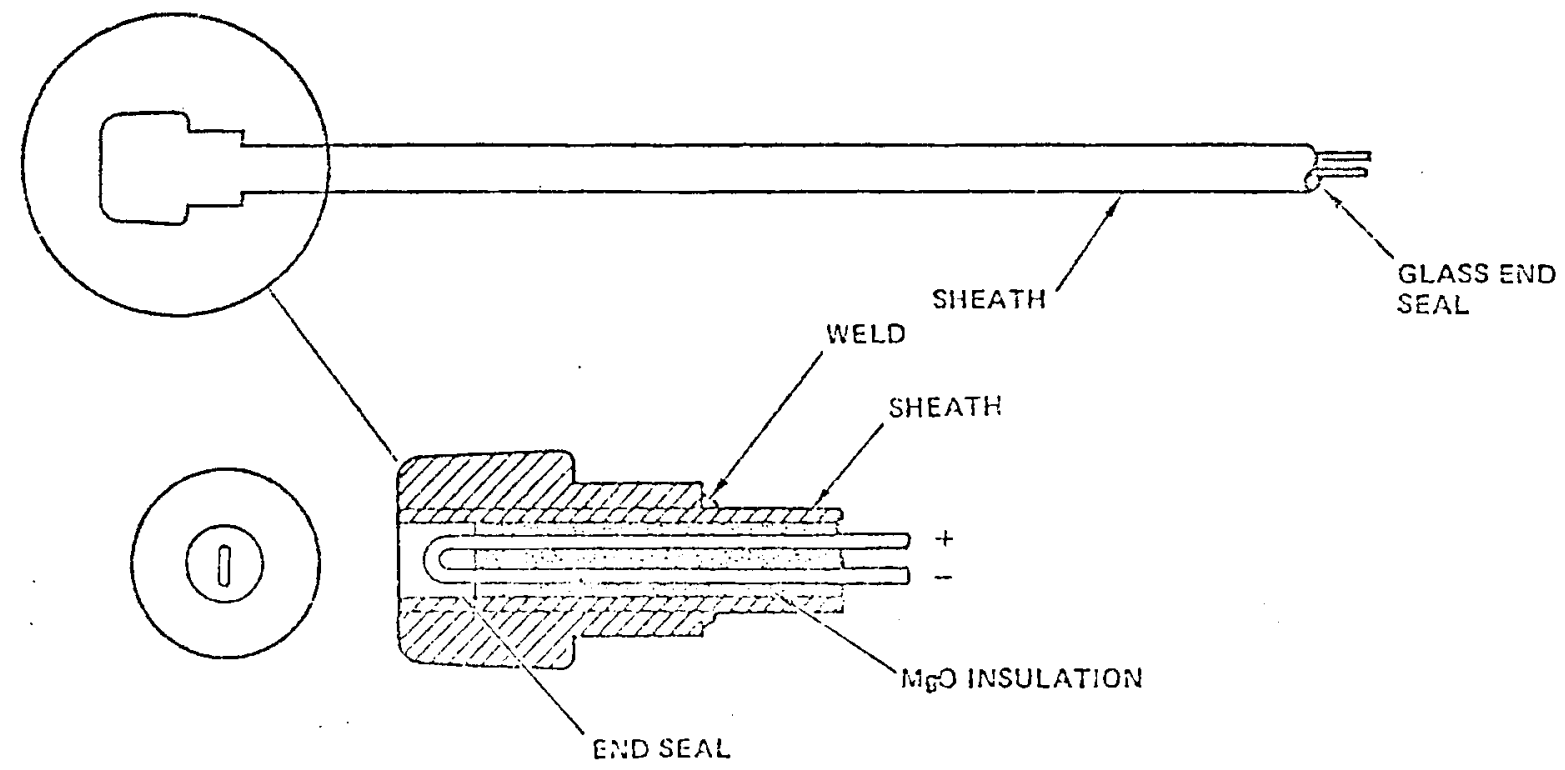

FIGURE 2-16. Contact Detector ${ }^{(2)}$

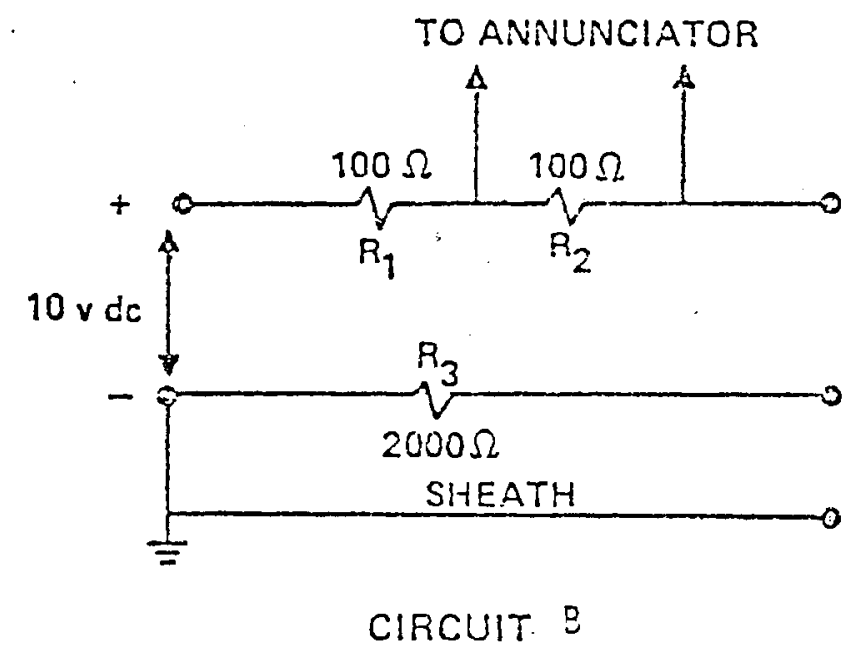

FIGURE 2-17. Contact Detector Circuit $8^{(2)}$ 


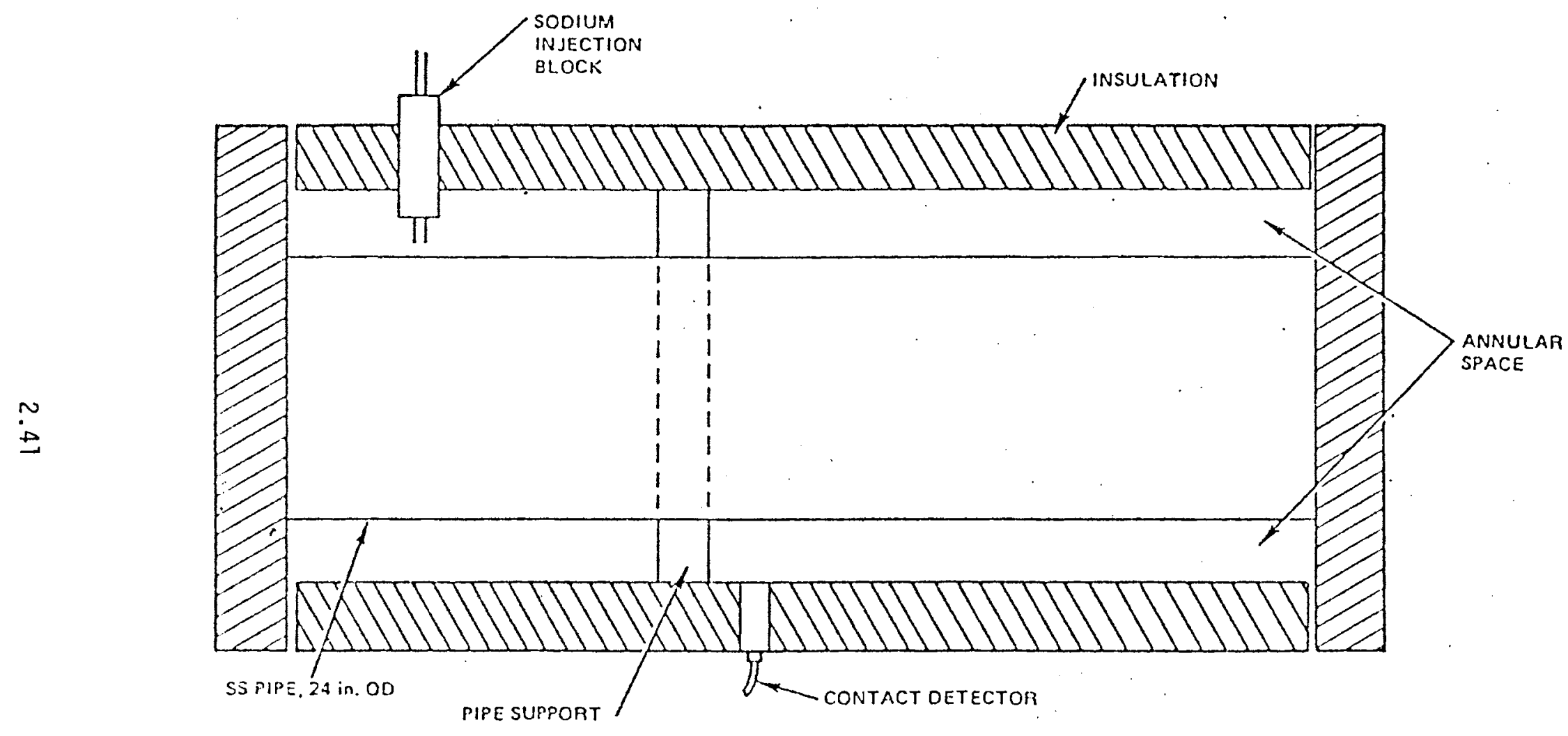

FIGURE 2-18. Contact Detector Installation for LMEC Tests(3) 


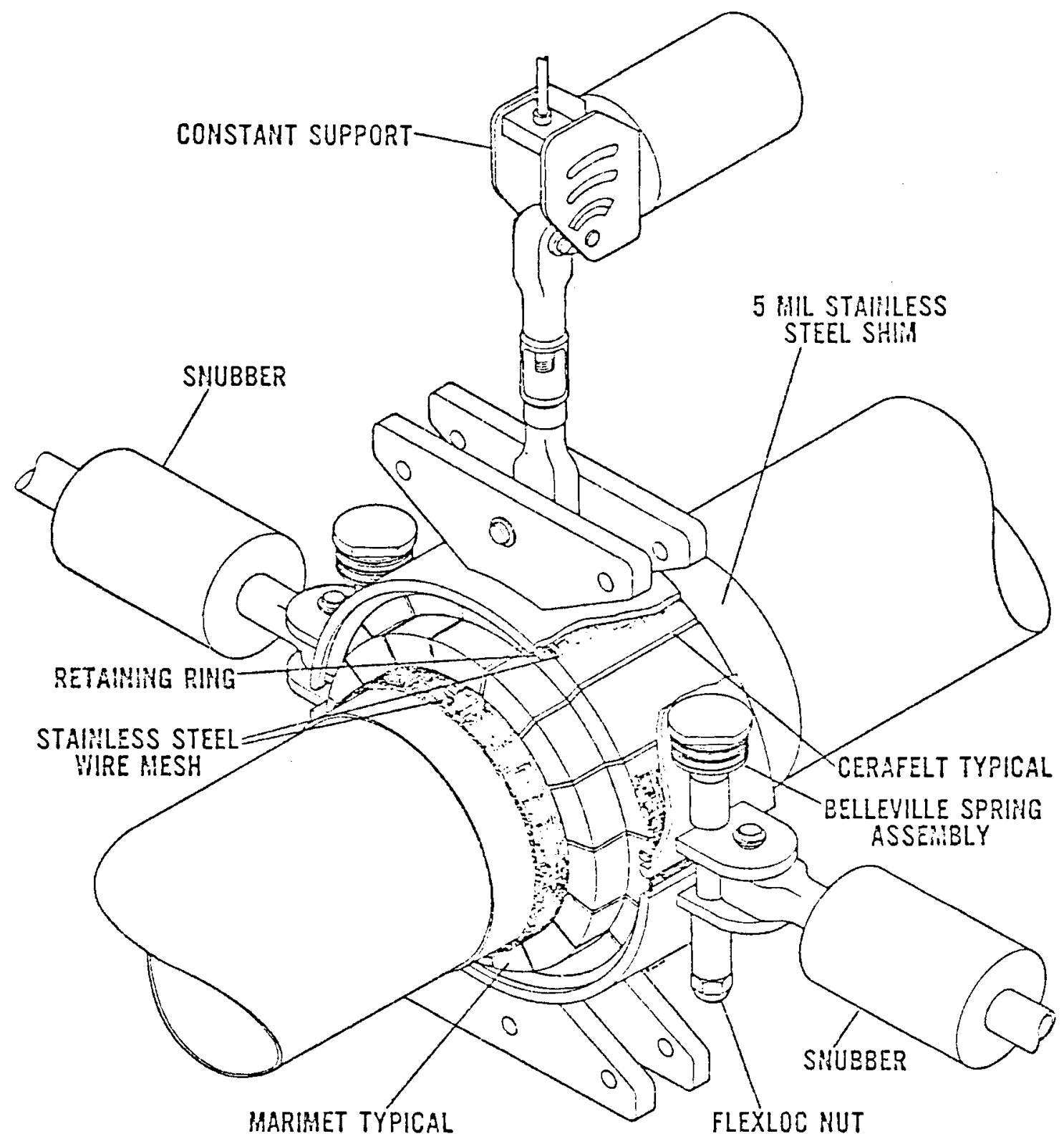

FIGURE 2-19. Typical CRBR Pipe Clamp Installation(a)

(a) This illustration was taken from FFTF plant documentation and is provided as a visual aid for the reader. 
2.1.8.1.2 PHTS Test Environment. Reference 3, page 17 indicated the contact detector responded in Test 7 in $8 \mathrm{hr} 38$ min. Test 7 (Table 2-14) shows a response in $2 \mathrm{hr} 39 \mathrm{~min}$. Reference 3, page 12 stated that the detector gave a response in $12 \mathrm{hr} 39 \mathrm{~min}$; however, sodium was not present in the detector sensing head upon examination. Approximately $2000 \mathrm{~g}$ of sodium had been injected into the cell. This appears to be an obvious example of a false indication. This supports the statement in Reference 5, page 175, "With this old spark plug type, I think in every application I have seen of it, there have been far more false indications than sodium leaks that it has picked up."

The contact detector did respond in Test $7 Y(0.1 \mathrm{hr})$ where approximately $4000 \mathrm{~g}$ of sodium were injected into the cell at $400^{\circ} \mathrm{F}$. This large spill was a result of operational difficulties with the sodium leak rate.

The contact detector did not respond in Tests 4 and 8 due to the sma 11 quantities of sodium injected into the cell. In addition, the installation of a pipe support member prevented sodium from contacting the detector.

The contact detector failed to respond in 8 of 10 tests (Tests 1 through 10, Table 2-14) under the PHTS test environment. In the eight tests in which the contact failed to respond, five had sodium spills of $400 \mathrm{~g}$ or more.

The contact detector failed to respond in the LMEC natural convection Tests 11 through 17 (Table 2-15). For these tests, leak rates of $2 \mathrm{~g} / \mathrm{hr}$ were used, with sodium spills of approximately $200 \mathrm{~g}$.

2.1.8.1.3 IHTS Test Environment. The contact detector failed to respond in Tests 5, 5X, and 6 . However, the installation of a pipe support member prevented sodium from reaching the detector.

The contact detector did respond in Test $3(19.23 \mathrm{hr})$, where $1200 \mathrm{~g}$ of sodium were spilled, at a leak rate of $100 \mathrm{~g} / \mathrm{hr}(12-\mathrm{hr}$ leak duration). The response by the contact detector was achieved only after sodium injection into the cell had ceased. It took over $7 \mathrm{hr}$ after sodium injection had ceased for the contact to respond. 
TABLE 2-14. Contact Detector Test Data (3)

\begin{tabular}{|c|c|c|c|c|c|c|c|}
\hline \multirow[b]{2}{*}{$\begin{array}{l}\text { Test } \\
\text { No. }\end{array}$} & \multicolumn{6}{|c|}{ Test Parameters } & \multirow[b]{2}{*}{$\begin{array}{c}\text { Detector } \\
\text { Response } \\
\text { (hr) }\end{array}$} \\
\hline & $\begin{array}{l}\text { Sodium } \\
\text { Leak } \\
\text { Rate } \\
(\mathrm{gm} / \mathrm{hr})\end{array}$ & $\begin{array}{c}\text { Test } \\
\text { Temperature } \\
\left({ }^{\circ} \mathrm{F}\right)\end{array}$ & $\begin{array}{l}\mathrm{O}_{2} \\
(\%)\end{array}$ & $\begin{array}{c}\text { Moisture } \\
\text { (ppmv) }\end{array}$ & $\begin{array}{c}\text { Actual } \\
\text { Na Leak } \\
\text { Duration } \\
\text { (hr) }\end{array}$ & $\begin{array}{c}\text { Total } \\
\text { Sodium } \\
\text { Leaked } \\
(\mathrm{gm})\end{array}$ & \\
\hline 1 & 100 & 980 & 1 & 1,000 & 10 & 1000 & NR \\
\hline 2 & 100 & $400-700$ & 1 & 1,000 & 10 & 1000 & $N R$ \\
\hline 3 & 100 & $640-920$ & 21 & 30,000 & $\begin{array}{l}6 \mathrm{hr} / \mathrm{raise} \\
\text { temp } / 6 \mathrm{hr}\end{array}$ & 1200 & 19.23 \\
\hline 4 & 0.4 & 980 & 1 & 1,000 & 250.0 & 100 & NR \\
\hline $5 x$ & $31.0^{*}$ & 400 & 21 & 10,000 & 0.016 & 31 & $N R$ \\
\hline 5 & 2.0 & $350-650$ & 21 & 30,000 & 200.0 & 400 & $N R$ \\
\hline 6 & $2.0^{\dagger}$ & 650 & 21 & 30,000 & 20.0 & 40 & $N R$ \\
\hline $7 x$ & 100 & 400 & 1 & 1,000 & 2.5 & $\sim 200$ & $N R$ \\
\hline $7 Y$ & $100^{t}$ & 400 & 1 & 1,000 & 2.1 & $\sim 4000$ & 0.1 \\
\hline 7 & 100 & 400 & 1 & $15,160^{\S}$ & 20 & 2000 & 2.6 \\
\hline 8 & 2 & 500 & 1 & 1,000 & 50 & 100 & $N R$ \\
\hline 9 & 100 & 980 & 1 & 1,000 & 9.5 & 950 & $N R$ \\
\hline $9 R^{\circ}$ & 100 & .80 & 1 & 1,000 & 4.3 & 430 & $N R$ \\
\hline 10 & 100 & 980 & 1 & 1,000 & 8.4 & 840 & $N R$ \\
\hline
\end{tabular}

$\because 31$ gms injected in less than one minute

t Operaticna! difficulties with solium leak rate

SOperational difficulties with moisture gensing probe

$N R=$ No response was observed

NU $=$ Not used 
TABLE 2-15. Contact Detector Test Data (2)

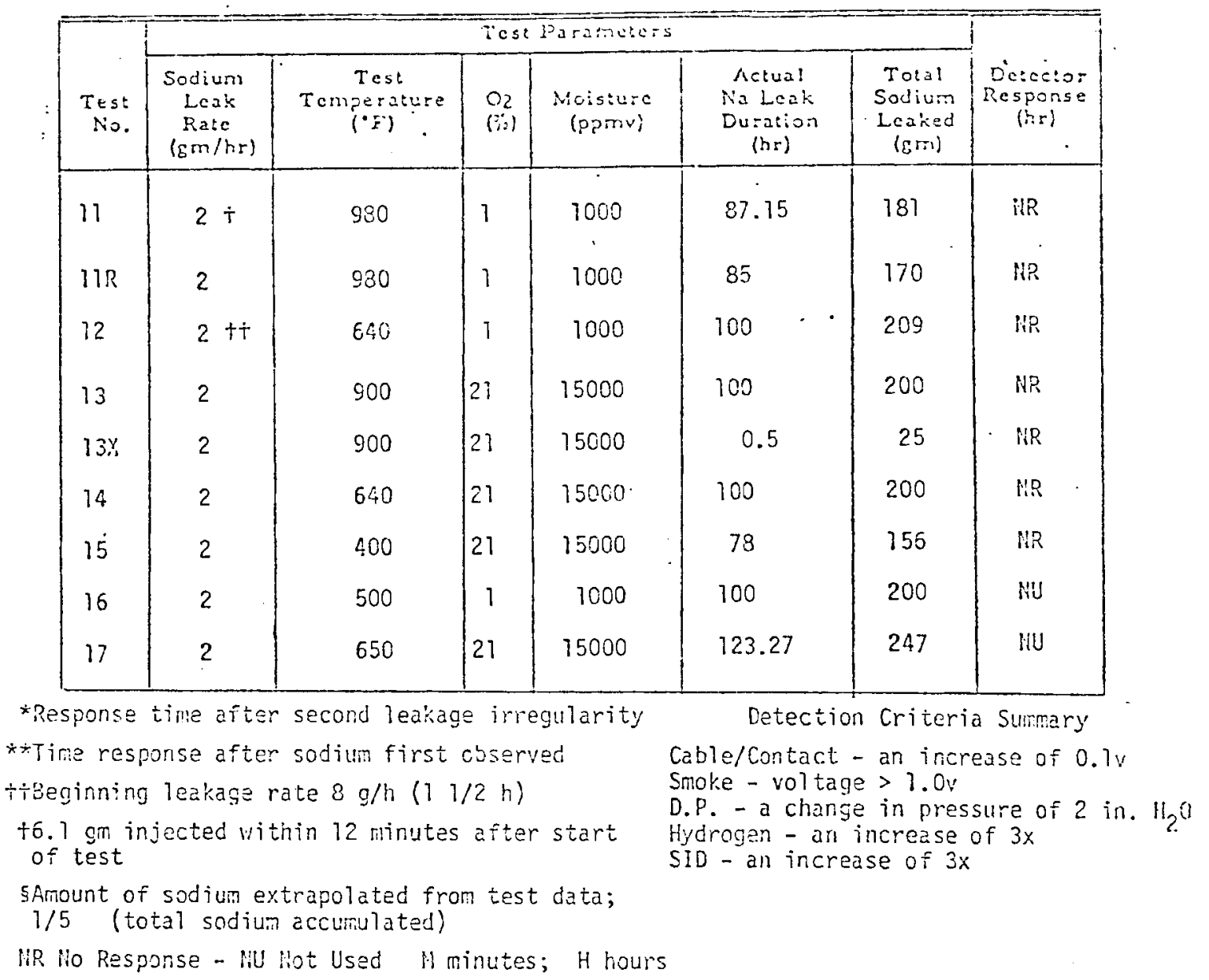

The contact detector did not respond in LMEC natural convection Tests 13 through 15 and 17 (Table 2-15). In these tests, leak rates of $2 \mathrm{~g} / \mathrm{hr}$ were used with approximately $200 \mathrm{~g}$ of sodium spilled.

\subsubsection{Observer Comments on the Contact Detector}

Because the centact and cable detectors are identical electrical1y, observer comments for both devices will be presented here. Figures 2-20 and 2-21 show the physical layout and circuit schematics of the cable and contact detectors tested at LMEC. 


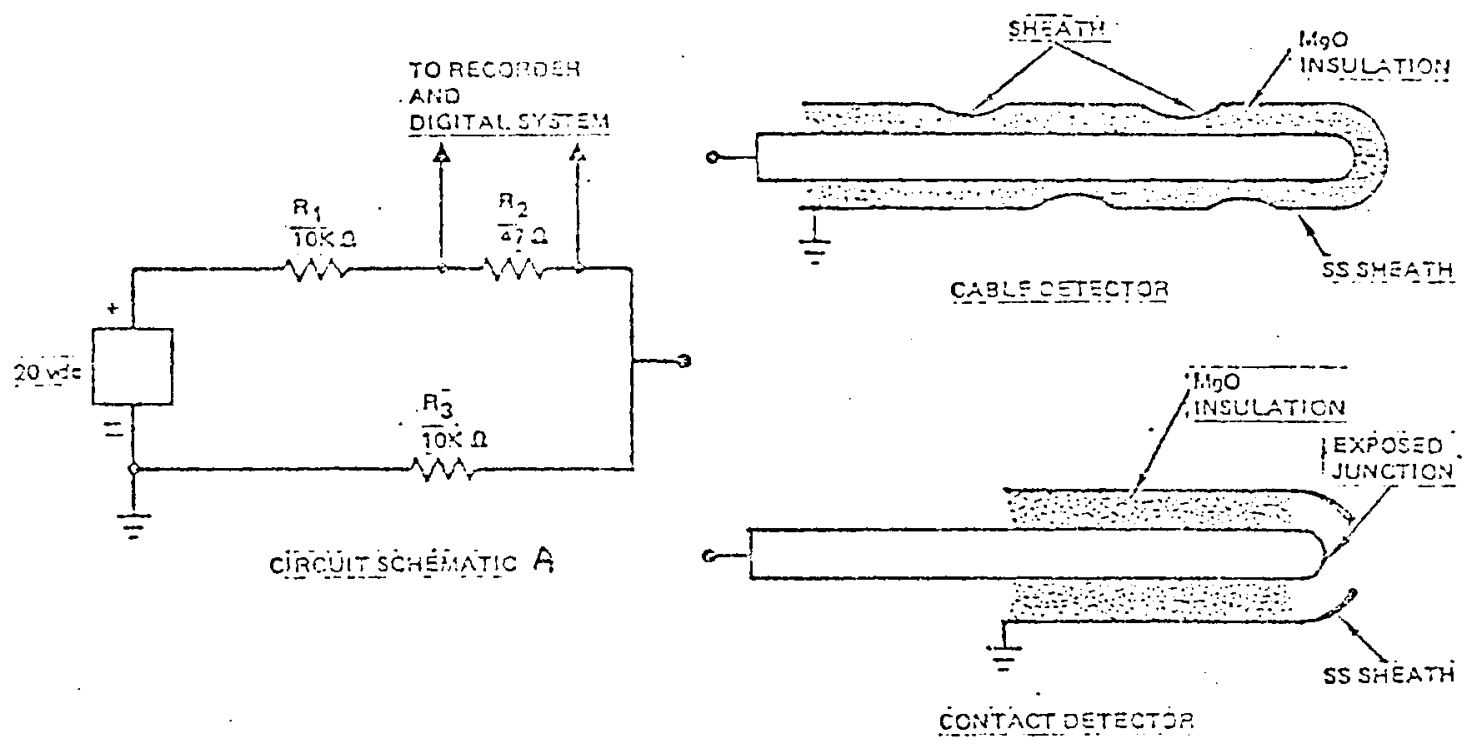

FIGURE 2-20. Cable and Contact Leak Detectors (2)

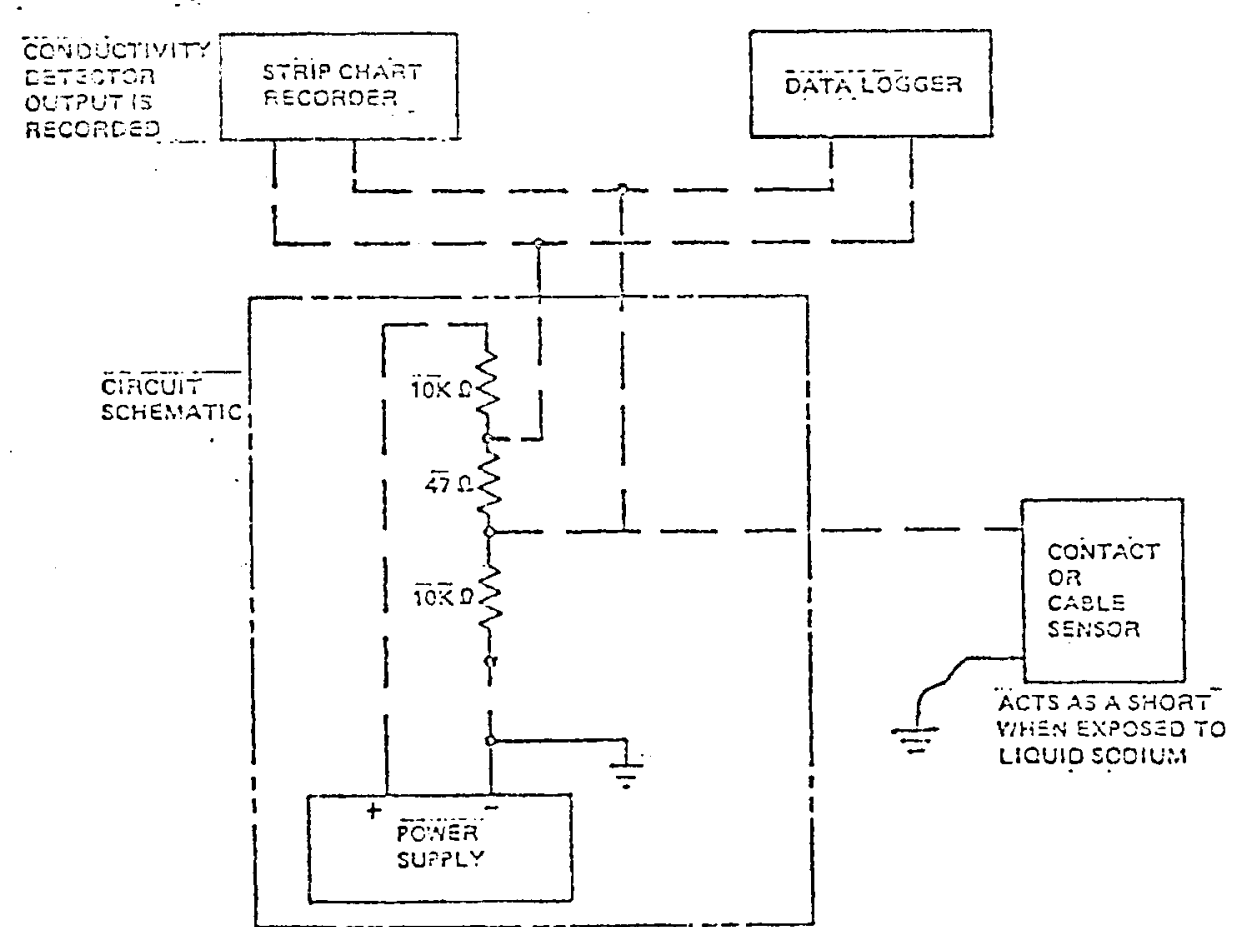

FIGURE 2-21. Cable and Contact Leak Detector Circuit Schematic (2) 
The performance of circuit $A$ with respect to the possibility of breakage during installation is of concern. Referring to Figure 2-22, the circuit $A$ sensor lead will be examined.

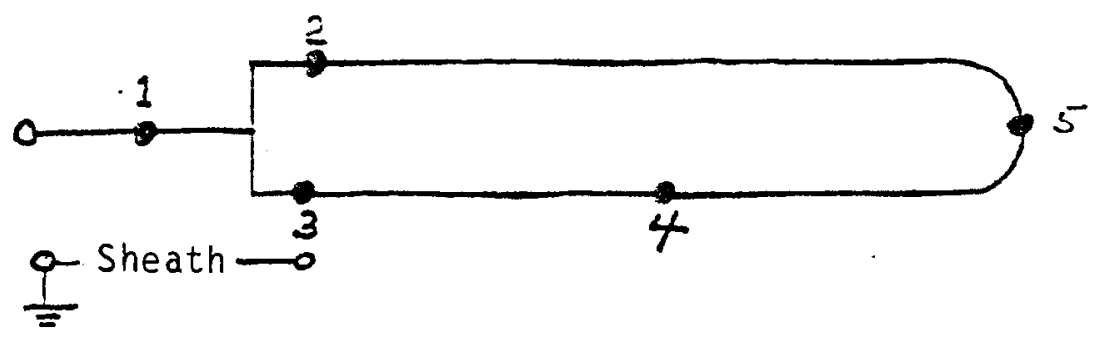

FIGURE 2-22. Circuit A Wire Sensor (PNL)

If there is a break in the sensing lead at point 1, the detector would not be monitoring for sodium leaks, and would not respond to leaking sodium. However, if a single break were to occur at point 5 , the detector would still give an indication. If breaks at points 2 and 3 were to occur simultaneously, the detector would not be monitoring leaks. Finally, if breaks were to occur at or between points 3 and 4 , or 4 and 5 , then leak detection between these points would not occur. Presently no method exists to determine that the circuit is operating properly and actually monitoring for leaks.

Cable and contact detectors are installed by feeding the sensor into a long guide tube ( $>20 \mathrm{ft}$ length) leading to the sensing location. Detector wiring could be broken or damaged during installation and removal, as in periodic inspection, and go unnoticed.

Advantages of utilizing circuit $A$ are the economic benefits of running a single sensing lead to the detection location. The range of circuit $A$ is $47 \mathrm{mV}$ to $94 \mathrm{mV}$, while that of circuit B is $0.45 \mathrm{~V}$ to $5 \mathrm{~V}$.

Recent AI reports $(1,2)$ indicate an alarm response criterion for circuit $A$ of $100 \mathrm{mV}$. A leak would, at most, produce a short across $R_{3}$, which would result in a voltage change of $47 \mathrm{mV}$ to $94 \mathrm{mV}, 6 \mathrm{mV}$ less than the stated AI criterion. 
Unlike circuit $A$, circuit $B$ (Figure 2-23) is a continuous self-monitoring system. A continuous $4.55-\mathrm{mA}$ current produces a $0.45-\mathrm{V}$ potential across $R_{2}$ $(100 \Omega)$. If the circuit is broken at any point, the voltage will drop to 0 volts. If a short circuit from a sodium leak occurs, $R_{3}$ is bypassed and a maximum $5-V$ potential will result across $R_{2}$. However, this is a three wire circuit which results in a greater potential for breakage.

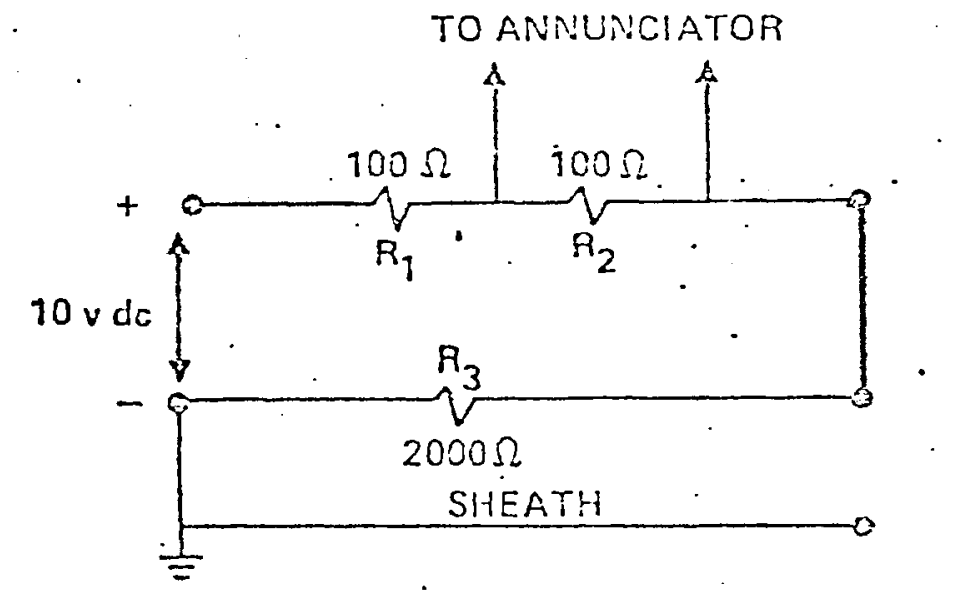

FIGURE 2-23. Circuit B

Another concern with the cable detector is the possible corrosion of the stainless steel sheath that might take place before detection (refer to Figure 2-24). Some observations show the cable detector being covered with sodium, yet no response indicated. There is the possibility that the sodium may not permeate and saturate the magnesium oxide, but in fact, form a surface coating that could preclude penetration. Corrosion products could form, inhibiting the conductivity of the sodium. Sodium may oxidize prior to reaching the detector. Corrosion of the stainless steel sheath could occur, thus eliminating electrical ground. Reference 1 indicated that tests conducted at Westinghouse-ARD ${ }^{(4)}$ under the intermediate system environment showed 


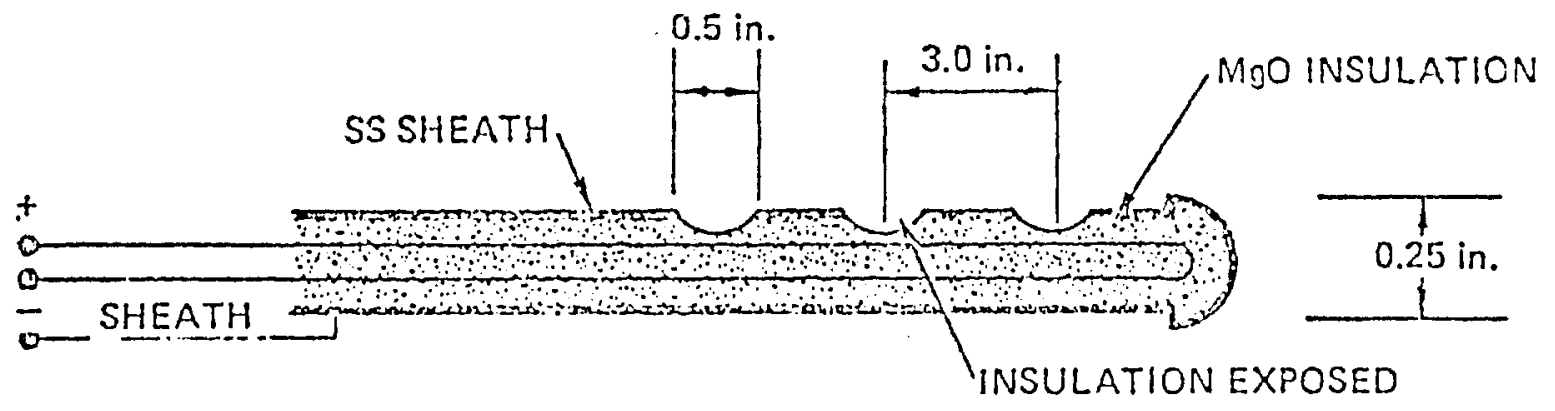

FIGURE 2-24. Cable Detector and Sheath ${ }^{(2)}$

corrosion rates of 0.3 to $0.5 \mathrm{mil} / \mathrm{hr}$ for sodium temperatures above $650^{\circ} \mathrm{F}$. An undetected leak that corrodes at a rate of $0.5 \mathrm{mil} / \mathrm{hr}$ for $250 \mathrm{hr}$ would penetrate 1/8 inch or halfway through the cable sensor. It is conceivable that a short circuit would never occur. If circuit $A$, Figure 2-22, is in use, a portion of the sensing lead may corrode (e.g., area between points 3 and 4), or in the worst case, complete corrosion through the detector could unknowingly result. We are unaware of any basic long term tests that have been performed where the cable (or contact) is covered with sodium at various temperatures typical of CRBR operation.

The cable and contact detectors are installed via guide tubes. It is possible that the contact detector may not be flush with the end of the guide tube stop; that is, it could be slightly below. If it is not in the proper position, some or all of the liquid sodium could drain down the guide tube and bypass the contact detector. It is also possible that the cable sensor may not be entirely outside the guide tube, thus eliminating part of the sensing area. In addition, if the cable is not lying flat, detector response would be affected. The effects of thermal cycling on a guide tube that is rigidly fixed at both ends could misalign and pinch the detector sensor. It will be necessary to visually inspect the detector after each installation.

A recent report ${ }^{(5)}$ indicated that rust had developed between the wire contacts of the spark plug (contact-type) detector. This could lead to a false alarm condition. The calcium silicate insulation used to cover the 
pipes is quite hygroscopic. Problems at AI have resulted in the release of copious quantities of moisture to the cell environs from insulation during heatup following a long shutdown. While some of these detectors are currently made to RDT standards and some are not, it should be noted that one of the contact detectors that had rust on it was made to the standard. Preservice and periodic inservice inspection is necessary.

\subsection{SODIUM TO SODIUM LEAK DETECTORS}

If sodium to sodium leaks were to occur, they would take place at the interface(s) of the Intermediate and Primary Heat Transport Systems. Descriptions of these interfaces and candidate detection systems were included in Section 7.5.5.2 of the PSAR. This section is reproduced below to orient the reader to the subsequent discussion of PNL's evaluation of sodium to sodium leak detectors.

\subsubsection{Intermediate to Primary Heat Transport System Leak Detection}

\subsection{Design Description}

The IHTS pressure is maintained at least 10 psi higher than the Primary Heat Transport System at the IHX to prevent radioactive primary sodium from entering the IHTS in the event of a tube leak. Maintaining a positive pressure differential across the IHX is a limiting condition for operation of the plant (Chapter 15 Technical Specifications). This provides assurance that a zero or negative differential will not exist during any extended interval. A loss of this pressure or a reversal of it is not expected to occur except during accident conditions. Such an occurrence would necessitate an orderly plant shutdown to correct the problem. Since a reverse differential cannot occur for a significant interval, the potential leakage of primary sodium of the intermediate system, through an IHX tube leak, is small.

Leakage of primary sodium into the IHTS, should it occur, will be detected by radiation monitors provided on the IHTS piping within the SGB. The radiation monitor system will provide an indication of the radiation level and will provide alarms for conditions of 
excessive radiation indicative of ingress of primary sodium. Since the only activity expected in the IHTS is a low level of tritium, the radiation monitors will be very sensitive to the presence of significant amounts of radioactive primary sodium in the intermediate system. For accidents which involve a loss of IHTS boundary integrity the radiological effects have been evaluated. The results of these evaluations are presented in Sections 15.3.2.3, 15.3.3.3, and 16.6.1.5.

Maintaining a positive pressure differential across the IHX assures that the leakage across the IHX tube barrier will result in an inflow of sodium into the primary system causing a loss of sodium inventory in the IHTS. The sodium inventory in the IHTS is monitored by tracking the sodium levels and correcting for loop temperature effects. Alarms are provided in the control room to alert the operator upon detection of a large loss of IHTS sodium inventory.

\subsection{Design Analysis}

Intermediate to Primary Heat Transport System leak detection is provided to comply with CRBRP General Design Criterion 36 "Inspection and Surveillance of Intermediate Coolant Boundary". In order to demonstrate how the intent of this criterion will be satisfied, an analysis of the minimum detectable leaks in the IHX is provided below.

The minimum detectable level change of sodium in the IHTS pump and expansion tank is approximately 3 inches which corresponds to about 150 gallons. In the event of a full-circumferential break of an IHX tube, the leak rate of intermediate sodium to the primary side of the IHX would be approximately $150 \mathrm{gpm}$. At this leak rate, the detection time would be about one minute assuming steady state temperature condition.

Based upon a 3 inch change, leakage as low as 6.25 gph would fall within the detection threshold. Over long time periods, the sensitivity of the detection system will be reduced by an insignificant amount due to other potential leakages from the system. If leakage occurs due to piping or component leaks, the external leak detection system will detect the leakage. A second potential source is leakage through the four sets of dump valves which has a maximum expected rate of one to two gallons per day. Since this leakage rate is essentially two orders of magnitude smaller than the leakage threshold, it will not have a consequential effect on detection sensitivity. 
Section 7.5.5.2 of the PSAR does not specifical7y designate candidate detector types or sodium to sodium leak monitoring techniques. Instead, it refers rather generally to level sensors, radiation detectors, and pressure sensors. PNL's evaluation of the PSAR detection information follows.

\subsubsection{Level Sensors}

The only reference to level sensors proposed for CRBRP use was a rather sketchy discussion in Reference 5. No detector descriptions were presented in the meeting documented in Reference 5, but sensor types were mentioned, including mutual inductance sensors: displacement units, differential pressure instruments, time domain reflectromeiry, ultrasonic time-of-flight sensor, conductivity $\mathrm{J}$-tubes and thermocouple arrays.

\subsubsection{Level Sensor Test Data Evaluation}

The PSAR contained no information on level sensor tests. Hence, PNL could not evaluate the test data.

\subsubsection{Observer Comments on Level Sensors}

PNL's evaluation found that FFTF is using the mutual inductance level sensor, although the rationale for its use was not stated. (5) The discussion presented in Reference 5 centered on a problem (or advantage) of each sensor type. While the displacement unit was reportedly the most accurate, the lack of substantive data made it impossible for PNL to meaningfully compare the candidate sensors.

\subsubsection{Radiation Detectors}

The PSAR states that radiation detectors will be used in the CRBRP, but provides no details regarding specific detectors or monitoring methods.

\subsubsection{Radiation Detector Test Data Evaluation}

PNL was unable to evaluate the radiation detector because of unavailable test data. 


\subsubsection{Observer Comments on Radiation Detectors}

If radiation detectors were developed for use as sodium to sodium leak monitors, they would serve as a backup detection system for the intermediate loops. Small leaks, difficult to detect with level sensors, could be monitored by the more sensitive radiation detectors.

\subsubsection{Pressure Sensors}

The pressure sensors that would indicate a loss of positive pressure differential across the IHX would not be sensitive to small leaks of interest. Therefore, they cannot be considered for the monitoring of small leaks. Pressure sensors should respond to intermediate or larger leaks.

\subsection{STEAM/WATER TO SODIUM LEAK DETECTORS}

The general requirements of the proposed system for detecting steam/water leaks to sodium are described in Section 7.5.5.3 of the PSAR, as reproduced below.

\subsubsection{Steam Generator Leak Detection System}

A steam Generator Leak Detection System is provided to detect smal1 (as low as 10-5 1b/sec) water-to-sodium and steam-tosodium leaks in the same generator modules, to identify the module in which the leak has occurred, and to alert the control room operator enabling him to take manual corrective action to prevent the leak rate from increasing. Leak detection instrumentation is provided for:

1. Sodium exiting from each evaporator and superheater.

2. Sodium filled vent 1 ines from each evaporator and superheater.

3. Bulk sodium in the IHTS cold leg.

4. Argon cover gas in the IHTS pump tank.

The design and operational requirements for the proposed system are provided in PSAR Sections 7.5.5.3.1 and 7.5.5.3.2. Both sections (through Amendment 34, February 1977) are reproduced here in their entirety. 


\subsection{Design Description}

\section{General}

Steam or water leakage into sodium produces hydrogen and oxygen, some of which remains dissolved in the sodium and some leaves the the sodium and reaches the cover gas spaces. The leak detection is based on measurement of the hydrogen concentration in both sodium and in the cover gas spaces. Oxygen concentration measurements are used in the sodium only and are complementary to the hydrogen detectors, thus providing a diverse method to ensure early detection.

To provide a sensitive leak detection capability, the background concentrations of oxygen and hydrogen are maintained as low as practicable. The hydrogen in the sodium is removed by cold trap precipitation of sodium hydride. Oxygen in the sodium is removed in the same way by sodium oxide precipitation. The background concentration of hydrogen in the system is normally maintained below $100 \mathrm{ppb}$ through cold trap operation. 0xygen concentration is maintained at about 2 ppin.

\section{Hydrogen Detectors}

The measurement of hydrogen in the sodium is performed by allowing the hydrogen to diffuse through a thin walled nickel membrane, and detecting the hydrogen with an ion gauge and an ion pump. The monitor may operate in a static mode using the ion gauge to monitor steady state hydrogen concentration, since hydrogen content is directly related to the pressure measured in the chamber. The monitor may also operate in a dynamic mode, using the ion pump to constantly pump the chamber since the hydrogen concentration is directly related to the ion-pump current. The hydrogen detection in the expansion tank cover gas utilizes a gas chromatograph. A continuous monitoring hydrogen detector similar to the in-sodium detectors is also provided for the cover gas.

\section{Oxygen Detectors}

oxygen electro chemical cells are used to continuously monitor in-sodium concentration and consist of a reference oxygen electrode separated from the sodium by a solid electrolyte. The electrical potential drop between the reference electrode and the sodium measures the in-sodium oxygen concentration. 


\section{Detectors Location}

The three steam generation loops utilize identical hydrogen and oxygen level detectors. The liquid phase hydrogen detectors are located at each superheater module exit and in the piping at the exit of each evaporator module. Hydrogen detectors are also located in the sodium filled vent lines of each module and in the IHTS pump cover gas space. Hydrogen detectors as well as oxygen detectors are located in the IHTS cold leg piping to monitor bulk sodium. Figure 5.7-4 gives the instrumentation location.

\section{Indication in Control Room}

Measurements of the hydrogen and oxygen detectors are monitored by the Data Handling and Display System. Each channel is limit checked and its trend is limit checked. High alarm, high rateof-rise alarm and channel failure alarm are provided to the Plant Annunciator System.

\section{System Operation}

The in-sodium hydrogen leak detector detects two leak signal categories:

1. a strong signal in a single pass,

2. detection of a gradual hydrogen concentration increase or decrease through several passes through the sodium.

Figure 7.5-4 illustrates typical first pass hydrogen concentration change as a function of water leak rate. As illustrated, a change in hydrogen concentration of a few ppb would be indicated at the detector for leak rates in the range of $10^{-4} 1 \mathrm{~b} / \mathrm{sec}$. Approximately one minute is required for the hydrogen to reach the detector and signal a leak. Detection capability can be extended to smaller leak sizes through the use of a rate of rise detection system. Several passes of sodium through the system would be required to allow the hydrogen concentration to build up. The sensitivity of this sytem will allow detection of leaks in the range of $10^{-5} \mathrm{lb} / \mathrm{sec}$. Figure $7.5-5$ illustrates the hydrogen concentration change with time for various sizes of leaks.

\subsection{Design Analysis}

A Steam Generator Leak Detection System is provided to comply with CRBRP General Design Criteria 3a which calls for provision of leak detection in the Steam Generators. In order to show how the criterion will be satisfied, a review of leak damage studies is presented with the resulting instrumentation requirements. 


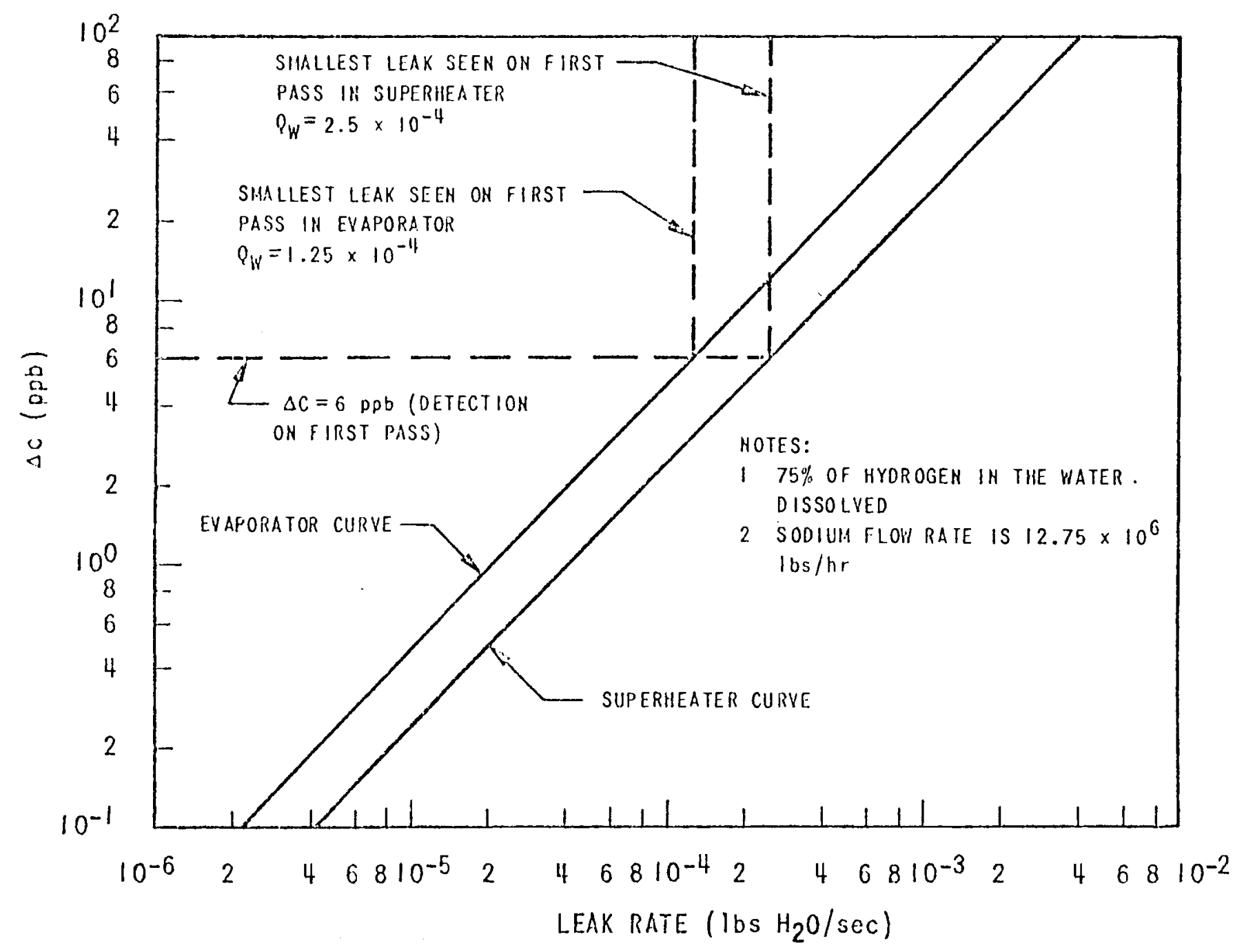

FIGURE 7.5-4. First Pass Hydrogen Concentration Change Vs. Leak Rate (from PSAR) 


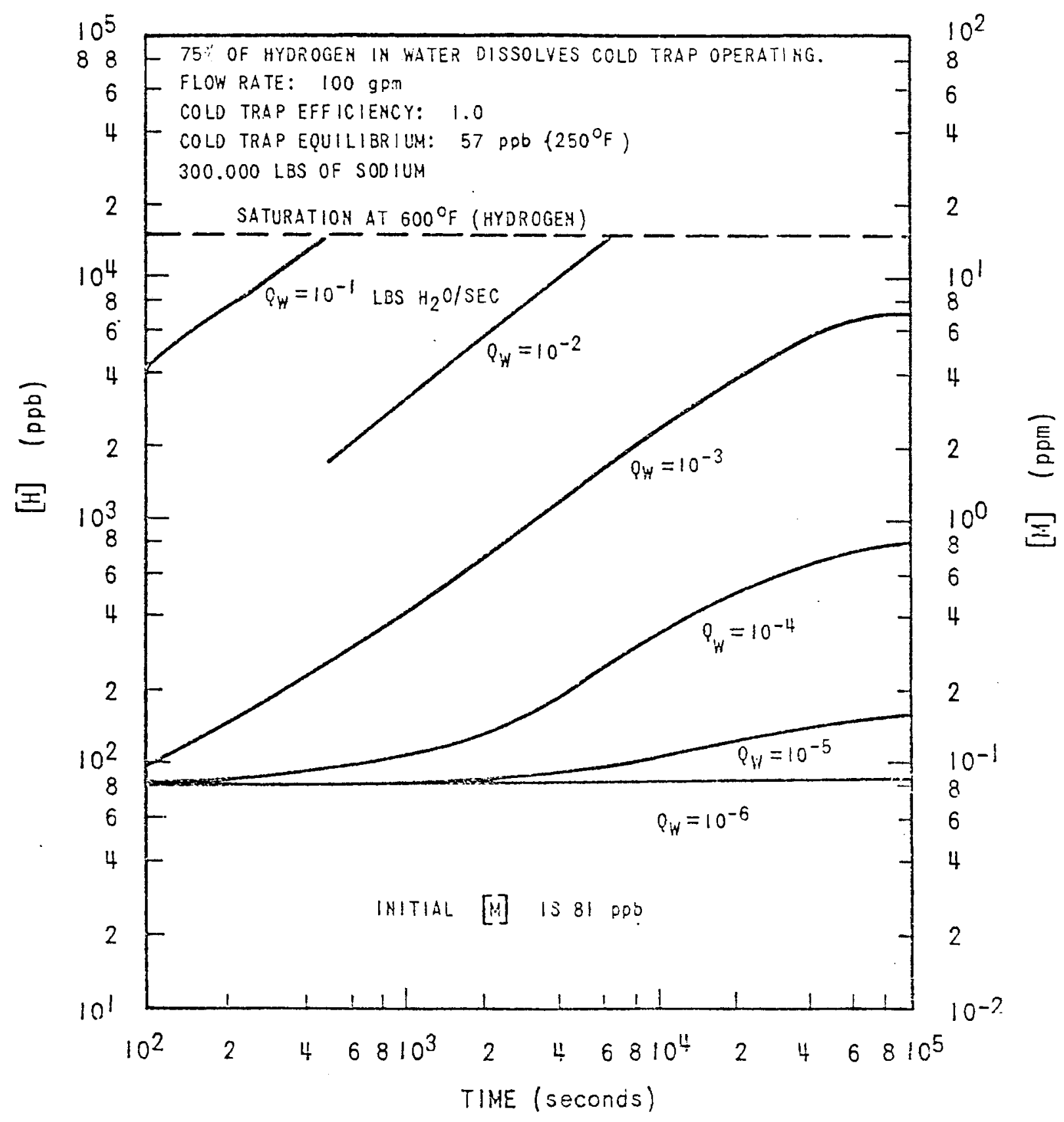

FIGURE 7.5-5. Hydrogen Concentration Vs. Time for Various Water Leak Rates (from PSAR) 


\section{Leak Damage Studies}

Experimental studies have been conducted in the United States and in Europe over the past ten years which have given a broad base background to the understanding of the behavior of leakage damage effect. Most of the experimental data taken with 2-1/4 Cr-1 Mo material have been obtained by injecting water or steam through hole type geometries at selected target configurations (jet leaks). In general, results of these studies have indicated that both adjacent tube wastage and self wastage are possible damage mechanisms, as described in Reference 1.

Adjacent tube wastage will occur with the proper leak size and orientation. For very specific conditions and geometries, some experiments have been performed where adjacent tube wastage occurred very rapidly in a localized area. Relating these specific conditions to CRBRP, adjacent tube wastage could occur which would result in tube failure in a very short period of time, less than one minute. However, it is not likely that leaks would be optimized as to leak geometry, location and orientation, as those utilized for the experiments. In the event that this did occur, the steam generator rupture discs provide necessary protection.

The second class of damage is self wastage around the leak site. Some experiments have noted that some very small leaks have experienced a sudden enlargement after a period of relatively steady operation as reported in Reference 1. The effect of this type of characteristic is currently under study by the GE/ANL Steam Generator Systems Development Program.

\section{Design Requirements}

The design requirements for the Steam Generator Leak Detectors have been selected as described below.

\section{SGS Leak Detection Requirements}

$\begin{array}{lccc} & \begin{array}{c}\text { In-Sodium } \\ \text { Hydrocen Detectors }\end{array} & \begin{array}{c}\text { Cover Gas } \\ \text { Hydrogen Cetectors }\end{array} & \begin{array}{c}\text { Oxygen } \\ \text { Detectors }\end{array} \\ \text { Sensitivity } & 3 \mathrm{ppb} & 2 \mathrm{ppm} & 24 \mathrm{ppb} \\ \text { Range } & 0.04-2 \mathrm{ppm} & 5-1000 \mathrm{ppm} & 0.1-10 \mathrm{ppm} \\ \text { Response Time } & \leq 30 \mathrm{sec} . & \leq 30 \mathrm{sec} . & \leq 30 \mathrm{sec} .\end{array}$

* Not applicable to gas chronatograph 
Instrument Sensitivity

- The wastage rate studies for jet leaks show that leaks below $10^{-4} \mathrm{lb} / \mathrm{sec}$ persist without major damage for more than one loop transit time. The loop transit time can be calculated from a $12.75 \times 10^{6} \mathrm{lbs} / \mathrm{hr}$ flow rate and $3 \times 10^{5} \mathrm{lbs}$ sodium inventory in the IHTS loop; the hydrogen generated from the quantity of $\mathrm{H}_{2} \mathrm{O}$ leaked in one transit time divided by the total sodium inventory yields an increase of $3.15 \mathrm{ppb}$ in the concentration of hydrogen, thus a $3 \mathrm{ppb}$ sensitivity for the hydrogen detectors.

- A resolution of $3 \mathrm{ppb}$ change in the hydrogen background concentration ranging from 75 - $100 \mathrm{ppb}$ (i.e., a change of 3-4\%) under steady-state SG operation is a design goal for the leak detector.

- The oxygen detector is as sensitive as the hydrogen detector. Taking into account an oxygen background concentration of about $1200 \mathrm{ppb}$, the sensitivity is $24 \mathrm{ppb}$.

Instrument Range

- Detection capability of leaks up to $10^{-1} \mathrm{lb} / \mathrm{sec}$. i.e., those which are expected to activate the Sodium-Water Reaction Pressure Relief System;

- The cover gas hydrogen concentration operational range is expected to be up to $1000 \mathrm{ppm}$ (at start-up condition).

Instrument Availability

- Sodium loop leak detection capability provides continuous monitoring and indication of the impurity level whenever sodium and water/steam co-exist in the steam generator modules.

Operation Requirements

- In order to effect an orderly plant shutdown which minimize plant unavailability, the following operator actions are required. 


\begin{tabular}{|c|c|c|}
\hline Approximate Lenk Size & Detection Hethod & Action \\
\hline$<10^{-5} \mathrm{ib} / \mathrm{sec}$ & Not detectable & Continue operation \\
\hline $10^{-5}$ to $10^{-4} \mathrm{ib} / \mathrm{sec}$ & Rate of rise detection & $\begin{array}{l}\text { Initiate orderly loop } \\
\text { shutdown }\end{array}$ \\
\hline $10^{-4}$ to $10^{-3} \mathrm{lb} / \mathrm{sec}$ & First pass detection & $\begin{array}{l}\text { Initiate rapid loop } \\
\text { shutdown with depressuri- } \\
\text { zation and steam side } \\
\text { blowdown }\end{array}$ \\
\hline $10^{-3}$ to $10^{-1} \mathrm{lb} / \mathrm{sec}$ & First pass detection & $\begin{array}{l}\text { SWRPS actuation riay } \\
\text { result }\end{array}$ \\
\hline
\end{tabular}

For leakages greater than about $0.1 \mathrm{lb} / \mathrm{sec}$ of water, the pressure buildup in the system will occur rapidly, causing the SodiumWater Reaction Pressure Relief System to be activated (See Section 7.5.6).

Additional information contained within PSAR Table 7.5-7 is reproduced below and schematically shown in Figure 2-25, reprinted from Mckee.

\subsubsection{Hydrogen Detectors}

The hydrogen detector proposed for CRBRP water to sodium leak detection is shown in Figure 2-26. The nickel membrane is inserted into the liquid sodium. On the other side of the nickel membrane is a vacuum created by an ion pumping system. Hydrogen resulting from a leak diffuses through the nickel membrane into the vacuum, where it can be detected by:

! measuring the pressure rise,

! employing a mass spectrometer, or

! monitoring ion purnp current.

Ion pump current monitoring underwent the most extensive testing because it is the simplest and most reliable of the three techniques.

\subsubsection{Hydrogen Detector Test Data Evaluation}

PNL evaluated test procedures and resulting data. The laboratory's findings are documented below. 


\begin{tabular}{|c|c|c|c|c|}
\hline System & $\begin{array}{l}\text { Measured } \\
\text { Parameters }\end{array}$ & Instrument & Measurement Location & Purpose \\
\hline \multirow[t]{5}{*}{$\begin{array}{l}\text { Leak Delection } \\
\text { (cont'd) }\end{array}$} & $\begin{array}{l}\text { Intermediate to } \\
\text { Primary Leak }\end{array}$ & Level probe & IHTS expanston tank & Detect leak in IHX \\
\hline & $\begin{array}{l}\text { Stean Generator } \\
\text { Leaks }\end{array}$ & Hydrogen detectors & $\begin{array}{l}\text { Sodium exiting evaporator and } \\
\text { superheater }\end{array}$ & \multirow{4}{*}{$\begin{array}{l}\text { Detect snall water-sodium and } \\
\text { steam-sodium leak in steam } \\
\text { generator, identify leaking } \\
\text { module, provide signal for } \\
\text { operator action }\end{array}$} \\
\hline & $\begin{array}{l}\text { Steam Generator } \\
\text { Leaks }\end{array}$ & Hydrogen detectors & $\begin{array}{l}\text { Sodium filled vent lines from } \\
\text { each evaporator and superheater }\end{array}$ & \\
\hline & $\begin{array}{l}\text { Steam Generator } \\
\text { Leaks }\end{array}$ & $\begin{array}{l}\text { Hydrogen and Gas } \\
\text { Chrona tograph }\end{array}$ & Argon cover gas in IHTS pump & \\
\hline & $\begin{array}{l}\text { Stean Generator } \\
\text { Leaks }\end{array}$ & $\begin{array}{l}\text { Hydrogen and } \\
\text { Oxygen Detectors }\end{array}$ & Sodiun in IUTS cold leg & \\
\hline
\end{tabular}

FIGURE 7.5-1. Part Relating to Leak Detection from the PSAR 


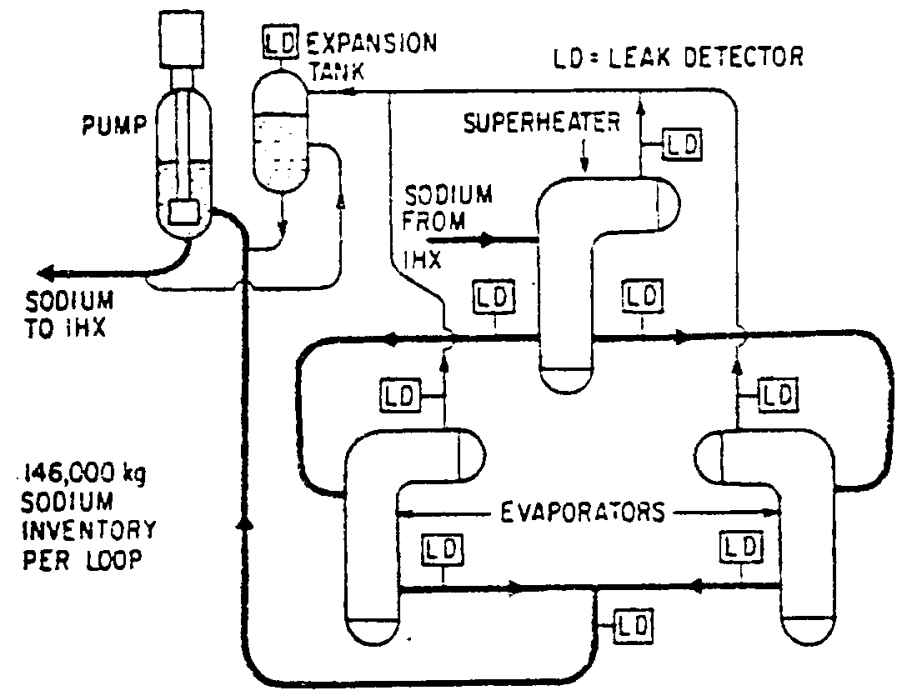

FIGURE 2-25. CRBR IHTS Leak Detection System (12

(12)

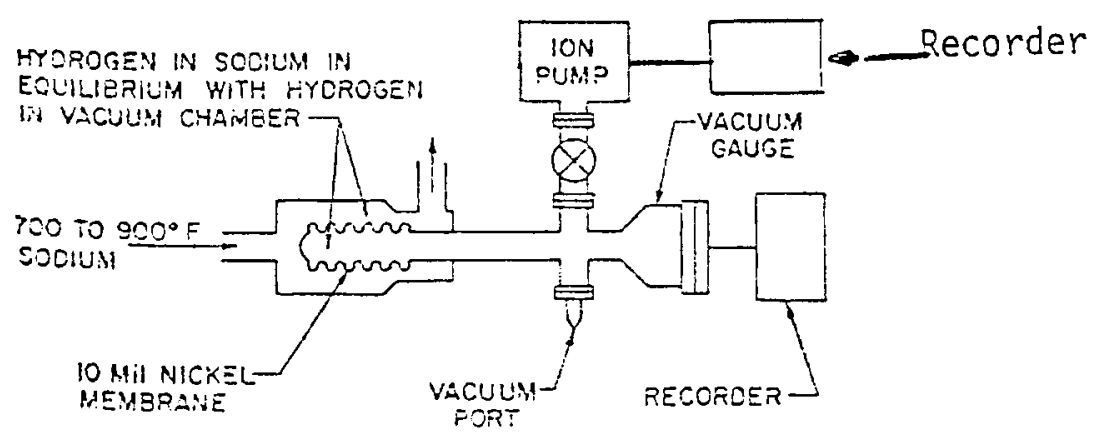

FIGURE 2-26. Hydrogen Detector Schematic (12)

2.3.1.1.1 Test Conditions. Hydrogen detectors have been studied extensively. $(10,12-20)$ According to McKee's comprehension summary of hydrogen detector testing, (12) two setups were used to examine the devices for CRBRP: the Atomics International 30-MW Modular Steam Generator (MSG) on the Sodium Components Test Installation (SCTI) at the Liquid Metals Engineering Center (LMEC), and the Core Component Test Loop (CCTL) at Argonne National Laboratory (ANL). 
The test design was based on the following parameters and ranges:

- leak rate range: $0.45 \mathrm{mg} \mathrm{H} 2^{\mathrm{O} / \mathrm{s}}\left(9.9 \times 10^{-7} 1 \mathrm{~b} \mathrm{H} \mathrm{H}_{2} \mathrm{O} / \mathrm{s}\right)$ to $100 \mathrm{mg} \mathrm{H} \mathrm{H}_{2} \mathrm{O} / \mathrm{s}$ $\left(2.2 \times 10^{-4} 1 \mathrm{~b} \mathrm{H}_{2} \mathrm{O} / \mathrm{s}\right)$

- temperature range: $204^{\circ} \mathrm{C}$ to $510^{\circ} \mathrm{C}$

- steam injection in the sodium inlet line

- hydrogen injection at the top and bottom tubesheet

- sodium flow rates: $25 \mathrm{~kg} / \mathrm{s}(55 \mathrm{lb} / \mathrm{s})$ to $189 \mathrm{~kg} / \mathrm{s}(416 \mathrm{lb} / \mathrm{s})$.

2.3.1.1.2 Test Results. The lowest leak rate producing a rate-of-rise sufficient to activate the detector's alarm was $4.54 \mathrm{mg} \mathrm{H}_{2} \mathrm{O} / \mathrm{s}\left(10^{-5} \mathrm{lb} / \mathrm{s}\right)$. This corresponds to a rate-of-rise of $2.1 \mathrm{ppb} \mathrm{H} / \mathrm{min}$. Table 2-16 summarizes some of the most informative response time data for the hydrogen detector.

TABLE 2-16. Hydrogen Detector Response Timęs:

Steam/Water-to-Sodium Leaks (12)

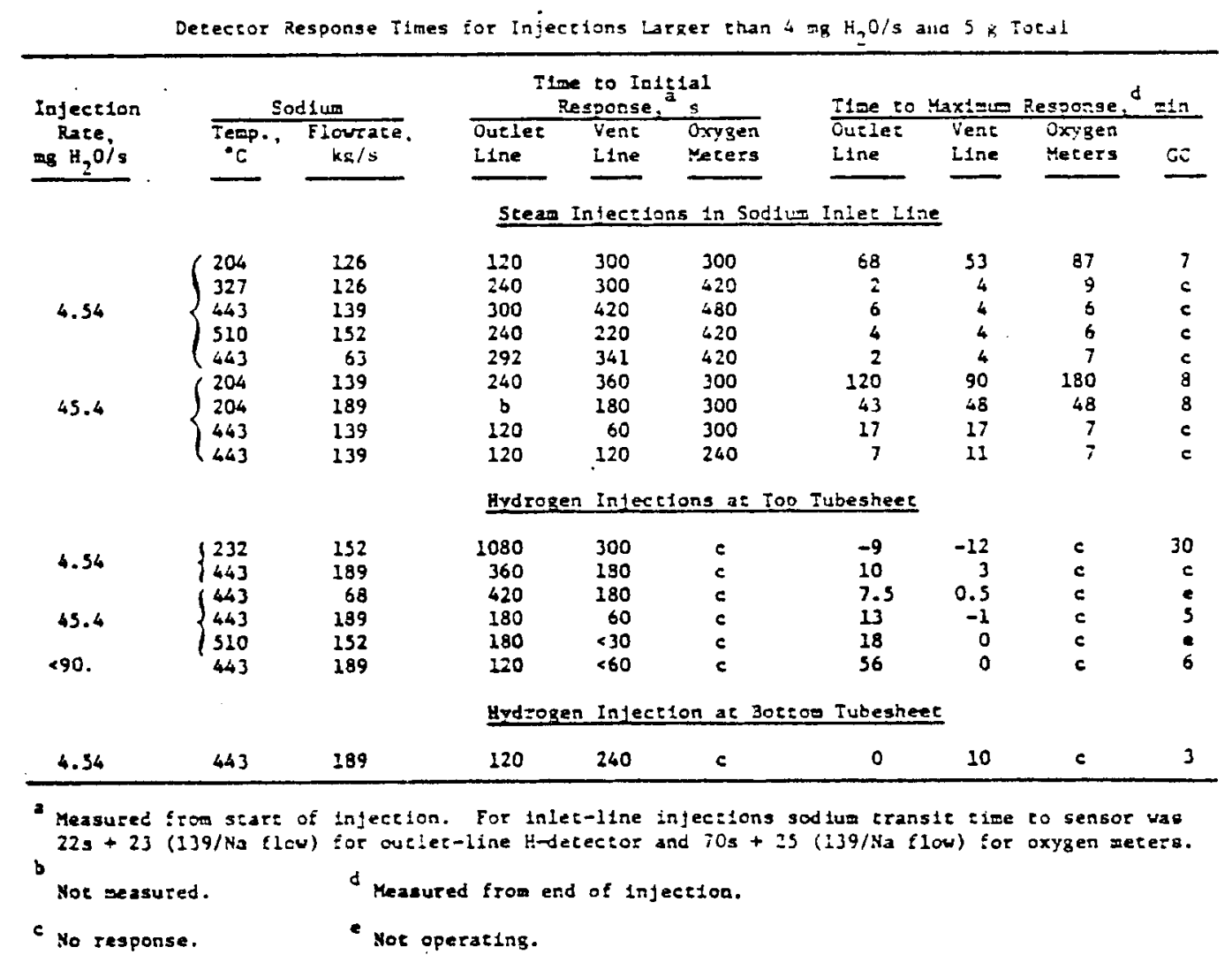


Steam injection test data indicate that hydrogen detectors placed at both the sodium outlet and vent lines responded quickly, except when tested under low sodium temperature $\left(204^{\circ} \mathrm{C}\right)$ conditions. However, this discrepancy was predictable; hydrogen must be soluble in sodium for the detectors to work properly, and, at low temperatures, hydrogen is not very soluble in sodium.

In the hydrogen injection tests, the detector on the vent line responded faster than those on the outlet lines. The distance from the top tube sheet to the vent line detector, combined with the stagnant sodium flow in this area, enhances the vent line hydrogen detector response to injections at this location.

No tests were performed at the upper PSAR requirement limit injection rate of $10^{-1} \mathrm{lb} / \mathrm{s}(45.4 \mathrm{~g} / \mathrm{s})$.

\subsubsection{Observer Comments on the Hydrogen Detector}

According to the PSAR, the hydrogen detector response time should be 30 seconds. This time interval is not defined further. Test data indicate that, for smal? leaks, the time to initial response typically ranged from 100 to 200 seconds.

In the PSAR, design requirements called for an in-sodium hydrogen detector range of 0.04 to $2.0 \mathrm{ppm}$. A later operational requirement set the range at $10^{-1} \mathrm{lb} / \mathrm{s}$ to $<10^{-5} \mathrm{lb} / \mathrm{s}$. Consistency in units would be helpful in eliminating confusion and explaining these two sets of requirements.

Two inherent problems were found with the hydrogen detector:

1. Changes in the ion pump are reflected in the ion pump current. Specifically, aging, length of service, and cathode changes will alter the background ion pump current. However, these changes occur slowly with time and, because the detector works on a rate of rise or dynamic mode, will have little effect on detector performance.

2. There is currently no technique available for calibrating the detector in-situ. Methods that would leak or inject hydrogen upstream to the detector at a predetermined rate have been discussed, but no performance data are available for assessment. 


\subsubsection{Gas Chromatographs}

The gas chromatograph (GC) analyzes gas samples extracted from the IHTS cover gas. The technique entails separating various gases on an absorbent, then measuring the concentration of the gases. Gas concentration may be measured by analyzing the changes in thermal conductivity of input and output gas (two specified points along the column). The GC is an off-the-shelf instrument and has not been adapted specifically for LMFBR applications.

\subsubsection{Gas Chromatograph Test Data Evaluation}

PNL examined the available test data and noted the following features.

\subsection{Test Conditions. The GC was tested simultaneously with the} hydrogen detector. The test conditions described in Section 2.3.1.1.1 prevailed.

2.3.2.1.2 Test Results. Gas chromatograph test results are summarized in Table 2-16. As shown, the GC either tended to reach maximum response quickly or else it did not respond at all. When the solubility of hydrogen in sodium was low, the GC responded quickly. In contrast, when the solubility of hydrogen in sodium was high, the GC did not respond. These two conditions correspond to low and high sodium temperatures, respectively. Cold traps remove dissolved hydrogen from the sodium, preventing its escape to the cover gas and leading to the GC no-response condition.

\subsubsection{Observer Comments on the Gas Chromatograph}

The GC does not provide any information on leak location, but it does respond well at low sodium temperatures.

The PSAR does not stipulate any performance requirements in terms of GC sensitivity, response time, range, etc. Hence, PNL could not evaluate GC performance against predetermined standards. 


\subsubsection{Oxygen Detectors}

Oxygen detectors are electrochemical cells immersed in sodium (see Figure 2-27). A reference oxygen electrode is separated from the sodium by a $\mathrm{ThO}_{2}-\mathrm{Y}_{2} \mathrm{O}_{3}$ solid electrolyte. The electrical potential difference between the reference electrode and the sodium is a measure of the oxygen content in the sodium.

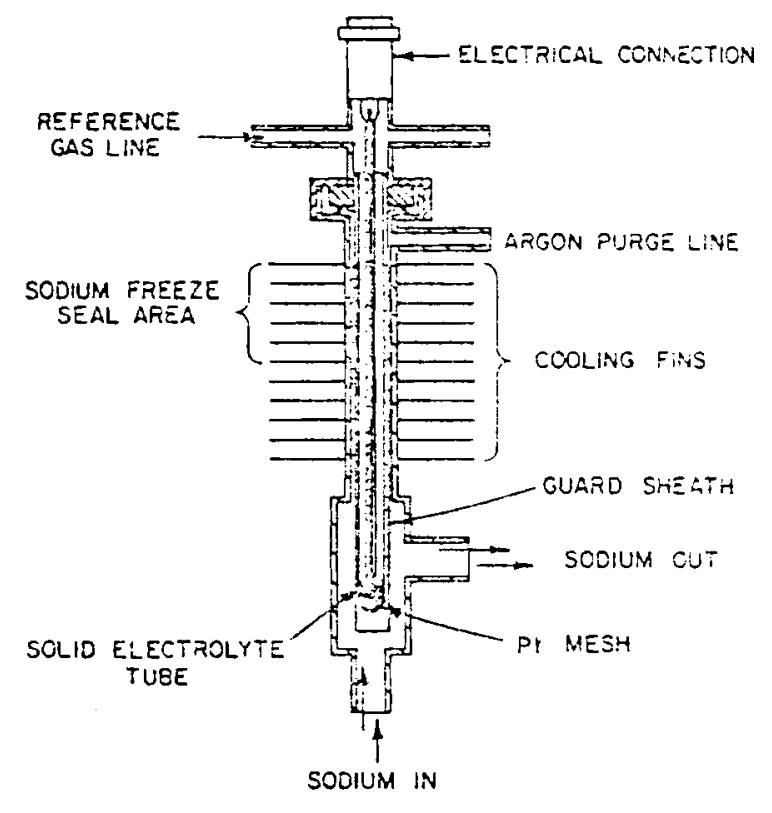

FIGURE 2-27. Oxygen Detector $(23)$

\subsubsection{Oxygen Detector Test Data Evaiuation}

Oxygen detector data were evaluated by PNL. Results of the laboratory's analysis are documented in the following subsections.

2.3.3.1.1 Test Conditions. Conditions under which the oxygen detectors were tested are the same as those for the $G C$ and the hydrogen detectors (see Section 2.3.1.1.1).

2.3.3.1.2 Test Results. Table 3-1 summarizes the results for the oxygen detector tests. The oxygen detectors did not respond to the hydrogen gas injections. Hence, the resulting data base is smaller than that of the hydrogen detectors. 
Initial response and maximum response times were both slower for the oxygen detectors than for the hydrogen detectors.

\subsubsection{Observer Comments on the Oxygen Detector}

PNL evaluated oxygen detector performance against the requirements stipulated in the PSAR: sensitivity of $24 \mathrm{ppb}$, a range of 0.1 to $10 \mathrm{ppm}$, and a response time $\leq 30$ seconds. Test data reported time to response, hydrogen injection rates, and other conditions; however, these findings are not directly comparable to PSAR requirements. PNL did determine that the oxygen detector does meet the PSAR sensitivity requirements.

PNL also found several difficulties inherent in the oxygen detector:

1. The solid electrolyte is quite fragile and has been reported to be subject to breakage during installation and removal tests. This will be a limiting factor in oxygen detector applications.

2. The noise level for oxygen meters has not been measured but the prediction is that it can be made sufficiently low. This will require further research and development. .

3. An in-situ calibration technique has not been developed for the oxygen meter. 
, 


\subsection{LEAK DETECTION SYSTEM EVALUATIONS}

Descriptions and test data available in the PSAR and other cited sources for the individual leak sensors were documented in Section 2.0 of this report. Based on this information, PNL evaluated those leak detection systems proposed for CRBR use. The results of the PNL assessment are presented in this section. The information or test data needed for a complete evaluation are also detailed.

\subsection{SODIUM-TO-ATMOSPHERE LEAK DETECTION SYSTEMS}

Table 7.5-3 summarizes the sodium-to-gas leak detection methods scheduled for use at the CRBR. The primary methods of detection are placed into five categories: 1) radiation, 2) aerosol, 3) cable and contact, 4) pressure and temperature monitoring, and 5) visual inspections. The backup method of detection is achieved by vault aerosol, cable monitoring, and changes in sodium tank level. PNL will address radiation, aerosol, and cable and contact monitoring. Where information and test results are deemed insufficient, PNL will define the information or test results required to make a proper system evaluation.

\subsubsection{Radiation Monitoring}

As stated in Section 2.1.6.1, the references contained no information regarding the radiation detector test program or data. Consequently, PNL is unable to evaluate this device.

PNL requests information concerning the operational performance of the radiation detector. The PSAR (Q 120.34-1, Amendment 16, Apri1 1976) states that, at lower temperatures $\left(<600^{\circ} \mathrm{F}\right)$, the only acceptable methods of leak detection are achieved with radiation monitors. Further, the detector is capable of detecting sodium concentrations of $10^{-15}$ to $10^{-16} \mathrm{gm} / \mathrm{cc}$. The PSAR states that, for sodium at low temperatures $\left(<600^{\circ} \mathrm{F}\right)$, radiation detectors are the principal detection method for monitoring the PHTS. Because the equilibrium $\mathrm{Na}^{24}$ level will not be obtained until approximately 60 hours after plant startup, the sensitivity of the radiation detectors will be undetermined. 
The aerosal detectors will likely be the primary means of detection for small size sodium leaks at temperatures ranging from 400 to $600^{\circ} \mathrm{F}$. Therefore, test data is requested which will show that the aerosal detectors are capable of rapid detection of small sodium leaks at low sodium temperatures (400 to $600^{\circ} \mathrm{F}$ ).

\subsubsection{Aerosol Monitoring}

Based on the test data evaluation of Section 2.0, the sodium ionization, differential pressure, hydrogen, and smoke detectors have all shown the potential for detecting leaks as required under the PSAR detection criterion. Test data on the SIMP detector is limited, such that PNL cannot comment on the aerosol detection capability of this device. Additional discussion concerning the engineering capability, detector location adequacy, zone of leak detectability and sensitivity of the aerosol detection subsystems is presented in Section 4.1.

Aerosol detector test results were confusing and inconclusive. The PSAR states that aerosol monitoring will be a primary and backup detection method at CRBRP. The PSAR does not state which aerosol detector (SID, DP, etc.) will be used, nor does it specifically pinpoint device position in the plant.

The laboratory-scale testing performed at LMEC has shown that the aerosol detectors have the potential for detecting the smallest of sodium leaks. However, PNL evaluators conclude that the test data do not show the reproducibility or predictability required to make a realistic engineering judgment, due to:

1. detection criteria changes,

2. test parameter changes,

3. injection rate malfunctions

4. lack of sniffer tube geometric complexity (simulating CRBR application),

5. lack of thermal gradients along sniffer tube (plate-out uncertainty),

6. lack of simulating actual CRBR recirculation rates,

7. sampling flow rate changes, 
8. forced versus natural convection flow uncertainties,

9. lack of electric heating tape simulation scheduled for use on the inner stainless steel liner,

10. breaks in sampling line,

11. calibration uncertainty, and

12. lack of comparable tests.

The sensitivity and zone of leak detectability cannot be determined because of the stated test uncertainties. Therefore, PNL feels that an adequate, redundant, and reliable sodium-to-gas leak detection system does not presently exist. PNL is aware of further test work planned in the form of Verification Tests at LMEC and Long-Term Environmental Performance Tests at EBR-II.

PNL requests test data that will show that the aerosol detectors can reliably detect small to intermediate size sodium leaks. The data previously furnished by LMEC is not sufficient to conclude that aerosal detectors can reliably detect small to intermediate size sodium leaks. Only a limited number of tests are comparable. Additional tests should be performed, in which the test parameters, the detection criterion for the detector, and the sampling flow rate are held constant. A decision as to the use of natural or forced convective flow at CRBR is needed. Conclusive test results should be provided, illustrating that "aerosol plate-out" does not impede detector sensitivity for 140-ft sampling tubes with geometries and thermal gradients typical of CRBR. Also needed are conclusive test results showing that detectable aerosol concentrations will actually exist in each cell at CRBR under those recirculation and cooling rates scheduled for use at CRBR. Electric heating tape should cover the inner stainless steel liner about the piping. It should be shown that the aerosol detector system can be calibrated in-situ and the calibration technique should be described. This calibrated system should include the aerosol sampling tube. Sampling tubes must route through several cells. It should also be shown that if a break occurs along the sampling line, this break can be determined to insure proper cell leak monitoring. If a manifold sampling system for PHTS or IHTS piping is to be used at CRBR, then test data should be provided that would 
show the detectable range achievable using this configuration for both air and inerted environments over the temperature range of 400 to $1000^{\circ} \mathrm{F}$. Test data is needed to show that, for small-diameter, tightly insulated auxiliary piping, small sodium leaks can be consistently detected via aerosol monitoring over the temperature range of 400 to $1000^{\circ} \mathrm{F}$.

\subsubsection{Cable and Contact Monitoring}

The cable detector test data evaluation in Section 2.0 showed that this detector failed to respond in 12, or 57\%, of the 21 tests performed at LMEC. This considerable failure rate occurred although the detector was positioned directly below the sodium leak. In one test, as much as $4000 \mathrm{~g}$ of sodium had leaked. In general, approximately $200 \mathrm{~g}$ of leaked sodium had not been detected.

The contact detector fajled to respond in $86 \%$, or 18 of the 21 tests performed at LMEC.

Based on the data evaluation of Section 2.0, and the high no-response rate for the cable and contact detectors, PNL considers that the data do not show the reproducibility or predictability required to meet the PSAR leak detection criterion. In the CRBR, the cable detector will monitor small, intermediate, and large size leaks; the contact detector will monitor intermediate and large size leaks. The cable detector has not shown that it can reliably detect small size leaks. Furthermore, the contact detector has not shown that it can reliably detect intermediate size leaks.

PNL requests additional data on the operational performance of the cable and contact detectors with test conditions prototypic of CRBR. Cable detectors are to be used inside guard vessels, below major components and in pipe annuli. LMEC data have shown that the cable detector will respond repeatedly to sodium leaks around reactor piping and major components. When the cable detector is placed at the bottom of the reactor guard vessel annulus, it must then be capable of detecting small sodium leaks from a distance equal to the inlet and outlet pipe weld interface to the bottom of the reactor guard vessel. Simulation tests for other major components (IHX, pumps, steam generators) should also be performed under PHTS and IHTS test conditions. 
The contact detector is scheduled to monitor valves at CRBR. It is necessary to provide test data demonstrating contact detector performance in monitoring this confined valve geometry.

Also requested are data showing that the cable and contact detector will respond to oxidized sodium. Furthermore, because sodium reacts vigorously with many materials, data is requested that will show that the cable and contact detector is capable of repeatedly detecting leaks with sodium of an impure nature. Specifically, if there is a potential for the escaping sodium to react with surrounding materials (e.g., insulation, seals, metal surface coating, wiring insulation, etc.) then develop tests which show that this question of chemical purity is/is not of concern. Some observations have shown that the cable and contact detector were covered with sodium, yet there was no response. In addition, a portion of the sensor may corrode. Provide test data showing the effects of rust buildup (IHTS) on the sensing wires of the contact detector, and the subsequent sensitivity and response capability of this detector as a result of the rust buildup.

\subsection{SODIUM-TO-SODIUM LEAK DETECTION SYSTEMS}

Level sensors, radiation detectors, and pressure sensors were mentioned in the PSAR as the devices likely to be used for detecting sodium to sodium leaks in the CRBR. Available descriptions and test data, discussed in Section 2.2, do not provide a sufficient basis for detector system analysis. Hence, PNL cannot evaluate the level sensors, radiation detectors, or pressure sensors in terms of the four parameters requested. However, information required to make this evaluation is described in the following paragraphs.

A system of each type will have to be selected and described in detail to permit making a judgment on the engineering capability.

The location of each sensor/detector in the PHTS, IHX or the IHTS must be specified. The required response time versus leak size must also be supplied to judge the adequacy of locations. 
With the above information, an experimental program will be required to verify both the zone of detectability and sensitivity. The experimental program shall provide statistically significant results to support any conclusions.

\subsection{STEAM/WATER-TO-SODIUM LEAK DETECTION SYSTEMS}

The three devices proposed for CRBRP use in detecting steam/water leaks to sodium were hydrogen detectors, gas chromatographs, and oxygen meters. PNL's evaluation of each device is presented below, along with recommendations for further testing or necessary information.

\subsubsection{Hydrogen Detectors}

The performance of hydrogen detectors has not been evaluated for the effect on response time and sensitivity when decarbonization of Croloy or other contaminants are present. A testing program must be conducted showing these performance parameters for various contaminants. The program must have an adequate number of tests to demonstrate consistency and repeatability.

A test program for the hydrogen detector performance in the argon cover gas must demonstrate the performance level specified in the PSAR. An appropriate number of tests to evaluate the performance parameters and to demonstrate repeatability and consistency is required.

Because these detectors do not respond within the PSAR requirement of 30 seconds, some improvements in detector design are required. A new testing program to demonstrate this performance is needed.

Furthermore, hydrogen detector performance has not been documented for leak sizes up to $10^{-1} \mathrm{lb} / \mathrm{s}$. In-situ calibration is not possible at this time and is required by the rate-of-rise detection concept now used for leak detection. These two features will require an appropriate testing program to demonstrate performance.

\subsubsection{Gas Chromatographs}

The PSAR calls for a gas chromatograph to monitor the argon cover gas in the IHTS, but does not specify any performance requirements. However, it would be useful to compare argon cover gas monitoring performance data for the gas chromatograph with that of the hydrogen detector. 


\subsubsection{Oxygen Meters}

The data base for oxygen meters is less than that for hydrogen detection. The oxygen meter is like the hydrogen detector in that it does not have a response time of $\leq 30$ seconds. Consequently, some design changes must be made so the device will be able to meet the PSAR stated detection criterion.

In-situ calibration techniques must be developed for oxygen meters. Because the meter works on rate-of-rise detection, this does not obviate the need for calibration. In addition, the fragility of the ceramic electrolyte must be examined to see if a solution can be found to provide better protection.

Specific test programs are required to assess the performance of the oxygen meter for temperature dependence effects, electronic signal noise levels, contaminated sodium, and background oxygen levels. An appropriate testing program is required to show reliability, repeatability and consistency. 


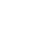




\subsection{SUMMARY}

Sensor subsystems are described in this section in terms of engineering capability, location adequacy, detectability zones, and sensitivity. The summaries herein are based on the information and evaluations presented in Sections 2.0 and 3.0 .

\subsection{SODIUM-TO-ATMOSPHERE LEAK DETECTION SYSTEMS}

PNL's evaluation of the eight sodium-to-atmosphere leak detectors is summarized in the following paragraphs.

\subsubsection{Engineering Capability}

\subsubsection{Sodium Ionization Detector}

Test data evaluations indicate that the sodium ionization detector could be capable of detecting the smallest of sodium leaks $(<2 \mathrm{~g} / \mathrm{h})$. However, as shown in the LMEC Natural Convection Tests 16 and 17 , leaks of $2 \mathrm{~g} / \mathrm{h}$ in tightly insulated 3-in. pipe are not detectable by the SID. It may be necessary to provide venting if cell aerosol monitoring is to be utilized, or provide a sufficient annular space, if annuli monitoring is recommended.

Preliminary SID testing was limited to laboratory evaluations characterized by highly controlled testing conditions and apparent expertise. Further testing will be necessary under conditions more prototypic of CRBR. The SID is a simple device, but it is necessary to get the leaked sodium to the detector. It is possible that gas leaks could occur (and have at LPIEC) in the sampling system, resulting in cell sampling uncertainty and, perhaps no leak detection, or, detection beyond the $250-\mathrm{h}(<100 \mathrm{~g} / \mathrm{h})$ PSAR criterion. This gas leak malfunction could occur following a seismic event (Operating Basis Earthquate, $O B E)$. Regulatory Guide 1.45 states that the leakage detection systems shall be capable of performing their function following seismic events (OBE) that do not require plant shutdown. 
To date, the total SID system (SID and sampling line) cannot be completely calibrated. Therefore, the actual flow of aerosol up to the detector will be uncertain. Reference 5, page 203 states,

Westinghouse is planning to put a small filament next to the heated filament in the sodium ionization detector. This filament will release a sodium aerosol from time to time which will settle on the main sensing filament and be ionized. This will calibrate the sensor. It is not the same as flowing an aerosol into the sensor. It is the next best thing.

\subsubsection{Differential Pressure Detector}

The test data evaluated in this report have shown that the DP could be capable of detecting small sodium leaks under both PHTS and IHTS environments. Unlike the SID, the DP detector has the added capability of accumulating (filter) microgram quantities of sodium aerosol which can be chemically analyzed; this constitutes leak detection. This chemical analysis of filter technique has been shown to be the most reliable and consistent method for low-temperature, low-leak rate $(2 \mathrm{~g} / \mathrm{h})$ sodium leak detection. The DP should respond tc sodium of a non-pure state (sodium oxide and poliutants) at CRBR temperatures and environmental operating conditions.

\subsubsection{Smoke Detector}

The test data analysis indicated that the smoke detector response was at times very rapid, but as pointed out in the PHTS and IHTS analysis, the rapid response is puzzling when compared to those similar tests where the smoke detector failed to respond at a17. For example, in Test 9 (natural convection) the smoke detector responded five times faster than the SID, with the SID detection most sensitive at three times the initial background current. However, the smoke detector failed to respond in all of Tests 11 through 17 (natural convection). Only limited data were available to permit comparison of matched test parameters and conditions (i.e., PHTS versus IHTS environment, forced versus natural convection flow).

A detailed study by HEDL ${ }^{(9)}$ examined the ionization and photo-electric detector response to the combustion products of insulation, Mobiltherm, hydraulic fluid and cables to be used at FFTF. Under laboratory conditions, 
the detectors responded to all but one of the tests within minutes. This report recommended the use of the ionization detector because of its lower current requirements, insensitivity to long-term smoke contamination, and ease of sensitivity adjustment. The pertinent conclusions from this study are:

1. The ionization detector, as the primary candidate for use in the FFTF plant, was responsive to the products of combustion from all of the FFTF combustibles used in the tests.

2. The ionization detector sensitivity may be easily adjusted in place. Should false alarms present a problem in some areas of the plant, the sensitivity may be reduced. The detector was shown to be responsive to the combustion products from all materials tested with somewhat more smoke required to produce an alarm at the lower sensitivity.

3. The photoelectric detector, the backup candidate, was responsive to the smoke from all of the materials tested. However, this detector type is susceptible to loss of sensitivity when exposed to some smokes. One would expect that exposure to some atmospheres containing contaminant material may have the same effect over long periods of exposure.

4. The ionization detector did not show a trend toward long-term changes in sensitivity. However, for a short time after exposure to combustion products, the sensitivity is changed.

The HEDL results are promising; however, sma11-cell 1aboratory conditions were in effect. LMEC test data show that a number of test parameters affect the smoke detector performance. Additional tests would be necessary to determine if the smoke detector can reliably detect small sodium leaks $(100 \mathrm{~g} / \mathrm{h})$ under forced and natural convection aerosol flow and CRBR environmental conditions.

\subsubsection{Hydrogen Detector}

The hydrogen detector (gas chromatograph) demonstrated the potential to detect the smallest of sodium leaks (Tests 4 and 14) under PHTS and IHTS environmental conditions. The detection range of this detector is 20 to $1500 \mathrm{ppm}$. The hydrogen detector has shown that it is capable of detecting 
sodium leakage at temperatures ranging from $271^{\circ} \mathrm{F}$ to $980^{\circ} \mathrm{F}$. The hydrogen detector has responded with as little as $19.48 \mathrm{~g}$ of sodium spilled.

However, the test data analysis has pointed out a number of puzzling results for both natural and forced convection, PHTS versus IHTS, test data. The data have shown that it is not correct to infer that, under IHTS environmental conditions where larger quantities of moisture are available to react with sodium, the capability to respond to sodium leakage is greater than that of a PHTS environment (i.e., Test 16 versus Test 17 , Tests 11 and 12 versus Test 8 ).

\subsubsection{Surface Ionization Monitor for Particulates}

The engineering capability of the SIMP detector cannot be determined at this time due to lack of test data.

\subsubsection{Radiation Detector}

The engineering capability of the radiation detector cannot be determined at this time due to the absence of test data.

\subsubsection{Cable Detector}

The forced convection test data have shown that the cable detector responded to $980^{\circ} \mathrm{F}$ sodium at $100 \mathrm{~g} / \mathrm{h}$ leak rate in $1.66 \mathrm{~h}$ (Test 1). However, at the much lower leak rate of $0.4 \mathrm{~g} / \mathrm{h}$, with $980^{\circ} \mathrm{F}$ sodium (Test 4 ), the detector failed to respond. For lower sodium temperatures $\left(400^{\circ} \mathrm{F}\right)$ the detector failed to respond to significant quantities (2000 to $4000 \mathrm{~g}$ ) of sodium injected at $100 \mathrm{~g} / \mathrm{h}$ (Tests $7,7 Y$ and $7 X$ ). The detector failed to respond in Test 8 to a $2 \mathrm{~g} / \mathrm{h}$ leak at $500^{\circ} \mathrm{F}$.

Detector location is an obvious key parameter in trying to determine detector response criteria. However, the cable detector was placed directly under the injection nozzle during LMEC testing; this is considered optimum positioning to enhance leak detector capability. At CRBR, cable detectors are utilized inside guard vessels (bottom) and below major components. When considering the response in the PHTS environment (sodium temperatures 980 to $730^{\circ} \mathrm{F}$ ), one must determine whether it is possible that leaked sodium may 
cool down before reaching the cable detector. If this cooling were to occur during smal1 leak events $(<100 \mathrm{~g} / \mathrm{h})$, one could conservatively estimate from the data that at minimum, $5000 \mathrm{~g}$ of sodium could be released before the cable detector responded.

Under the IHTS environment at CRBR, sodium temperatures will range between $650^{\circ} \mathrm{F}$ and $940^{\circ} \mathrm{F}$. However, the IHTS environ has a high oxygen (ambient) content that tends to oxidize leaking sodium. The test data have indicated that the cable detector response under ambient conditions is erratic. The detector failed to respond in Test $5 \mathrm{x}$. However, in Test $5,104.2 \mathrm{~h}$ were required for the cable to respond. Tests $5 X$ and 6 were plagued with operational difficulties. In Tests $13,13 x, 14$ and 15, the detector did not respond in three of the four tests, at a leak rate of $2 \mathrm{~g} / \mathrm{h}$.

The conductivity of sodium oxide has not been determined. Depending on the leak size and actual sodium temperature upon contact with the cable detector, it may not respond at all to sodium oxide. Again, depending upon the location, temperature and size of the leak, a conservative estimate of $5000 \mathrm{~g}$ of sodium may be required to indicate a response from this detector.

\subsubsection{Contact Detector}

Test data generated in the PHTS environment showed that the contact detector has not responded to as much as $1000 \mathrm{~g}$ of $980^{\circ} \mathrm{F}$ sodium leaked at $100 \mathrm{~g} / \mathrm{h}$. There are limited data for tests of 100 hours or greater, with leak rates of $100 \mathrm{~g} / \mathrm{h}$. A number of the $\mathrm{LMEC}$ mockup tests were plagued with operational difficulties, adding a degree of uncertainty to the results. The data for the LMEC natural convection tests showed that the contact detector did not respond to very small leaks ( $200 \mathrm{~g}$ leaked) over a 100-hour period. In 8 of 10 mockup tests in which the contact detector failed to respond, 5 tests had sodium spilis of $400 \mathrm{~g}$ or more. The data show that it may take quantities in excess of $100 \mathrm{~g}$ of sodium in order to indicate a leak response by the contact detector. 
There is considerable uncertainty as to whether the contact detector will respond in the IHTS environment. In the IHTS, the oxygen level is 21 percent. This ambient oxygen tends to react chemically with pure liquid sodium to form sodium oxide. Limited data, the high percentage of no response indications, false response indications, and the uncertainty of the detector response when sodium oxide is present, must be considered when trying to evaluate contact detector performance in the IHTS environment. This uncertainty in response for the IHTS environment to the presence of sodium oxide could conceivably mitigate detector response.

\subsubsection{Location Adequacy}

\subsubsection{Sodium Ionization Detector}

The PSAR (Table 7.5-3, Section 2.3.3) shows that the SID will be used to monitor major piping, guard vessels, and individual PHTS and IHTS cells. Designated as an aerosol detector, the SID maintains a distinct detection threshold and relies on vapor/aerosol formation and transport for detection. The forced convection test data shows that the DP may be more suitable for monitoring iow-temperature sodium leaks in the IHTS than the SID (Tests 7 through 8). However, Tests 13,14 and 15 (natural convection) show that the SID can detect small sodium leaks with sodium temperatures of 640 to $900^{\circ} \mathrm{F}$.

To date, the decision to use natural convection or forced convective flow at CRBR has not been made. If natural convection is selected, the possibility of stagnant regions and roll cell formation could significantly affect the sampling location of the aerosol detector. Convection currents along a horizontal length of hot leg piping differ from those along a vertical length.

The information available at this time is not sufficient to determine the adequacy of the proposed locations stated in the PSAR (Table 7.5-3).

\subsubsection{Differential Pressure Detector}

Comments regarding the sodium ionization detector (Section 4.1.2.1) apply to the differential pressure detector as well. The adequacy of DP locations proposed for CRBR cannot be fully determined from the limited data available. 


\subsubsection{Smoke Detector}

Smoke detectors are currently scheduled for use in air-filled IHTS cells at CRBR to monitor the cell atmosphere for sodium aerosol/vapor leakage. Cell sampling by the smoke detector in the IHTS is adequate. However, this detector responded very rapidly in the PHTS environment in Tests 8 and 9, and should be considered for PHTS monitoring pending further tests.

\subsubsection{Hydrogen Detector}

The PSAR does not specify the location of the hydrogen detectors in CRBR. The PSAR states:

Other Backup Detection Methods

Exposure of sodium in an inerted cell will affect the quantities of hydrogen, oxygen, and water vapor in the atmosphere by depleting oxygen and water and releasing hydrogen. Monitoring (Inert Gas Receiving and Processing I\&C System) of the atmosphere oxygen and water vapor serves as a leak detection method.

The PSAR does not state whether the hydrogen detector will be used in the PHTS or IHTS, or where the detectors will be sampling.

\subsubsection{Surface Ionization Monitor for Particulates}

The location adequacy of the SIMP cannot be determined at this time due to the lack of test data.

\subsubsection{Radiation Detector}

Because of the absence of test data, the location adequacy of the radiation detectors cannot be determined at this time.

\subsubsection{Cable Detector}

The preliminary locations of the cable detector (as specified in the PSAR) were judged to be acceptable. However, if there is a possibility of an installation error via guide tube insertion, means should be provided for visual inspection after installation in both PHTS and IHTS environments. 


\subsubsection{Contact Detector}

The contact detector is small and readily adaptable to valve applications. The PSAR notes that it has been selected to monitor valve leakage in the PHTS and IHTS bellows seal valves. Due to the unreliability, and inconclusive test results of the contact detector at LMEC, the use of this instrument for monitoring valve leakage is of concern. This is particularly of note because this device has been selected to monitor the component (bellows valves) that has shown itself to be highly prone to failure (see Appendix $\mathrm{C}$ ).

\subsubsection{Detectability Zones}

\subsubsection{Sodium Ionization Detector}

The zone of leak detectability for the SID cannot be determined at this time due to uncertainties in:

- aerosol formation and transport phenomena (7)

- lack of test data using long sampling line lengths with geometric complexities and thermal gradients typical of $\operatorname{CRBR}^{(8)}$

- aerosol concentration versus time and vault size

- sampling line gas leakage potential

- non-pure sodium aerosol response data

- forced versus natural convection current flow

- filament life and ionization effects due to non-pure sodium aerosol sampling

- limited test data for a specified SID detection criterion

- lack of response to smal1, tightly insulated auxiliary piping (Tests 16 and 17)

- the lack of a total system calibration capability.

Additional information will be required to make a realistic engineering determination of the leak detection zone for the SID. 


\subsubsection{Differential Pressure Detector}

The zone of leak detectability for the DP cannot be determined at this time due to uncertainties in:

- aerosol formation and transport phenomena $(7)$

- lack of test data using long sampling line lengths with geometric complexities and thermal gradients typical of $\mathrm{CRBR}^{(8)}$

- aerosol concentration versus time and vault size

- sampling line gas leakage potential

- forced versus natural convection current flow.

The DP detector has shown that it can respond to, and detect, very small sodium leaks (i.e., chemical analysis technique) under both PHTS and IHTS environments. The DP was shown capable of detecting leaks in Tests 16 and 17 where $3-i n$. tightly insulated pipe was used. These results are promising; however, the available test data to date are limited.

\subsubsection{Smoke Detector}

A number of parameters can affect smoke detector performance. LMEC and HEDL laboratory tests indicate that the smoke detector has the potential for detecting small sodium leaks via cell monitoring $\left(1500 \mathrm{ft}^{3}\right)$. For cells of $150,000 \mathrm{ft}^{3}$ and larger (CRBR), cell cooling and recirculation become significant areas of concern that could alter the smoke detector performance. These large cells may require the use of a number of smoke detectors, with specific sampling points chosen to enhance leak detection.

\subsubsection{Hydrogen Detector}

The hydrogen detector has responded favorably in small cell $\left(1500 \mathrm{ft}^{3}\right)$ laboratory tests when used to monitor cell gas buildup. However, the results in some tests were puzzling (see Section 2.1.4).

The response of this detector to large cell monitoring is not clear at this time. Mitigating effects such as cell cooling and recirculation, plateout, and $\mathrm{H}_{2}$ gas accumulation in stagnant regions could hinder or preclude detection. 


\subsubsection{Surface Ionization Monitor for Particulates}

The zone of leak detectability for the SIMP cannot be determined at this time due to lack of test data.

\subsubsection{Radiation Detector}

The zone of leak detectability for the radiation detector cannot be determined at this time due to lack of test data.

\subsubsection{Cable Detector}

The zone of leak detectability for the cable detector depends upon the following:

- leak location relative to the detector

- sodium temperature

- sodium chemical purity (sodium oxide effects)

- quantity leaked

- path complexity versus aerosol/vapor or 1iquid sodium flow

- natural convection versus forced convection effects

- the degree of uncertainty in installation if visual inspection of the sensor is not achievable.

The parameters listed above must be considered when trying to determine the detectability zone of the cable detector. The laboratory testing and results achieved at LMEC have not provided sufficient data for PNL to determine a detection zone for the cable detector at this time. The information requested in Section 3.1.3 must be reviewed before the zone of leak detectability for the cable detector is determined.

\subsubsection{Contact Detector}

The monitoring boundary of the contact detector will vary with valve size $(0.5$ to $4 \mathrm{in.}$ ) This relatively confined detection zone may enhance leak detectability by restricting liquid sodium dispersal and aerosol migration . 
Contact detectors have previously been tested in the annular pipe region, and, to our knowledge, no test has been performed where the contact detector was tested under those geometric conditions that would simulate placement in a valve. Tests of this nature, where sodium is confined to the inner valve volume, may prove that the contact detector will be adequate for valve leak monitoring. However, this detector is currently considered a very erratic and unreliable device, preventing determination of a specific zone of leak detectability.

\subsubsection{Sensitivity}

\subsubsection{Sodium Ionization Detector}

LMEC natural convection test data ${ }^{(2)}$ showed that the SID did respond to small cell, small leak rate spills which created aerosol concentrations between $10^{-10}$ and $10^{-11} \mathrm{~g} / \mathrm{cc}$. Furthermore, in an actual CRBR environment, additional mitigating effects can preclude or retard detection sensitivity. Ten areas of data deficiency listed in Section 4.1.3.1 apply when trying to make an engineering determination of the SID sensitivity. Specific information concerning these questionable areas will have to be reviewed in order to determine the SID sensitivity.

\subsubsection{Differential Pressure Detector}

As noted in Section 2.0 the quantities of sodium accumulated during natural convection Tests 11 through 17 depended on the temperature of the injected sodium and the environmental conditions. Under PHTS conditions, major quantities of sodium had accumulated via floor sampling; under IHTS conditions, the majority of sodium accumulated via ceiling sampling.

The response in Tests 11 and $11 \mathrm{R}\left(980^{\circ} \mathrm{F}\right.$, PHTS environment) was quite rapid compared to the response of Tests 13 and $13 \times\left(900^{\circ} \mathrm{F}\right.$, IHTS environment). Test 12 (PHTS) and Test 14 (IHTS) were similar, with detection times being within 3 to 4 hours. Of note is the $8-h$ (floor) response of Test 14 . One would infer from the sodium accumulated on the filter that the detector response at the ceiling $(12 \mathrm{~h} 19 \mathrm{~min})$ would be quicker than that at the floor due to larger quantities of accumulated sodium at the ceiling. This result was also noted in Tests $11 R$ (ceiling) and 13 (floor). 
When trying to determine the sensitivity of the DP, one must determine how low a differential change in pressure is possible and what minimum quantity of sodium is detectable by the chemical analysis of filter technique. It may be possible to lower the detection criterion of the DP to a pressure less than 1 in. of $\mathrm{H}_{2} \mathrm{O}$. Albeit, there is a point at which the detector could become too sensitive, such that false alarms would be a problem.

No information specifies a minimum quartity of sodium detectable by chemical analysis techniques, which would indicate leak detection. Does $10 \mu \mathrm{g}$ or $50 \mu \mathrm{g}$ constitute leak detection via the chemical analys is of filter technique? If 10-ug quantities are sufficient for leak detection, then the sensitivity of the detector is determined by the quantity of aerosol that reaches the filter versus the time chosen for chemical analysis of the filter.

\subsubsection{Smoke Detector}

In Tests 3, 5X, and 9, the smoke detector monitoring the cell atmosphere responded better than, or as well as, the SID that was sampling the 1-in. pipe. Note that during Test 9 (natural convection) the SID detection criterion was three times that of the initial background current, which was the most sensitive SID detection criterion used at LMEC. In Test 8 , the smoke detector responded very rapidiy, whereas the SID (annulus and cell) failed to respond.

In Tests 11 through 17 , the smoke detector failed to respond in every test. This result is puzzling when one compares the data from previous LMEC Tests 1 through 10. Specific test data have shown that the smoke detector can respond to smail sodium leaks more rapidly than the SID, DP, and hydrogen detectors. However, the smoke detector is scheduled to be used only as a backup leak detector in the IHTS. Further testing could prove that the smoke detector is the most sensitive aerosol detector.

\subsubsection{Hydrogen Detector}

Hydrogen detector sensitivity in the sampling areas cannot be determined because of the uncertainty of specific test results, indicating that a number of parameters can affect the detector sensitivity. Some of the parameters are: 
- leak rate

- quantity of sodium leaked

- sodium temperature

- environmental variables for the PHTS and IHTS

- gas migration and transport

- gas reaction potential

- the plateout potential under cell cooling and recirculation.

\subsubsection{Surface Ionization Monitor for Particulates}

The sensitivity of the SIMP in the sampling areas cannot be determined at this time due to lack of test data.

\subsubsection{Radiation Detector}

The absence of available test data for the radiation detector precludes a determination of detector sensitivity.

\subsubsection{Cable Detector}

Cable detector sensitivity is a complex parameter to determine. The test data have shown that the cable detector has not reliably detected leaks at or below $100 \mathrm{~g} / \mathrm{h}$. Further, it may not have adequate sensitivity to detect leaks in excess of $100 \mathrm{~g} / \mathrm{h}$ if sodium oxide at low temperature is present.

\subsubsection{Contact Detector}

The contact detector will be utilized to monitor valve leaks in the PHTS and IHTS boundaries at the CRBRP. LMEC test data indicate that the contact detector sensitivity in responding to small size leaks (i.e., leaks at or below $100 \mathrm{~g} / \mathrm{h}$ ) is very poor. The contact detector did not respond in $80 \%$ of the LMEC Mockup Tests 1 through 10. In addition, the detector failed to respond in $66 \%$ of the tests at $100 \mathrm{~g} / \mathrm{h}$. The contact detector did not respond in Tests 11 through 17 . This detector may display adequate sensitivity in monitoring valve leaks of the intermediate size, but no data are available as yet for sodium leaks of this size.

The sensitivity of this detector could very well be dependent upon the degree of purity of the sodium leaked. The sensitivity of the contact detector in the PHTS environment may be greater than that experienced in the IHTS environment due to the oxidation of the sodium in the IHTS environment. 


\subsection{SODIUM-TO-SODIUM LEAK DETECTION SYSTEMS}

The engineering capability, location adequacy, zone of detectability, and sensitivity, cannot be determined for sodium-to-sodium leak detection systems for the reasons given in Section 3.2. PNL will be able to address these questions when the information requested in Section 3.2 is made available.

\subsection{STEAM/WATER-TO-SODIUM LEAK DETECTION SYSTEMS}

PNL's evaluation of the hydrogen detectors, gas chromatographs, and oxygen meters proposed for CRBRP use is summarized in the following sections.

\subsubsection{Engineering Capability}

The chemical reaction between water and sodium produces both hydrogen and oxygen. Detection of hydrogen forms a sound bas is for detecting this chemical reaction and, ultimately, leaks.

\subsubsection{Hydrogen Detector}

The riydrogen detector samples the hydrogen dissolved in the sodium. Any conditions decreasing the solubility of hydrogen in sodium will adversely impact the detector response time. Only one condition--temperature--has been shown to influence the solubility; at low temperatures, hydrogen has low solubility in sodium.

Hydrogen detector test data presented earlier in Table 3-1 clearly demonstrate that the device does detect hydrogen. However, detector performance has not been documented for effects resulting from decarbonization of croloy or other sodium contaminants. Use of the detector in the argon cover gas for the IHTS pump has not been documented by either analytical or experimental work. Available data do not verify that the detector reliably meets the response time requirements of $\leqslant 30$ seconds. The performance has not been demonstrated for large leaks $\left(10^{-1} \mathrm{lb} / \mathrm{s}\right)$ and in-situ calibration methodology has not been developed. The detector location is being used to provide leak location information. However, this information will be suspect unless there is verification that the detector nearest the leak responds first. A proven 
in-situ periodic calibration scheme would provide a good loss for this type of verification. In short, the hydrogen detector does perform adequately, yet several important questions remain to be answered.

\subsubsection{Gas Chromatograph}

The limiting factor in the gas chromatograph is the escape probability of hydrogen from the sodium to the argon cover gas. The test data in Table 3-1 illustrate this fact because in 1ess than $50 \%$ of the tests the GC did not respond. PNL believes that this is the result of hydrogen escape probabilities rather than GC performance. The GC does provide excellent performance at low sodium temperatures when hydrogen is the least soluble.

\subsubsection{Oxygen Meters}

The data base for oxygen meters is smaller than for hydrogen detectors because many tests have been conducted using hydrogen gas injection. However, oxygen meters tend to respond more slowly than hydrogen detectors but with the same consistency and frequency. The problem areas that need to be investigated are: means for in-situ calibration, fragility of the ceramic electrolyte, electronic signal noise levels and temperature dependence. Furthermore, the data do not support the PSAR requirement for a response time of $\leq 30$ seconds. In summary, the oxygen meter does work and will detect water leaks, but there are areas requiring further development and validation.

\subsubsection{Location Adequacy}

\subsubsection{Hydrogen Detectors}

Hydrogen detectors are currently used to monitor all outputs from the superheater and two evaporators. Because these are the only components in which the $\mathrm{H}_{2} \mathrm{O}+\mathrm{Na}$ reaction can occur, they should, and are, being monitored. Furthermore, backup is supplied by the oxygen meter and gas chromatograph systems. 
The PSAR (Table 7.5-1) requires a inydrogen detector for the argon cover gas in the IHTS pump. No tests have been conducted, or reported, in the reviewed literature, on the performance of this detector in the argon cover gas environment. Because this area is not located near any major component, no leak location information is provided. However, a hydrogen detector placed here would serve as a backup system to the gas chromatograph.

\subsubsection{Gas Chromatograph}

There are two components per secondary loop where there is argon cover gas: the IHTS pump and the iHTS expansion tank. Location of these two components, parallel or series, may dictate a preference for which to monitor. Presently, the PSAR calis for the pump to be monitored and the components in paraliel. At LMEC most data have been taken from the expansion tank with a series configuration, while at Ail the cover gas over the steel vessel was monitored. These locations do not correspond with that specified in the PSAR. However, the FSAR specified location is preferred.

\subsubsection{Oxygen Meters}

According to the PSAR, the oxygen meters are to be located only in the sodium in the IHTS cold leg. For redundancy, two oxygen meters will be emplaced at this location. However, if located where specified, these meters will not provide any significant information about which component has developed a leak.

PNL believes that the oxygen meters could be located at other positions in the IHTS to provide more precise leak site information. But, other monitoring devices may be more suitable for filling this need. These devices should be compared to oxygen meters to determine which best fill the needs.

\subsubsection{Detectability Zone}

\subsubsection{Hydrogen Detector}

Hydrogen detectors are locatea to monitor a single component. However, because the sodium loop is common to all the components, every hydrogen detector should respond to a leak. An exception would be if the operating 
conditions are such that the hydrogen would not reach the detector; for example, at low temperatures hydrogen is not very soluble in sodium. Therefore, each detector monitors a single component (first to respond) and the total system. The only exception is the detector located in the argon cover gas in the IHTS pump, which monitors the special conditions and total system.

\subsubsection{Gas Chromatograph}

The gas chromatograph will detect leaks that occur throughout the IHTS and for which hydrogen escape to the argon cover gas is highly favored.

\subsubsection{Oxygen Meter}

The present location dictates that there will be a response from any water/steam to sodium leak within a loop of the IHTS. The response of an oxygen meter in conjunction with the hydrogen detector and the GC tells an operator whether a leak is from a hydrogen source, an oxygen source, or a water/steam leak. However, very little information is provided about leak location. PNL believes that the oxygen meter is one device that could provide more information about leak location by being a backup system to the hydrogen detectors on the vent 1 ines and outlet 1 ines.

\subsubsection{Sensitivity}

\subsubsection{Hydrogen Detector}

The hydrogen detector has been extensively tested with test data available as low as $0.45 \mathrm{mg} \mathrm{H} 2 \mathrm{O} / \mathrm{s}\left(9.9 \times 10^{-7} 1 \mathrm{~b} \mathrm{H} \mathrm{H}_{2} \mathrm{O} / \mathrm{s}\right)$. The sensitivity parameter is very important because of the nonlinear growth rate phenomena associated with wastage. Therefore, it is imperative that very small leaks be detected. Table 3-1 shows that the detector does respond consistently to leaks of $4.54 \mathrm{mg} \mathrm{H} \mathrm{H} \mathrm{O} / \mathrm{s}\left(10^{-5} \mathrm{lb} / \mathrm{H}_{2} \mathrm{O} / \mathrm{s}\right)$. Other data for leak sizes of $0.45 \mathrm{mg} \mathrm{H} 2 \mathrm{O} / \mathrm{s}$ reveal a marginal response that would be insufficient for indicating a leak. The PSAR sensitivity requirement of $3 \mathrm{ppb}$ change in hydrogen is within the range of reported, repeated and consistent performance. However, there are conditions that have not been studied which could affect the sensitivity that could be encountered in operation at CRBR. These conditions were spelled out in Section 4.3.1.1, under hydrogen detector engineering capability. 


\subsubsection{Gas Chromatograph}

The gas chromatograph is a highly sensitive instrument whose sensitivity can be obtained from the manufacturer since it is an off-the-shelf instrument. However, the system sensitivity is determined by the escape probability of hydrogen from sodium. This probability function has been defined only to the extent that it is higher at low $\left(200^{\circ} \mathrm{C}\right)$ temperatures than at high $\left(>500^{\circ} \mathrm{C}\right)$ temperatures. The data in Table 3-i show an excellent performance at low temperature, with performance worsening as the temperatures increased. The literature shows that, at low temperature, the smallest leak detected is $4.54 \mathrm{mg}$ $\mathrm{H}_{2} \mathrm{O} / \mathrm{s}$. However, there is no sensitivity requirement specified in the PSAR for the gas chromatograph.

\subsubsection{Oxygen Meter}

The PSAR states that the oxygen detector will have a sensitivity of $24 \mathrm{ppb}$, a range of 0.1 to $10 \mathrm{ppm}$ and a response time $\leq 30$ seconds. None of the data have supported a response time as low as 30 seconds. Experimental response times are in the vicinity of 4 minutes for large injections and longer for smaller injections. (20) The data reported by McKee and Skladzien (20) do indicate an adequate response for instrument diagnostics for the leak sizes specified in the PSAR. At this time the data indicates that the oxygen sensitivity does meet the PSAR requirements. However, the effects of contaminated sodium, temperature, electronic noise, and background oxygen levels on the sensitivity, will require better documentation before a sensitivity assessment can be completed. 


\section{REFERENCES}

1. J. A. Morejon, Summary of Design and Development Status of the Liquid Metal to Gas Leak Detection System for the CRBRP. N099 TI 661007, Atomics Internationa 1, Division of Rockwell Internationa 7, August 1976.

2. G. Amaro and J. Morejon, Natural Convection - Sodium Leak Detection Tests. N707-TR-520-005, Atomics Internationa], Division of Rockwel1 International.

3. J. A. Morejon, Sodium-to-Gas Leak Detection Mockup Tests. N707-TR520-004, Atomics Internationa], Division of Rockwel] International, October 1975.

4. CRBRP Nuclear Island, Primary Pipe Integrity Status Report. WARD-D-0127, Westinghouse Electric Corporation, Advanced Reactors Division, Madison, PA 15663, December 1975.

5. LMFBR Instrumentation and Control Program Planning Meeting. ERDA-74158, NTIS, Springfield, VA 22151, 1976.

6. Liquid Metal Fast Breeder Reactor Program Plan - Element 5 - Sodium Technology. WASH-1705, Second Edition, NTIS, Springfield, VA 22157 , 1972 .

7. A. K. Postma and P. S. Trent, An Analys is of Aerosol Transport in the FFTF Reactor Guard Vessel AnnuTus Related to Detection by Means of a Sodium Ionization Detector. HEDL-TC-669, Hanford Engineering Development Laboratory, Richland, WA 99352, September 1976.

8. J. A. Morejon, Leak Detection Response Time Characterization and Optimization Tests. TP-707-520-004, Atomics Internationa7, Division of Rockwel1 Internationa 1, February 1975.

9. J. B. Hersha11, Response of Commercial Smoke Detectors to Combustion Products from FFTF Combustibles. HEDL-TIME 76-76, Hanford Engineering Development Laboratory, Richland, WA 99352, September 7, 1976.

10. J. Kremser and A. Lacroix, Some Aspects of Sodium Technology Issued from the Operating Experience of Rapsodie and Phenix. International Conference on Liquid Metal Technology in Energy Production, 1976.

11. P. H. Lustig, Feasibility of an On-Line Fission-Gas-Leak Detection System. NASA-TM-X--2870/E--7007, Nationa7 Aeronautics and Space Adminsitration, Lewis Research Center, Cleveland, OH, August 1973. 
12. J. M. McKee, Water-to-Sodium Leak Detectors: Development and Testing. International Conference on Liquid Metal Technology in Energy Production, CONF-760503-PROC, 1977.

13. R. Hans and H. J. Weiss, "Sodium Contamination Measurement with Plugging Meter and Hydrogen Leak Detection System." Siemes Rev, XLII, No. 5, p. 225-228, 1975 .

14. M. W. Wrightson, K. Mckinley, W. E. Ruther, and J. T. Holmes, EBRI-II Water-to-Sodium Leak Detection System. International Conference on Liquid Metal Technology in Energy Producticn, 1976.

15. D. R. Vissers, J. R. Holmes, C. C. McPheeters, V. M. Kolbs, L. G. Berthome, P. A. Nelson, and L. Burris, Hydrogen-Meter Leak Detector for LMFBR Steam Generators. ANL-8047, October 1973.

16. E. Cambillaro, Tube Tightness Survey During Phenix Steam Generator Operation. International Conference on Liquid Metal Technology in Energy Production, CONF-760503-PROC, 1977.

17. C. C. McPheeters, D. R. Vissers, M. A. Slawecki, and P. A. Nelson, "Design and Performance of Hydrogen Meter for Detecting Water-to-Sodium Leaks in LMFBR Steam Generators." ANS-Trans, 14:614, 1971.

13. M. M. Wrightson and J. T. Holmes, "Test Phase of the Water-to-Sodium Leak Detection System at EBR-II." ANS-Trans, 22:603, 1975.

19. I. Ikemoto and M. Hori, Detection of Sma11-Leak Sodium-Water Reaction in the Prototype LMFBR Steam Generator by In-Sodium Type Hydrogen Detector. CONF 71054B, pp. 155-170, Ju7y 1972 .

20. J. M. Mckee and S. B. Skladzien, Evaluation of Steam-to-Sodium Leak Detectors on the SCII, Phase II. ANL-CT-73-27, Argonne National Laboratory, IL., December 1973.

21. H. Nei, I. Ohshima, K. Ujihara, and H. Hori, Acoustic Detection for Sma11-Leak Sodium-Water Reaction. Power Reactor and Nuclear Fuel Development Corporation.

22. J. A. Ford, A Recent Evaluation of Foreign and Domestic Wastage Data from Sodium-Water Reaction Investigation. APDA-CTS-73-05, January 1973.

23. W. E. Ruther and S. B. Skladzien, Investigation of Possible Line-Length Effects in the Measurement of Oxygen and Hydrogen Impurities in Sodium. ANL-7893, Argonne National Laboratory, Argonne, IL, March 1972.

24. Proposed Reference Design for the Clinch River Breeder Reactor Plant. Proceedings of the Breeder Reactor Corporation October 1974 Information Session, PMC-74-02, October 1974. 
APPENDIX A

PRIMARY AND INTERMEDIATE COOLANT

SYSTEM BOUNDARIES 
TABLE 3.1-1 (PSAR)

COMPONENTS WHICH COMPRISÉ

THE REACTOR COOLANT BOUNDARY

The list of Components or Parts of Components which comprise the Reactor Coolant Boundary per the definitions of PSAR Section 3.1.2 is as follows:

Primary Heat Transport System (PHTS) Piping and Appurtenances

PHTS Pump Tank

PHTS Pump Tank Drain Line Up To and Including the Second Isolation Valve

PHTS Pump Shaft Seal

PHTS Pump Instrument Penetrations

PHTS Check Valve Body

PHTS Check Valve Freeze Vent

PHTS Hot Leg Freeze Vent

Intermediate Heat Exchanger (IHX) Shel1

IHX. Shell Freeze Vent

IHX Tube Bundle (including Tube Sheets)

IHX Bellows Seal

IHX Downcomer

IHX Vent Line

IHX Vent Line Freeze Vent

IHX Cold Leg Pipe Drain Up To and Including the Second Isolation Valve Reactor Vessel

Closure Head

Stationary Outer Ring

Large Rotating Plug (LRP)

Intermediate Rotating Plug (IRP)

Small Rotating Plug (SRP)

LRP Riser Assembly

IRP Riser Assembly

SRP Riser Assembly

In-Vessel Transfer Machine Port Plug

Ex-Vessel Transfer Machine Port Plug

Control Rod Drive Mechanism Nozzle Extensions

Control Rod Drive Mechanism Motortubes.

Upper Internals Structure Jacking Mechanism Column Supports

Upper Internals Structure Jacking Mechanism Seals

Liquid Level Monitor Port Plugs

Surveillance Specimen Grapple Port Plug

Maintenance Port Plugs 
Table 3.1-2 (PSAR)

Components Which Conprise

The Intermediate Coolant Boundary

- Intermediate Heat Exchanger

- Inlet nozzle

- Downcomer and bellows

- Lower tubesheet

- Hemispherical head

- Tubes (intermiediate system is inside tubes)

- Upper tubesheet

- Interrediate channel

- Outlet nozzle

- Startud vent nozzles

- Superheater (1)

- Sodium inlet nozzle

- Vesser shell

- Tubes (Intermediate system is outside tubes)

- Sodium bleed vent

- Sodium outlet nozzles (2)

- Evaporators (2)

- Sodium inlet nozzle

- Vessel shell

- Tutes (Intermediate system is outside tubes) Sodium bleed vent

- Sodium outlet nozzle

- Intermediate Sodium Pump

- Inlet nozzle

- Discharge nozzle

- Fump tank

- Gas Equalization line

- Instrument penetrations

- Shaft Seal

- Intermediate Expansion Tank

- Expansion Tank Shelt

- Nozzles (10) 
- Sodium Venturies (Loop 2 onty)

- Instrumentation Bosses

- Intermediate Sodium Dump Valves

- Pump outlet

- Evaporators

- Superheater

- Expansion tank vent

- Piping

- 24" Hot leg

- 18" between steam generator to mixing tee

- 18" $\times 36^{\prime \prime}$ pump inlet mixing tee

- 24" cold leg

- Reducers

- Elbows

- Tees

- 4 " drain lines

. $36^{\prime \prime}$ pump suction piping

- 8" expansion tank return line

- 2" IHX vent line

- 2" Expansion tank, pump tank equalization line

- 5" Expansion tank vent line

- Miscellaneous Components (not actualiy parts of the IHTS)

- Sodium and Gas Rupture Discs

- Hydrogen Detector Valves 
$\bullet$

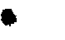


APPENDIX B

CRBR SYSTEMS 


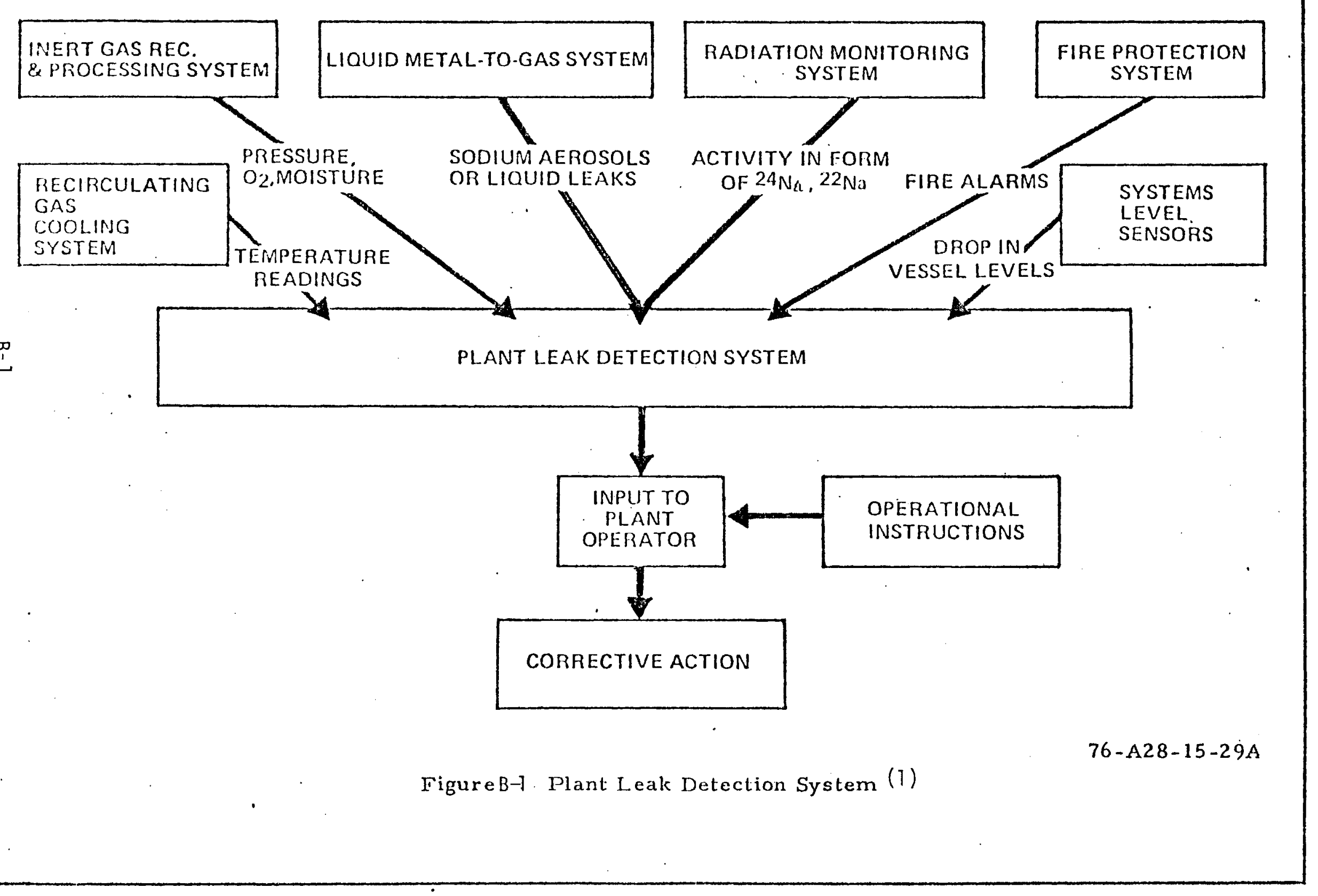


FIGURE B-2
FLOW DIAGRAM OF MAJOR CRBRP SAFETY RELATED SYSTEMS
$(a)$

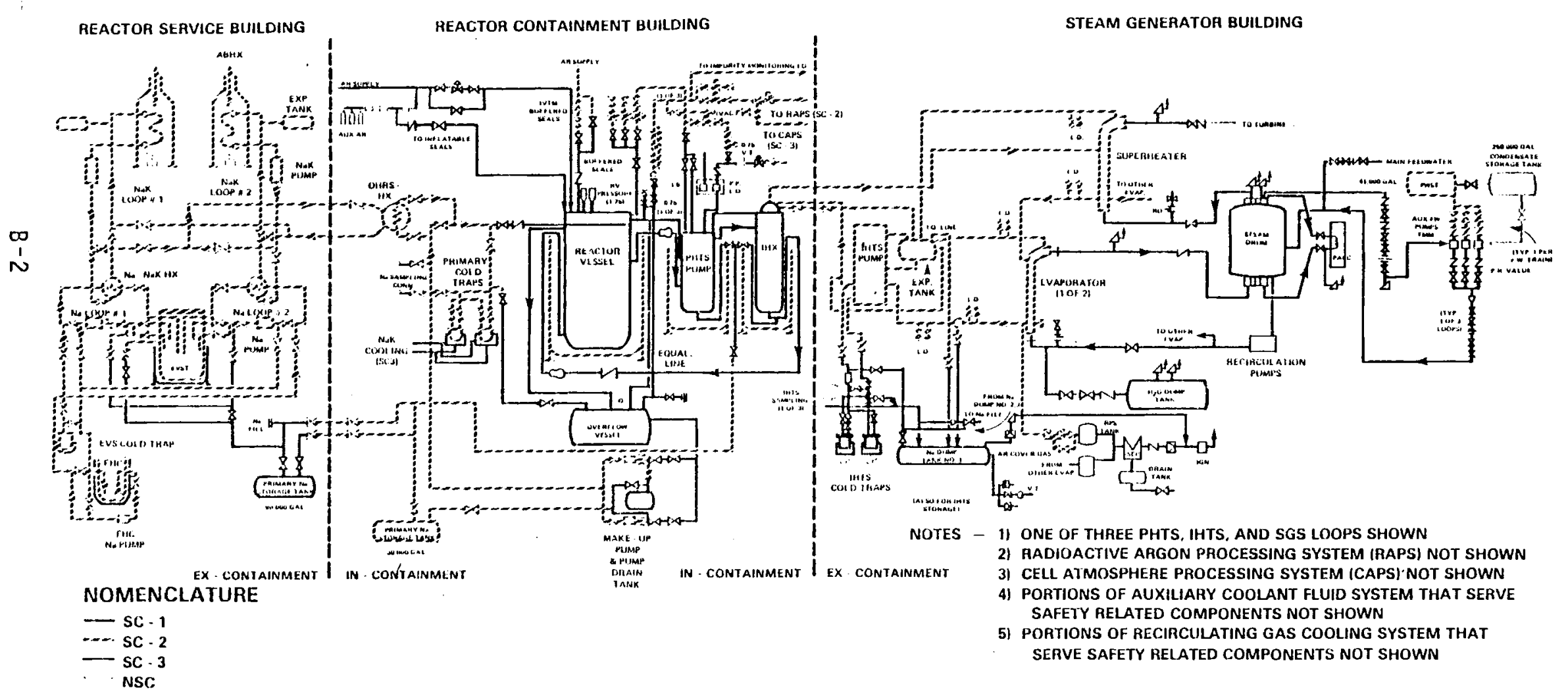

(a) NRC supplied information. 


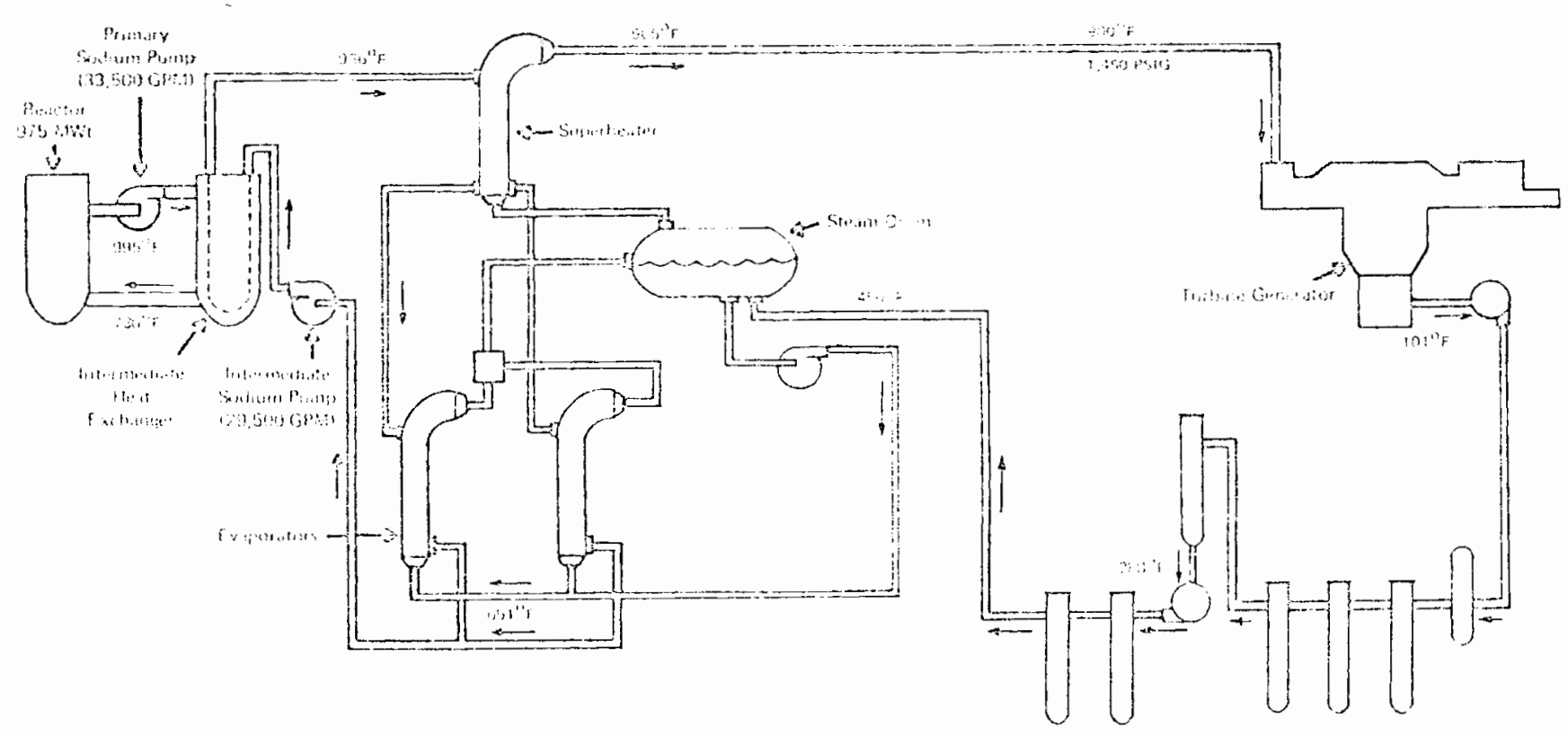

Figure $B-3$

SCHEDATIC OF PLA:TT SYSTEIIS

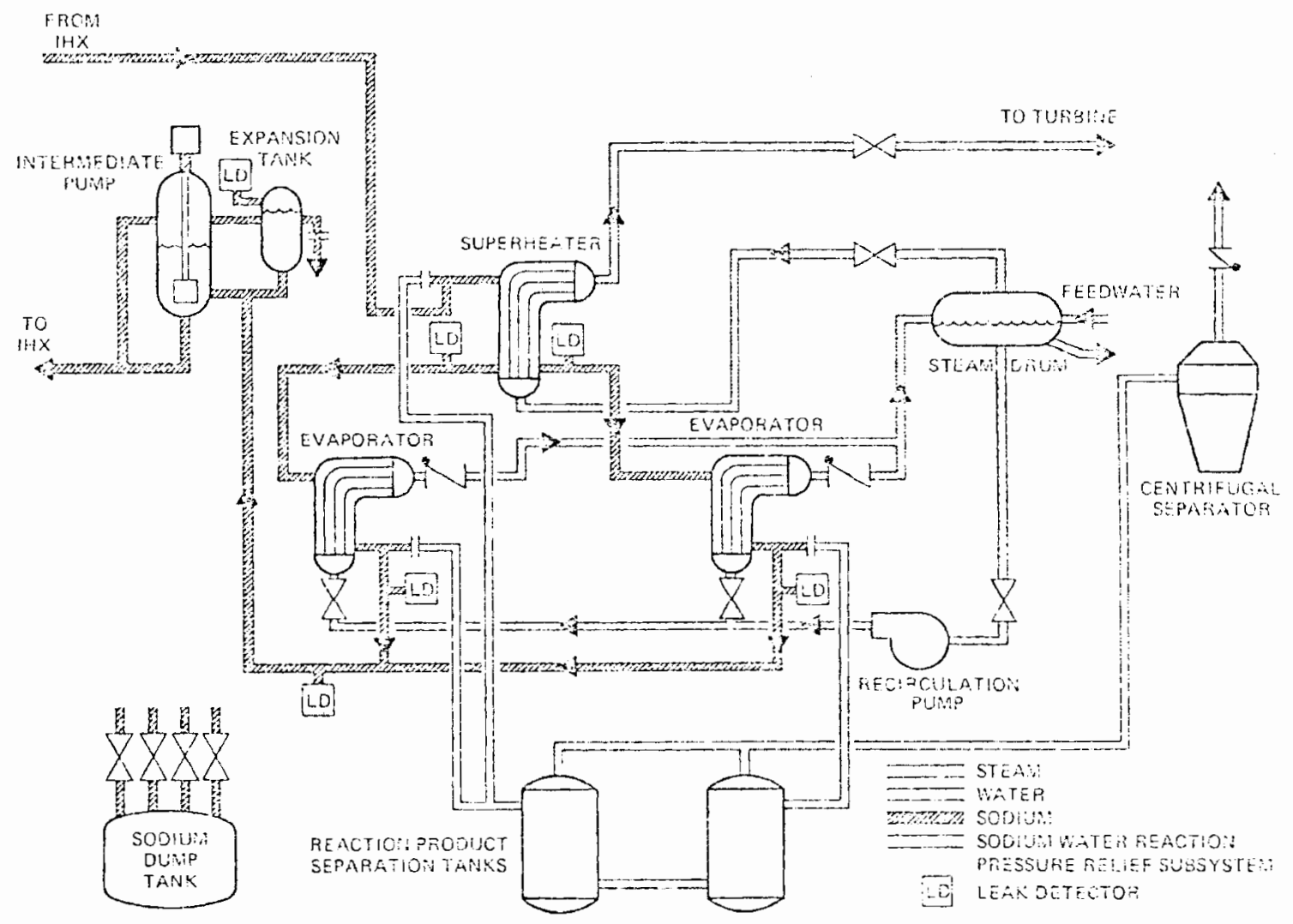

FIGURE B-4 CRBRP STEAM GENERATOR SYSTEM (24) 
. 
APPENDIX C

LMFBR LEAK HISTORY 
TABLE $c-1$
FAILURE DATA

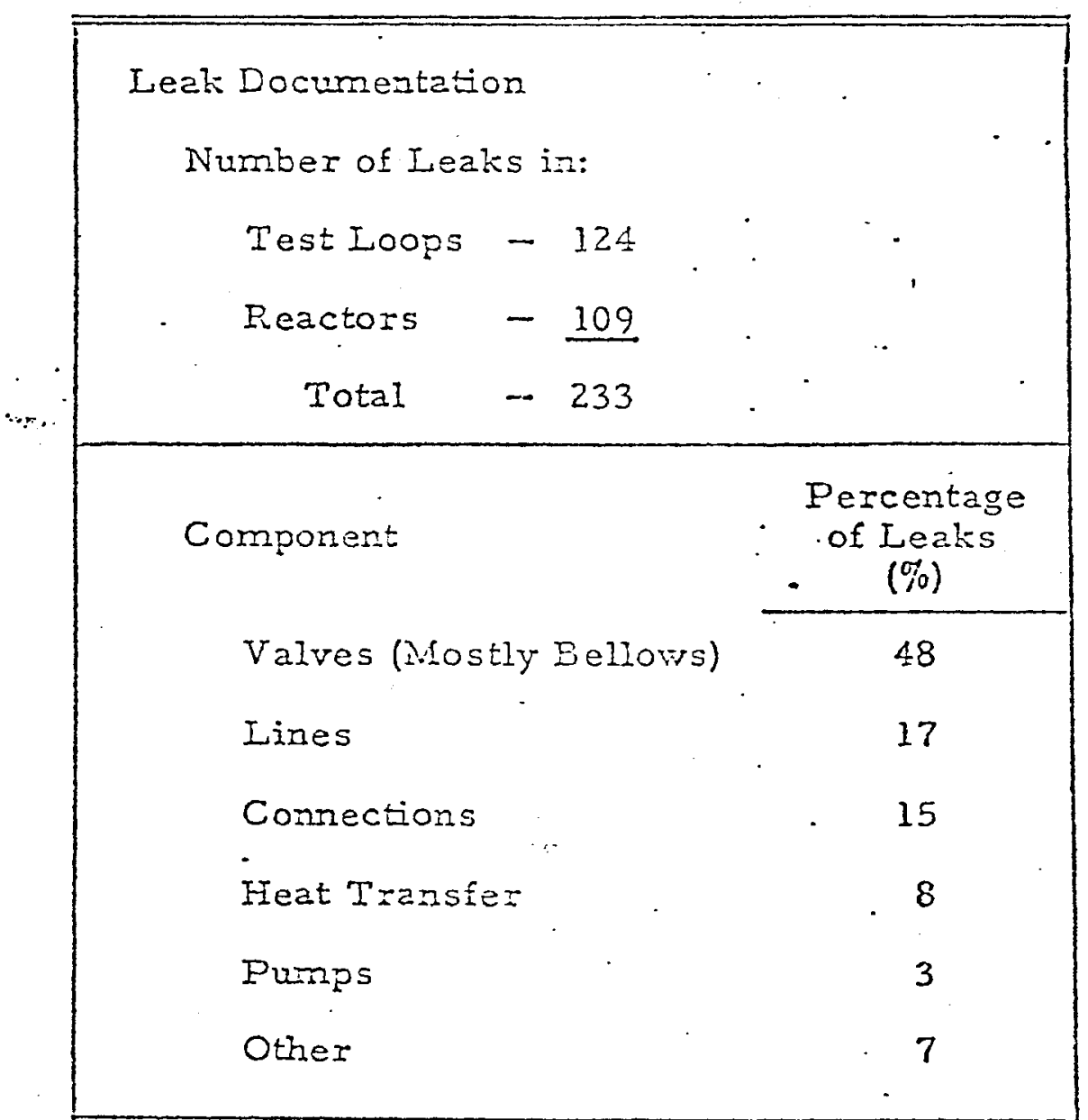


TABLE $6-2$

PAST REACTOR EXPERIENCE LIEAK DOCUMENTATION ${ }^{(1)}$

\begin{tabular}{|c|c|c|c|c|c|c|c|}
\hline \multirow[b]{2}{*}{ Reactor } & \multirow[b]{2}{*}{$\begin{array}{l}\text { Total } \\
\text { Leaks }\end{array}$} & \multirow{2}{*}{$\begin{array}{c}\text { Largest } \\
\text { Leak } \\
\text { (lb) }\end{array}$} & \multicolumn{5}{|c|}{ Detection Method } \\
\hline & & & $\begin{array}{c}\text { Leak Detaction } \\
\text { System } \\
\end{array}$ & LDS & Visual & Indirect & Unstated \\
\hline 1957 SRE & 26 & 10 & $\begin{array}{l}\text { Spark Plugs } \\
\text { Parallel Wires }\end{array}$ & 0 & 26 & 0 & 0 \\
\hline $1959 B R-5$ & 14 & 2 & & 5 & 2 & 7 & 0 \\
\hline 1962 HNPF & 13 & 10 & Spark Plugs & 3 & 5 & 0 & 5 \\
\hline $1963 \mathrm{DFR}$ & 7 & 4000 & Spark Plugs & 2 & 1 & 0 & 4 \\
\hline 1965 EBR-II & 23 & 600 & Spark Plugs & 4 & 17 & 0 & 2 \\
\hline .1966 FERMI & 11 & & Spark Plugs & 9 & 1 & 0 & 1 \\
\hline 1967 Rapsodie & 3 & 4000 & $\begin{array}{l}\text { Spark Plugs, } \\
\text { Parallel Wires, } \\
\text { Smoke Detector }\end{array}$ & 1 & 0 & 0 & 2 \\
\hline 1969 Sefor & 2 & 2 & Spark Plugs & 0 & 2 & 0 & 0 \\
\hline $1970 \mathrm{KNK}$ & 10 & 1100 & $\begin{array}{l}\text { Spark Plugs, } \\
\text { Smoke Detector } / \\
\text { Flame Photometer }\end{array}$ & - & - & - & - \\
\hline (9) & 109 & & & 24 & 54 & 7 & 14 \\
\hline
\end{tabular}

Spark Plug $=$ Contact Detector 


\section{DISTRIBUTION}

No. of

Copies

OFFSITE

A. A. Churm

DOE Chicago Patent Group

Chicago Operations office

9800 South Cass Avenue

Argonne, IL 60439

27 DOE Technical Information Center

4 U. S. Nuclear Regulatory Commission ATTN: Chief, Metallurgy Branch

Division of Systems Safety

Washington, DC 20555

2 U.S. Nuclear Regulatory Commission ATTN: Director

Division of Project Management

Washington, DC 20555

2 U.S. Nuclear Regulatory Commission ATTN: Library

Washington, DC 20555
No. of

Copies

ONSITE

DOE Richland Operations Office

H. E. Ransom

11 Battelle-Northwest

C. J. Morris (5)

Technical Information (5)

Technical Publications 
